\section{Pacific Northwest}

National Laboratory

Operated by Battelle for the

U.S. Department of Energy

\title{
Methodological Framework for Analysis of Buildings-Related Programs: The GPRA Metrics Effort
}
D.B. Elliott
K.A. Cort
D.M. Anderson
J.A. Dirks
D.B. Belzer
D.J. Hostick

June 2004

\footnotetext{
Prepared for the U.S. Department of Energy under Contract DE-AC06-76RL01830
} 


\title{
DISCLAIMER
}

This report was prepared as an account of work sponsored by an agency of the United States Government. Neither the United States Government nor any agency thereof, nor Battelle Memorial Institute, nor any of their employees, makes any warranty, express or implied, or assumes any legal liability or responsibility for the accuracy, completeness, or usefulness of any information, apparatus, product, or process disclosed, or represents that its use would not infringe privately owned rights. Reference herein to any specific commercial product, process, or service by trade name, trademark, manufacturer, or otherwise does not necessarily constitute or imply its endorsement, recommendation, or favoring by the United States Government or any agency thereof, or Battelle Memorial Institute. The views and opinions of authors expressed herein do not necessarily state or reflect those of the United States Government or any agency thereof.

\author{
PACIFIC NORTHWEST NATIONAL LABORATORY \\ operated by \\ BATTELLE \\ for the \\ UNITED STATES DEPARTMENT OF ENERGY \\ under Contract DE-AC06-76RL01830 \\ Printed in the United States of America \\ Available to DOE and DOE contractors from the \\ Office of Scientific and Technical Information, \\ P.O. Box 62, Oak Ridge, TN 37831-0062; \\ ph: (865) 576-8401 \\ fax: (865) 576-5728 \\ email: reports@adonis.osti.gov
}

\begin{abstract}
Available to the public from the National Technical Information Service, U.S. Department of Commerce, 5285 Port Royal Rd., Springfield, VA 22161 ph: (800) 553-6847 fax: (703) 605-6900

email: orders@ntis.fedworld.gov

online ordering: http://www.ntis.gov/ordering.htm
\end{abstract}

This document was printed on recycled paper. 
PNNL-14697

\title{
Methodological Framework for Analysis of Buildings-Related Programs: The GPRA Metrics Effort
}

\author{
D.B. Elliott \\ D.M. Anderson \\ D.B. Belzer \\ K.A. Cort \\ J.A. Dirks \\ D.J. Hostick
}

June 2004

Prepared for

the U.S. Department of Energy

under Contract DE-AC06-76RL01830

Pacific Northwest National Laboratory

Richland, Washington 99352 


\section{Summary}

The requirements of the Government Performance and Results Act (GPRA) of 1993 mandate the reporting of outcomes expected to result from programs of the federal government. The U.S. Department of Energy's (DOE's) Office of Energy Efficiency and Renewable Energy (EERE) develops official metrics for its 11 major programs using its Office of Planning, Budget Formulation, and Analysis (OPBFA). OPBFA conducts an annual integrated modeling analysis to produce estimates of the energy, environmental, and financial benefits expected from EERE's budget request.

Two of EERE's major programs include the Building Technologies Program (BT) and Office of Weatherization and Intergovernmental Program (WIP). Pacific Northwest National Laboratory (PNNL) supports the OPBFA effort by developing the program characterizations and other market information affecting these programs that are necessary to provide input to the EERE integrated modeling analysis. Throughout the report we refer to these programs as "buildings-related" programs because the approach is not limited in application to BT or WIP.

To adequately support OPBFA in the development of official GPRA metrics, PNNL communicates with the various activities and projects in BT and WIP to determine how best to characterize their activities planned for the upcoming budget request. PNNL then analyzes these projects to determine what the results of the characterizations would imply for energy markets, technology markets, and consumer behavior. This is accomplished by developing nonintegrated estimates of energy, environmental, and financial benefits (i.e., outcomes) of the technologies and practices expected to result from the budget request. These characterizations and nonintegrated modeling results are provided to OPBFA as inputs to the official benefits estimates developed for the federal budget.

This report documents the approach and methodology used to estimate future energy, environmental, and financial benefits produced by technologies and practices supported by BT and by WIP. However, the approach is general enough for analysis of buildings-related technologies, independent of any specific program. An overview describes the GPRA process and the models used to estimate energy savings. The body of the document describes the algorithms used and the diffusion curve estimates. 


\section{Acronyms}

\begin{tabular}{|c|c|}
\hline AFUE & annual fuel utilization efficiency \\
\hline AAMA & American Architectural Manufacturers Association \\
\hline BEAMS & Building Energy Analysis and Modeling System \\
\hline BT & Office of Building Technologies Programs \\
\hline BTS & Office of Building Technology, State and Community Programs \\
\hline CBECS & Commercial Buildings Energy Consumption Survey \\
\hline CFL & compact fluorescent lights \\
\hline $\mathrm{CO}$ & carbon monoxide \\
\hline COP & coefficient of performance \\
\hline DOE & U.S. Department of Energy \\
\hline EER & energy efficiency ratio \\
\hline EERE & Office of Energy Efficiency and Renewable Energy \\
\hline EF & energy factor \\
\hline EIA & Energy Information Administration \\
\hline EPAct & Energy Policy Act of 1992 \\
\hline EPRI & Electric Power Research Institute \\
\hline EREC & Energy Efficiency and Renewable Energy Clearinghouse \\
\hline FEDS & Facility Energy Decision System \\
\hline FRHOB & flame retention head oil burners \\
\hline GAMA & Gas Appliance Manufacturers Association \\
\hline GPRA & Government Performance and Results Act of 1993 \\
\hline IECC & International Energy Conservation Code \\
\hline kBtu & thousand Btu \\
\hline LBNL & Lawrence Berkeley National Laboratory \\
\hline LTS & Lincoln Technical Services \\
\hline MMBtu & million Btu \\
\hline MMTCE & million metric tons carbon equivalent \\
\hline MMton & million metric tons \\
\hline NEMS & National Energy Modeling System \\
\hline NOx & nitrous oxides \\
\hline ORNL & Oak Ridge National Laboratory \\
\hline PBFA & Office of Planning, Budget Formulation, and Analysis \\
\hline PM & particulate matter \\
\hline PNNL & Pacific Northwest National Laboratory \\
\hline QBtu & quadrillion Btu \\
\hline $\mathrm{R} \& \mathrm{D}$ & research and development \\
\hline RECS & Residential Energy Consumption Survey \\
\hline SCOP & seasonal coefficient of performance \\
\hline SEER & seasonal energy efficiency ratio \\
\hline $\mathrm{SO} 2$ & sulfur dioxide \\
\hline TBtu & trillion Btu \\
\hline VOC & volatile organic compound \\
\hline WIP & Office of Weatherization and Intergovernmental Programs \\
\hline
\end{tabular}




\section{Contents}

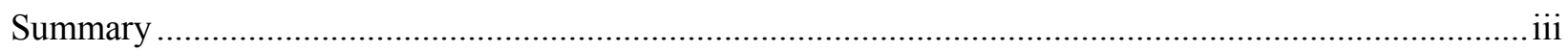

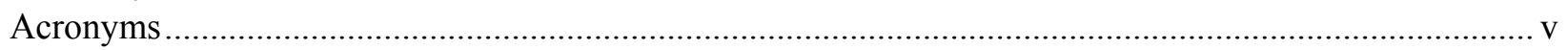

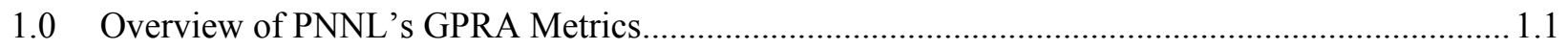

1.1 Estimating the Energy Savings of Buildings-Related Projects ........................................ 1.1

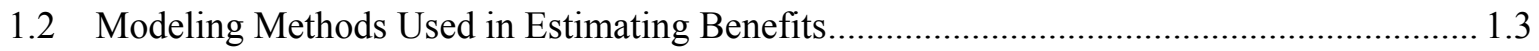

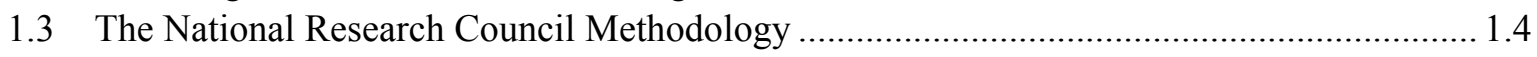

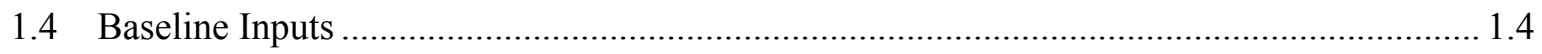

1.5 Adjustments to Estimates due to Budget Revisions ...................................................... 1.5

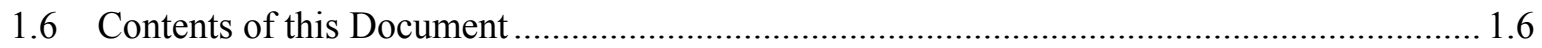

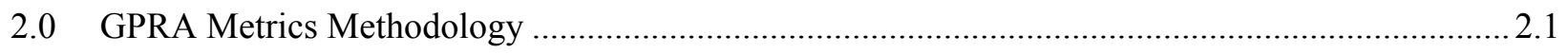

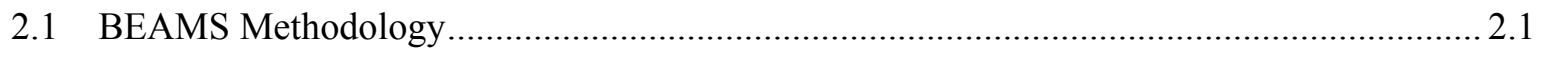

2.1.1 Whole-Building and Envelope Project Approach .............................................. 2.2

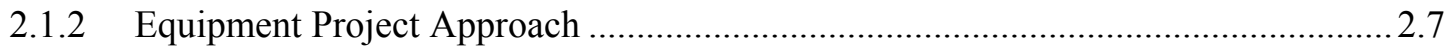

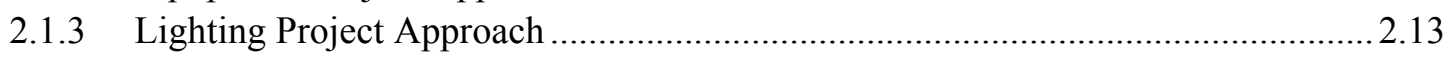

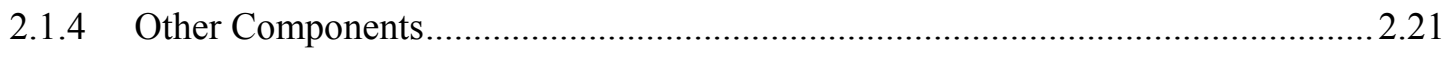

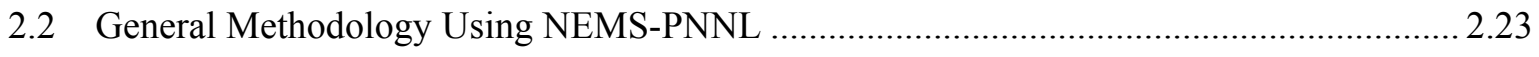

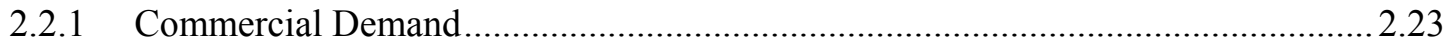

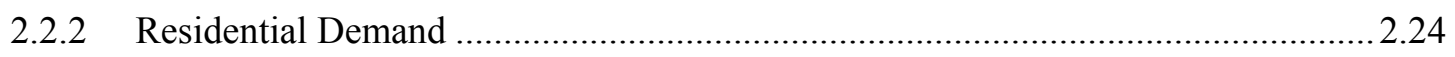

2.2.3 Methodology for Market Transformation-Type Projects .....................................2.2.25

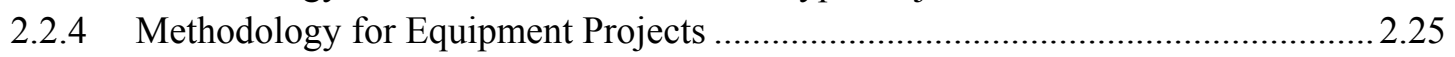

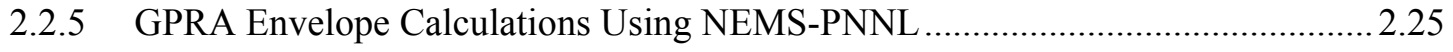

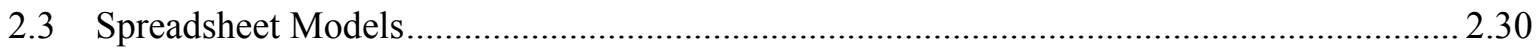

3.0 Technology Diffusion Models - Application to Selected Energy-Efficient

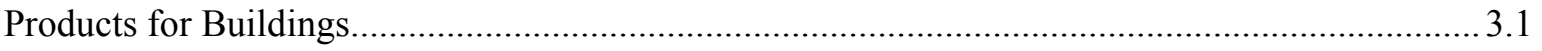

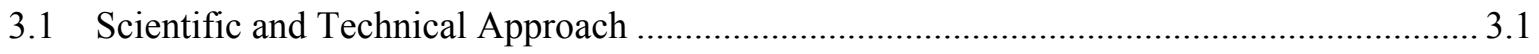

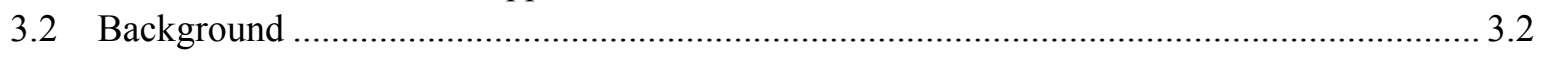

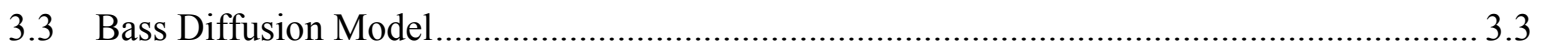

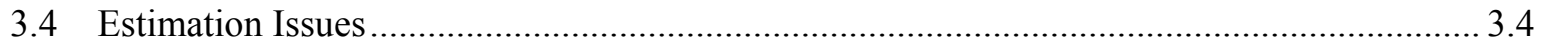

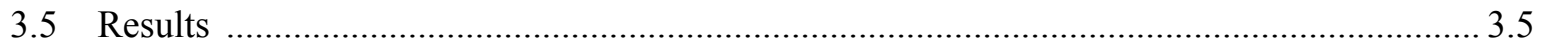

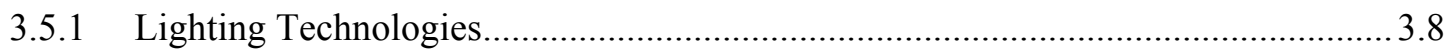

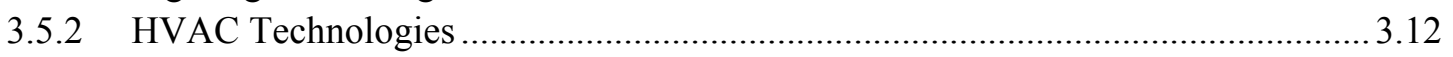

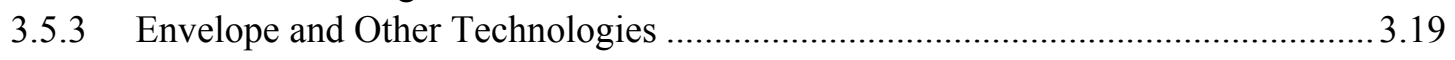

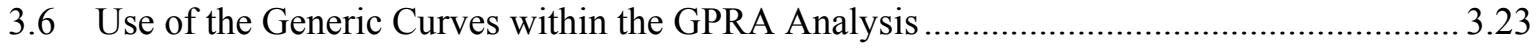

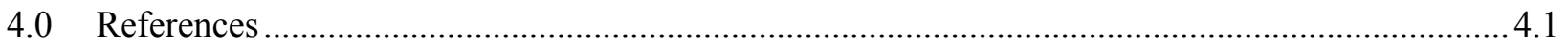




\section{Figures}

Figure 1.1. Impact of National Research Council Methodology (pure market acceleration case) ........... 1.5

Figure 2.1. Developing the Market Segment (BEAMS) .................................................................. 2.2

Figure 3.1. Actual and Predicted Penetration Rates: Electronic Ballasts.............................................. 3.9

Figure 3.2. Actual and Predicted Penetration Rates: T-8 Lamps ........................................................... 3.10

Figure 3.3. Actual and Predicted Penetration Rates: CFLs.............................................................11

Figure 3.4. Generic Lighting Diffusion Curve Compared With Other Lighting

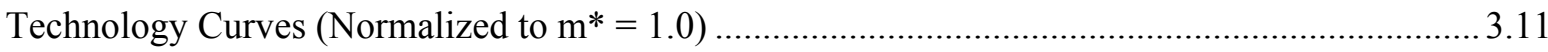

Figure 3.5. Actual and Predicted Market Penetration: Electric Heat Pumps ...................................... 3.13

Figure 3.6. Actual and Predicted Market Penetration Rates: Flame Retention Oil Burners ................... 3.15

Figure 3.7. Actual and Predicted Market Penetration for Condensing Gas Furnaces............................ 3.17

Figure 3.8. Predicted Market Penetration of Room Air Conditioners ................................................. 3.18

Figure 3.9. Generic HVAC Diffusion Curve Compared With Other HVAC Technology Curves

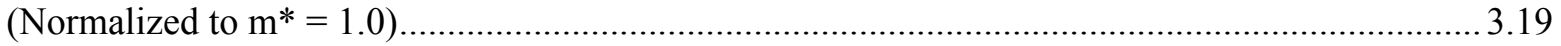

Figure 3.10. Actual and Predicted Market Penetration Rates: Advanced Refrigeration

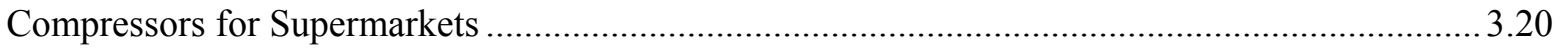

Figure 3.11. Actual and Predicted Market Penetration Rates: Residential Low-E Windows................ 3.22

Figure 3.12. Generic Envelope/Other Diffusion Curve Compared With Other Technology Curves

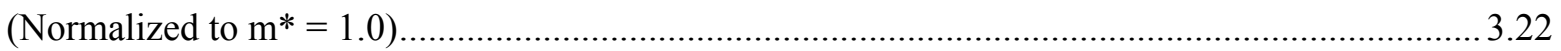

\section{Tables}

Table 2.1. Building Simulation Parameters ..................................................................................... 2.27

Table 2.2. Weights Given to Each City for Each Census Region (\%) ...............................................2.28

Table 2.3. Percentage of Floor Space in Each Size Category for Each

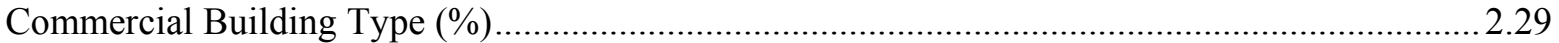

Table 2.4. Fraction of Floor Space in Each Size Category for Each Residential Type (\%) .................2.29

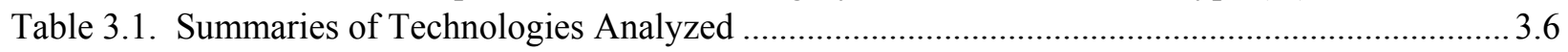

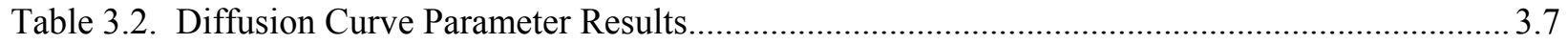

Table 3.3. Ballast Shipments and Penetration of Electronic Ballasts .................................................... 3.8

Table 3.4. Total Fluorescent Tube and T-8 Tube Shipments.............................................................. 3.9

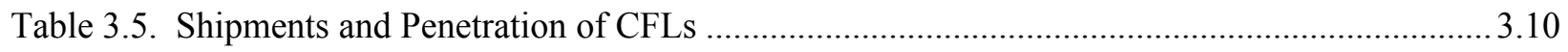

Table 3.6. Advanced Electric Heat Pump Shipments and Penetration ................................................ 3.12

Table 3.7. Sales and Market Penetration of Flame Retention Head Oil Burners (FRHOBs) ................. 3.14

Table 3.8. Market Penetration of High Efficiency Gas Furnaces ........................................................16

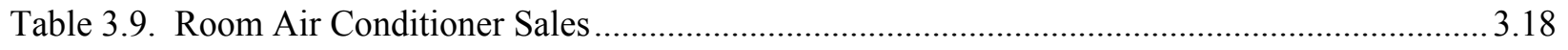

Table 3.10. Market Penetration of High-Efficiency Refrigerator Compressors for Supermarkets......... 3.20

Table 3.11. Market Penetration of Low-E Residential Windows ........................................................3.21 


\subsection{Overview of PNNL's GPRA Metrics}

The requirements of the Government Performance and Results Act (GPRA) of 1993 mandate the reporting of outcomes expected to result from programs of the Federal government. The U.S. Department of Energy's (DOE's) Office of Energy Efficiency and Renewable Energy (EERE) develops official metrics for its 11 major programs using its Office of Planning, Budget Formulation, and Analysis (OPBFA). OPBFA conducts an annual integrated modeling analysis to produce estimates of the energy, environmental, and financial benefits expected from EERE's budget request.

Two of EERE's major programs include the Building Technologies Program (BT) and Office of Weatherization and Intergovernmental Program (WIP). Pacific Northwest National Laboratory (PNNL) supports the OPBFA effort by developing the program characterizations and other market information affecting these programs that is necessary to provide input to the EERE integrated modeling analysis. Throughout the report we refer to these programs as "buildings-related" programs because the approach is not limited in application to BT or WIP.

To adequately support OPBFA in the development of official GPRA metrics, PNNL communicates with the various activities and projects in BT and WIP to determine how best to characterize their activities planned for the upcoming budget request. PNNL then analyzes these projects to determine what the results of the characterizations would imply for energy markets, technology markets, and consumer behavior. This is accomplished by developing nonintegrated estimates of energy, environmental, and financial benefits (i.e., outcomes) of the technologies and practices expected to result from the budget request. These characterizations and nonintegrated modeling results are provided to OPBFA as inputs to the official benefits estimates developed for the federal budget. The supporting analysis and data obtained through the metrics effort are used to estimate and validate progress toward strategic goals and objectives within BT and WIP and to communicate the benefits of EERE projects to all interested parties.

\subsection{Estimating the Energy Savings of Buildings-Related Projects}

No single model or approach is capable of capturing or adequately representing the diversity of activities supported by BT and WIP (not to mention the rest of the EERE portfolio). As such, PNNL has adopted a variety of analytical approaches including macro economic models, energy accounting models, and spreadsheets. This section briefly describes the analytical approaches used to estimate energy savings for BT and WIP.

PNNL reports the benefits of BT and WIP projects and technologies at several different levels: they are provided at the program (BT and WIP) level for use by senior EERE management in considering portfolio options, at the decision unit level for use by Program Managers to assess program direction and future progress toward goals and objectives, and at the project/activity level for use by project managers in planning and execution. 
PNNL assessed the benefits for a limited number of defined metrics:

- energy savings

- environmental benefits

- economic/financial metrics.

The buildings-related projects produce many other benefits, including reductions in peak energy loads, enhanced security due to reduced oil demand, reduced energy costs for low-income households, and increased comfort and health in buildings; however, these are not currently measured as part of the GPRA process.

The environmental impacts that are estimated as part of the GPRA process are only those directly related to the burning of fossil fuels; other impacts such as land use and localized water pollution are not measured. Within the economic metrics, the consumer cost savings (or energy cost savings) simply reflect monetization of the energy savings and do not include the incremental cost of the new technology or practice; nor are they discounted. For both the environmental impacts and consumer cost savings, calculations are based on EERE guidance for the GPRA Metrics effort (Draft letter, Office of Energy Efficiency and Renewable Energy. April 1, 2002. "Performance Planning Guidance (GPRA Data Call) FY 2004-FY 2008 Budget Cycle.” US Department of Energy, Washington, D.C.). Because environmental and economic benefits (energy cost savings) relate directly to projected energy savings, the balance of this overview focuses on just estimates of energy savings.

The benefit estimates are based on an evaluation of each project to determine the impact of successful project implementation (in other words, each project is assumed to meet its' stated goals). Our analysis considered project goals, technology characteristics (including performance and cost), the targeted market, and project milestones. Not all activities result in readily measurable energy savings as they are intermediate or enabling technologies or practices, or are contributing to the basic understanding (a "knowledge" benefit) of energy use in the building sector. For this GPRA analysis, we selected activities for which it was possible to develop measured energy savings.

The benefit estimates are developed based on a series of assumptions developed project-by-project. These input assumptions are critical to the analysis and are developed through an iterative process with the project managers. Note that because BT and WIP projects are in different stages of maturity, there are varying degrees of corroborative studies available on which project information can be substantiated. Additionally, newer projects may not have estimates of future costs well-coordinated with performance estimates. For example, research projects would be expected to have more tenuous estimates of price and performance characteristics of potential products than deployment-related projects that feature products closer to market adoption. PNNL recognizes the varying levels of maturity and distance from market across projects and that the cost and performance characteristics improve as projects mature or as they near commercialization. 


\subsection{Modeling Methods Used in Estimating Benefits}

PNNL calculated the buildings-related BT and WIP GPRA nonintegrated estimates of benefits using one of three methods:

- a PNNL adaptation of the National Energy Modeling System (NEMS-PNNL) ${ }^{\mathrm{a}}$

- Building Energy Analysis and Modeling System (BEAMS) ${ }^{\mathrm{b}}$

- $\quad$ spreadsheets designed for a specific project.

NEMS-PNNL allows the costs and benefit characteristics of a technology and its market penetration to be linked. However, NEMS-PNNL has difficulty representing some technologies, such as the wholebuilding projects (projects that use a systems approach, looking at integration and interaction of building components such as roofs, walls, and equipment and seeking to optimize energy efficiency through consideration of these interactions), because NEMS-PNNL is designed to model specific technologies, not the impacts of groups of interacting technologies.

BEAMS was built specifically for estimating the benefits of building-related projects and therefore allows various types of projects to be characterized, including whole-building, envelope, and equipment projects. A disadvantage of the BEAMS model is its reliance on externally-determined penetration rates (i.e., fraction of sales or fraction of installed base). Analyst judgment combined with available market information was used to construct the penetration functions used to model technology or project impacts. In addition, BEAMS cannot model equipment that competes against more than one baseline equipment type.

To aid in the development of external penetration rates, PNNL conducted a study to examine the historical market penetration (i.e., diffusion) for 10 energy-efficient products related to the buildings sector. Section 3.0 provides the most complete report of that study. PNNL estimated diffusion models for each product based on the specification proposed by F.M. Bass (1969). Bass was the first to suggest the S-curve or logistical functional form for the market diffusion of new products, and his concepts are still widely used in the marketing discipline today. PNNL incorporated the resulting models into the GPRA metrics analysis for many of the projects and technologies not modeled within the NEMS framework and designed the model development and empirical analysis to generate more credible predictions of the adoption process of important energy-efficiency technologies in the buildings sector. The technologies were placed into four separate categories: lighting; heating, ventilation, airconditioning and refrigeration (HVAC/R); envelope; and other.

PNNL used spreadsheets to model projects not easily modeled in BEAMS or NEMS-PNNL. For example, because some projects previously had developed their own set of spreadsheet tools for estimating impacts, PNNL adapted these tools for the GPRA estimation process. We describe each of the three methods used for deriving energy-saving estimates in more detail in Section 2.0 of this document.

\footnotetext{
a Any modification or alteration to the official NEMS model must be called out as such; for PNNL's GPRA effort, the modified version used is referred to as NEMS-PNNL.

${ }^{\mathrm{b}}$ The BEAMS model was previously known as BESET
} 


\subsection{The National Research Council Methodology}

A National Academy of Sciences report (NRC 2001) assessed the outcomes of energy efficiency and fossil energy research from 1978 to 2000 . One of the council's recommendations for assessing research development and deployment projects was that "DOE should adopt an analytic framework similar to that used by this committee as a uniform methodology for assessing the benefits and costs of its R\&D projects. DOE should also use this type of analytic framework in reporting to Congress under GPRA."

The National Research Council (NRC) committee assumed that the private sector would have developed the technology in the absence of DOE five years after DOE realized the benefits (also known as the "5year rule"). This assumption was made in order to more readily compare the impact of the various technologies analyzed, and was not based on empirical evidence or theory that most government efforts merely accelerate introduction of technologies into the marketplace. It should be noted that the NRC studied only research and development (R\&D) projects, so universal adoption of the 5-year rule by all projects, such as rulemaking and information efforts, goes beyond the NRC's intent. As such, this assumption was adopted, in part, as part of the uniform process for assessing prospective (future) benefits of EERE programs. However, alternative acceleration periods are assumed on a case-by-case basis.

The calculation methodologies for the projects characterized using the National Research Council methodology were modified to remove the estimated benefits that would have occurred in the absence of DOE funding. This change was implemented within the buildings-related estimates by determining the projects that act as acceleration-to-market activities rather than projects that would not have been developed or implemented in the absence of government funding (some projects, such as Weatherization Assistance and Appliance Standards, would most likely not be undertaken by the private sector and therefore do not have a form of the 5-year rule applied to them). This approach diminishes the project savings in future years, presuming that the private sector is expanding its development and production of these technologies. Figure 1-1 illustrates how applying this acceleration methodology impacts a project's estimates in its most simplified state. Note that the bell-shaped curve in Figure 1-1 depicts the difference (the net benefit from DOE R\&D, also shown as the shaded area) between the penetration without DOE $R \& D$ and the accelerated penetration with DOE R\&D.

\subsection{Baseline Inputs}

The nonintegrated benefits estimates produced for the GPRA effort represent the estimated future impacts of activity funding. In order to produce the estimated impacts, baseline forecast assumptions must first be established. To the extent possible, the underlying assumptions about building stock forecasts, future equipment efficiencies, future market shares, and future end-use loads were consistent across tools (i.e., NEMS-PNNL, BEAMS, and spreadsheets). We accomplished consistency by drawing most of the baseline characterization data from forecasts produced by the Energy Information Administration (EIA), a statistical agency within DOE. For example, the same version of NEMS used to develop the FY 2005 estimates was used to produce EIA's Annual Energy Outlook 2003. 


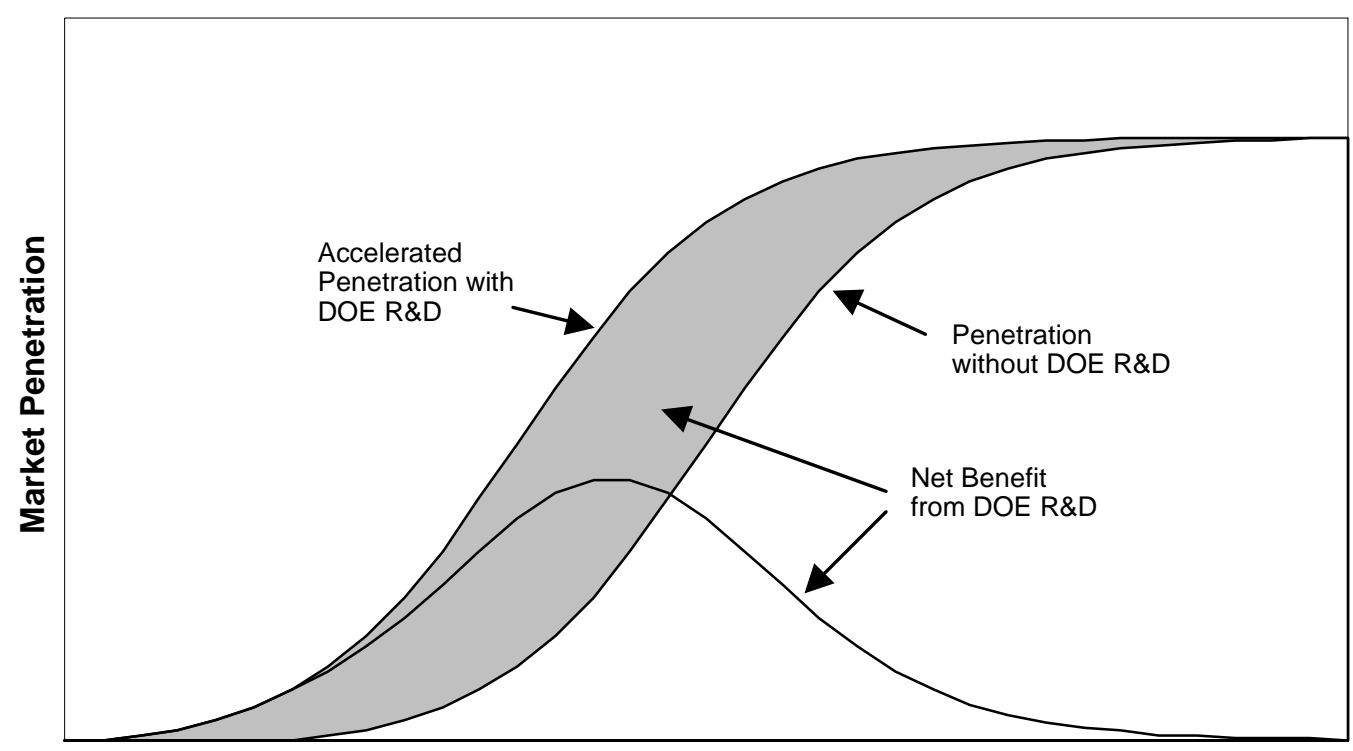

Year After Introduction

Figure 1.1. Impact of National Research Council Methodology (pure market acceleration case)

BEAMS also has a baseline forecast characterization, which is drawn from NEMS-PNNL, EIA's Annual Energy Outlook, the 1997 "Residential Energy Consumption Survey," and the 1999 "Commercial Buildings Energy Consumption Survey." PNNL verified the consistency of the baseline assumptions of the spreadsheet tools against EIA's data. Baseline data are updated as newer versions of these documents are released and incorporated into EIA's version of NEMS.

\subsection{Adjustments to Estimates due to Budget Revisions}

The budget formulation process involves much iteration, and the budget requested for various line items may change during that process. First, EERE develops an initial budget; next, an internal review budget is developed in conjunction with the Chief Financial Officer; eventually, the budget proceeds to the Office of Management and Budget (OMB), and subsequent versions are developed based on an appeal of the OMB pass back. Finally, the budget is formally submitted by the President to Congress (referred to in this document as the final budget request).

The project characterizations driving the benefits estimates are developed through close interaction with the BT and WIP project managers. The characterizations require the DOE project manager to make assumptions based on the requested level of funding, and the characterization then describes what would be accomplished at that level. However, because the budget request amount sometimes changes between the time that the characterization is developed and the time that the budget request is finalized, and also because changes occur between the final budget request (on which the final estimates are based) and the actual allocation, PNNL needs to be able to quickly recalculate the estimated benefits for the various projects. 
For small changes in budget levels, PNNL introduces a basic "budget adjustment" to the project estimates. We assume that to get to $\mathrm{X}$ savings, a total of $\mathrm{Y}$ budget must be spent, where $\mathrm{Y}$ is the cumulative budget over the projection period. A change in the annual budget results in a change in the cumulative budget. Revised savings are calculated for each year using the formula: new cumulative budget in year $z$ divided by old cumulative budget in year $z$. This adjustment mechanism implicitly suggests that either the fraction of expected sales or the performance of the project has changed but does not explicitly tie the change to one factor or the other.

For larger changes, we revisit the project inputs with the DOE project managers to determine the impact of a reduced (or increased) budget. Options for adjusting the models include changing the year of market introduction, changing the impact on sales (market penetration), modifying the performance objective, and adding or removing tasks or technologies within the project.

\subsection{Contents of this Document}

The remainder of this document consists of four sections. Section 2.0 provides more detailed information on the methodology behind the development of the GPRA benefits estimates. Section 3.0 provides more detailed information on the technology diffusion curves, and Section 4.0 lists the references for the document. 


\subsection{GPRA Metrics Methodology}

This section describes the calculation methodology used within BEAMS, NEMS-PNNL, and spreadsheets to estimate the energy savings for buildings-related projects.

\subsection{BEAMS Methodology}

BEAMS is a bottom-up accounting model that compares baseline energy use against specific EEREsponsored technologies. BEAMS also is used to centrally collect, store, and report all results produced by all the various estimation methods. In addition to energy savings forecasts, these results also include such items as associated emissions reductions and necessary investment.

BEAMS can estimate benefits for various projects: whole-building, envelope, lighting, HVAC, and water heating. BEAMS is used primarily to model projects that target whole-building energy use or envelope (building shell) improvements. Although BEAMS can model equipment projects, those projects are primarily estimated using NEMS-PNNL.

To determine energy savings for specific buildings-related projects, BEAMS requires information in the following areas:

- Project Performance Goals. The goals of each project are assessed in terms of energy savings (e.g., percent load reductions and equipment efficiency improvements) and used as inputs to BEAMS. PNNL gathers this information from each project by interviewing the project manager or reviewing project literature (e.g., technical reports, brochures, and websites).

- Target Market. Target markets are defined in terms of building sector (e.g., residential and commercial), building type (e.g., single family and educational), size (commercial only), income level (residential only), vintage (e.g., new or existing), and climate zone or region. Figure 2.1 illustrates the process used to define the project's targeted market segment within BEAMS, where certain building types, and building sizes are excluded from the mix (indicated with arrow curving downward), leaving a more specific market to target.

Once the target market has been identified, PNNL determines penetration into that market using technology diffusion curves (discussed in Section 3.0). Within BEAMS, market penetration is defined as either the fraction of sales for equipment and lighting projects or the fraction of installed base for envelope and whole-building projects. The penetration model requires only the year of introduction into the market, an estimate of market penetration in 2020 (provided by BT and WIP project managers), and the selection of the most appropriate diffusion curve category (e.g., lighting or HVAC). 


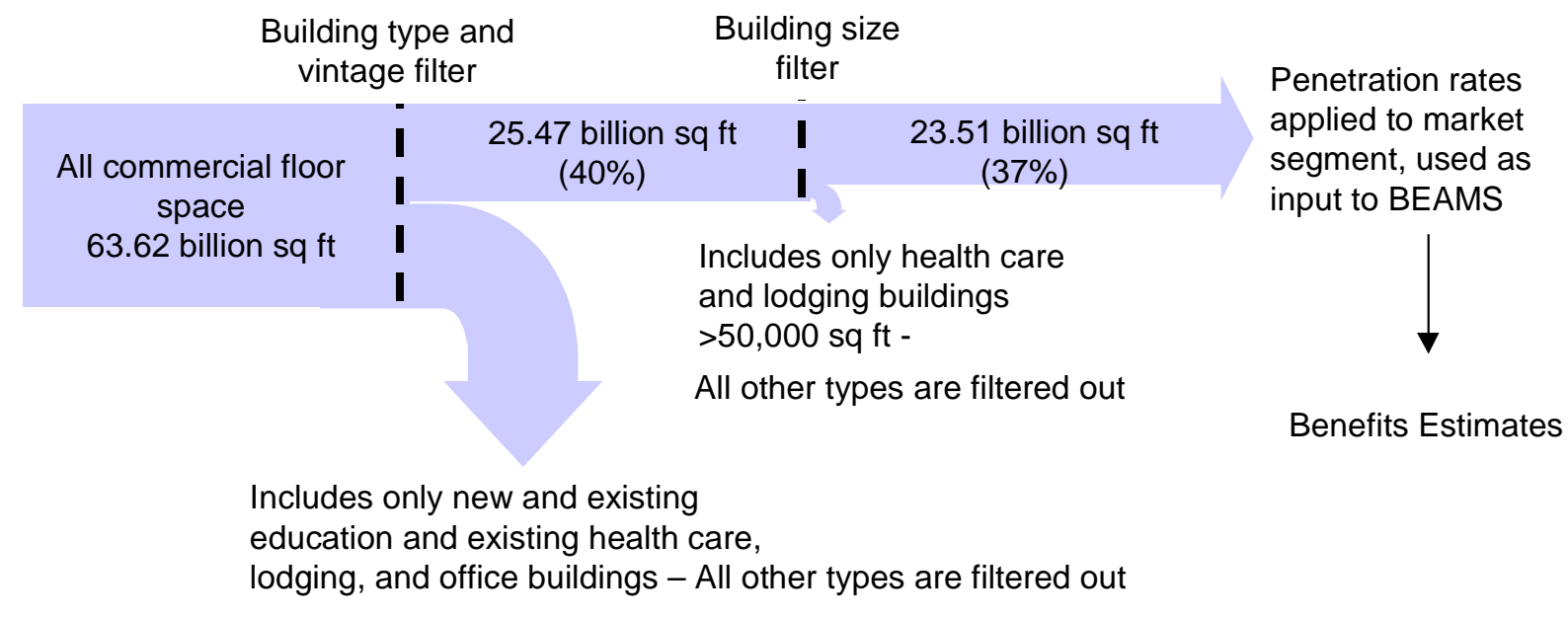

Figure 2.1. Developing the Market Segment (BEAMS)

- Private Investment (cost). Estimates of private investment for both the baseline and the EERE technology or practice are entered into BEAMS. Ideally, the investment costs would be considered when market penetration is developed; however, the current diffusion model used does not incorporate costs at this time. In addition to private investment, non-energy project benefits are also quantified when possible and entered into BEAMS.

All site-level energy savings and investment estimates are aggregated through a BEAMS-to NEMS-PNNL interface. After this aggregation, BEAMS calculates the primary energy savings, associated emissions reductions, and the dollar value of the energy savings. BEAMS contains a report generator that aggregates the project- and technology-level benefits into the decision units. Each of the BEAMS algorithm approaches is further documented below.

\subsubsection{Whole-Building and Envelope Project Approach}

This section addresses projects that target the building envelope or use a whole-building design approach. Envelope projects are modeled as improvements to the building envelope (shell measures, such as improvements to wall insulation and windows), whereas whole-building projects impact the total building system. Envelope and whole-building projects are both characterized by a reduction in space conditioning and/or water heating load resulting from changes in the building system or envelope. Additionally, whole-building projects may also result in reductions in lighting consumption. 
Calculating the energy savings associated with envelope and whole-building projects involves the following steps, which are discussed in the next subsections:

- Determine the size of the potential market.

- Determine the number of units affected by the buildings-related project.

- Determine the base end-use loads.

- Determine the end-use loads after project implementation.

- Calculate the energy savings.

\subsubsection{Determine Size of the Potential Market}

Building stock estimates are used to determine the potential market for each project.

Residential and commercial new and existing building stock totals for all years through FY 2025 were provided by the latest version of EIA's Annual Energy Outlook. The years 2026 through 2030 were extrapolated based on the annual growth from 2001 through 2025. The stock estimates have been developed for each market segment (e.g., building type, building vintage, and region) based on several assumptions bulleted below.

The building stock was disaggregated into north and south regions by using the EIA climate zones published in the "Residential Energy Consumption Survey" (EIA 1997) and the "Commercial Buildings Energy Consumption Survey" (EIA 1995, 1999). Climate zones 1 through 3 (i.e., zones with $>4,000$ heating-degree days) were designated as the north region, and zones 4 and 5 (i.e., zones with $<4,000$ heating-degree days) were defined as the south regions. Using this method, approximate percentages of north and south existing units and new construction were estimated:

- Residential single-family and multifamily housing

- $60 \%$ of the existing building stock is in the north.

- $40 \%$ of the existing building stock is in the south.

- New stock is divided evenly across regions.

- Residential manufactured housing

- $48 \%$ of the existing building stock is in the north.

- $52 \%$ of the existing building stock is in the south.

- $45 \%$ of the new building stock is in the north.

- $55 \%$ of the new building stock is in the south.

- Commercial buildings

- $59 \%$ of the existing building stock is in the north.

- $41 \%$ of the existing building stock is in the south.

- $55 \%$ of the new building stock is in the north.

- $45 \%$ of the new building stock is in the south. 
Using the assumptions listed above, the building stock numbers were segmented by building vintage and region. Using the budget year as the base year, PNNL classifies all construction beginning with the base year as new.

Each envelope or whole-building project has a specified target market: residential and/or commercial (and their subsets), new and/or existing vintages, and north and/or south regions. The potential market for any project is the set of targeted buildings. For example, a project targeting single-family construction includes only the forecasts for new and existing single-family construction in the north and south.

\subsubsection{Determine Number of Units Affected by the Buildings-Related Project}

The number of units affected by the buildings-related project is calculated using the fraction of installed base (penetration rate) that the project is expected to capture and the building stock. A penetration rate is applied to the appropriate market segment to compute the number of units impacted by the buildingsrelated project, as follows:

$$
u_{s, b, v, r, t}=P_{s, b, v, r, t} \times S_{s, b, v, r, t}
$$

$$
\text { Where } \begin{aligned}
\mathrm{u}_{\mathrm{s}, \mathrm{b}, \mathrm{v}, \mathrm{r}, \mathrm{t}}= & \text { number of units affected in year } t \text { (billion } \mathrm{ft}^{2} \text { or million households) for building } \\
& \text { sector } s, \text { building type } b \text {, vintage } v \text {, and region } r \\
\mathrm{P}_{\mathrm{s}, \mathrm{b}, \mathrm{v}, \mathrm{r}, \mathrm{t}}= & \text { penetration rate in year } t \text { for building sector } s \text {, building type } b \text {, vintage } v \text {, and } \\
& \text { region } r \\
\mathrm{~S}_{\mathrm{s}, \mathrm{b}, \mathrm{v}, \mathrm{r}, \mathrm{t}}= & \text { building stock in year } t \text { (billion } \mathrm{ft}^{2} \text { or million households) for building sector } s, \\
& \text { building type } b, \text { vintage } v, \text { and region } r .
\end{aligned}
$$

All equations in the BEAMS methodology section are broken out by building sector, type, vintage, and region. To keep the subsequent equations readable, the subscripts for these categorizations are omitted.

For new building stock, which represents annual construction, the product in Equation 2-1 provides the number of impacted units in year $t$. However, for existing buildings, this calculation actually yields a cumulative number, as represented below in Equation 2-2:

$$
U_{t}=\sum_{i=1}^{t} u_{i} \times \frac{S_{t}}{S_{i}}
$$

Where $\begin{array}{ll}\mathrm{U}_{\mathrm{t}} & =\text { cumulative surviving units impacted through year } t \\ \mathrm{u}_{\mathrm{i}} & =\text { number of units impacted in year } i \\ \mathrm{~S}_{\mathrm{t}} & =\text { building stock in year } t \\ \mathrm{~S}_{\mathrm{i}} & =\text { building stock in year } i\end{array}$

Within BEAMS, the existing building stock is defined as the total stock at the beginning of the base year, which subsequently gradually declines over time through events such as fires and demolition. The total units affected at time $t$ for existing buildings are, in effect, cumulative to that time period because penetration occurs against that same, entire (although gradually declining) stock each year. As a result, 
the number of existing-vintage installed units by year must be disaggregated, while also accounting for the effects of declining building stock on units from previous years. In other words, only the incremental units affected in a given year should be captured, and this additional step ensures that that occurs.

Equation 2-3 explicitly shows this step that addresses the problem of cumulative units for existing vintage buildings:

$$
u_{t}=U_{t}-\left(U_{t-1} \times \frac{S_{t}}{S_{t-1}}\right) \text { for } \mathrm{t}>1
$$

\subsubsection{Determine Base End-Use Loads}

End-use loads represent the baseline service requirements per square foot (commercial) or per household (residential) for heating, cooling, water heating, and lighting. The units for commercial building loads are $\mathrm{kBtu} / \mathrm{ft}^{2}$, or in the case of lighting, thousand lumen-hours $/ \mathrm{ft}^{2}$. For residential buildings the corresponding units are MMBtu/household and million lumen-hours/household. Baseline end-use loads are distinguished by building types (e.g., assembly, education, multifamily) as well as by vintage and climate zone. End-use loads were updated in June 2000 with energy use information derived from the Facility Energy Decision System (FEDS) software to reflect current energy technology and consumption behavior.

The performance improvements for envelope and whole-building projects are characterized by reductions in the end-use loads. Therefore, the base energy consumption does not have to be explicitly calculated. Instead, the load reduction is applied to the base load to determine the new load, and the resulting difference in loads is used to calculate energy savings.

\subsubsection{Determine End-Use Loads After Project Implementation}

The performance inputs for envelope and whole-building projects are defined in terms of percent load reductions. The load reductions are applied to the corresponding end-use load segment to determine the building-level load reductions by end use, as follows:

$$
\operatorname{lr}_{e, t}=L_{e, t} \times R_{e, t}
$$

Where $\quad \mathrm{lr}_{\mathrm{e}, \mathrm{t}} \quad=$ building-level load reduction (in $\mathrm{kBtu} / \mathrm{ft}^{2}$ or MMBtu/household, or in the case of lighting, thousand lumen-hours/ $\mathrm{ft}^{2}$ or million lumen-hours/household) in year $t$ for end-use $e$

$\mathrm{L}_{\mathrm{e}, \mathrm{t}} \quad=$ load in year $t\left(\mathrm{kBtu} / \mathrm{ft}^{2}, \mathrm{MMBtu} /\right.$ household, thousand lumen-hours/ $/ \mathrm{ft}^{2}$, or million lumen-hours/household) for end-use $e$

$\mathrm{R}_{\mathrm{e}, \mathrm{t}}=$ percent load reduction in year $t$ (provided in the project characterization) for enduse $e$.

The building-level load reductions are translated into aggregate load reductions by region as follows: 


$$
L R_{e, t}=I r_{e, t} \times u_{t}
$$

Where $\quad \mathrm{LR}_{\mathrm{e}, \mathrm{t}} \quad=$ regional load reduction in year $t$ for end-use $e$ (TBtu, or for lighting, trillion lumen-hours)

$\mathrm{r}_{\mathrm{e}, \mathrm{t}} \quad=$ building-level load reduction in year $t$ for end-use $e$

$\mathrm{u}_{\mathrm{t}} \quad=$ total number of units impacted in year $t$ (calculated in Equation 2-3 [existing] or Equation 2-1 [new]).

At this point, these potential load reductions are cumulated across years of the analysis. Each installation under the project continues to have savings impacts beyond the initial year of installation. The calculations, as shown in the equations below, provide aggregate load reductions in each year, while taking into account the effect of declining building stock for existing buildings. This declining building stock acts to reduce savings somewhat over time. For existing buildings:

$$
C L R_{e, t}=\sum_{i=1}^{t} L R_{e, i} \times \frac{S_{t}}{S_{i}}
$$

Where $\quad \mathrm{CLR}_{\mathrm{e}, \mathrm{t}} \quad=$ cumulative regional load reduction in year $t$ for end-use $e$ (TBtu or trillion lumenhours)

$\mathrm{LR}_{\mathrm{e}, \mathrm{i}}=$ regional load reduction in year $i$ for end-use $e$

$\mathrm{S}_{\mathrm{t}} \quad=$ building stock in year $t$

$\mathrm{S}_{\mathrm{i}} \quad=$ building stock in year $i$.

For new buildings:

$$
C L R_{e, t}=\sum_{i=1}^{t} L R_{e, i}
$$

Where $\quad \mathrm{CLR}_{\mathrm{e}, \mathrm{t}} \quad=$ cumulative regional load reduction in year $t$ for end-use $e$ (TBtu or trillion lumenhours)

$\mathrm{LR}_{\mathrm{e}, \mathrm{i}}=$ regional load reduction in year $i$ for end-use $e$.

\subsubsection{Calculate Energy Savings}

The cumulative regional load reductions must be translated into regional energy savings, requiring baseline assumptions for existing equipment efficiencies and existing equipment market shares. Equipment efficiencies were developed based on EIA's Annual Energy Outlook 2003 Supplemental Tables. Equipment market shares are broken out by market segment and are estimated based on the 1997 "Residential Energy Consumption Survey" (EIA 1999), the 1999 "Commercial Buildings Energy Consumption Survey" (EIA 1999) and NEMS data files for 2003.

First, the cumulative regional load reductions are divided by the baseline equipment efficiencies, yielding potential energy savings by equipment type and end use. For envelope projects, this efficiency is the stock efficiency, or the efficiency of the existing installed base of equipment. Envelope projects do not replace any existing pieces of equipment, impacting only the building shell. In contrast, whole-building 
projects completely renovate a building and would likely impact newly replaced or installed equipment. Sales, or current-year, equipment efficiencies are used in this case. The potential energy savings assume that each equipment type has $100 \%$ of the market, so the actual equipment market shares must then be applied. The market share for each equipment type is multiplied by the potential energy savings to determine the actual energy savings. Equation 2-8 illustrates the energy savings by equipment type and end use calculations:

$$
C E S_{e, f, q, t}=\frac{C L R_{e, t}}{e_{e, f, q, t}} \times M_{e, f, q, t}
$$

Where $\quad \mathrm{CES}_{\mathrm{e}, \mathrm{f}, \mathrm{q}, \mathrm{t}}=$ cumulative regional energy savings in year $t$ for end-use $e$, fuel type $f$, and equipment type $q$ (TBtu, or for lighting, billion $\mathrm{kWh}$ )

$\mathrm{CLR}_{\mathrm{e}, \mathrm{t}}=$ cumulative regional load reduction in year $t$ for end-use $e$

$\mathrm{e}_{\mathrm{e}, \mathrm{f}, \mathrm{q}, \mathrm{t}}=$ equipment efficiency in year $t$ for end-use $e$, fuel type $f$, and equipment type $q$ (for lighting, this is lumens/watt, for other equipment this may be in terms of AFUE, $\mathrm{COP}$, SCOP, or EF)

$\mathrm{M}_{\mathrm{e}, \mathrm{f}, \mathrm{q}, \mathrm{t}}=$ market share in year $t$ for end-use $e$, fuel type $f$, and equipment type $q$.

After converting lighting savings to TBtu, all calculated savings are aggregated by building sector, type, vintage, region, and fuel type to determine the total site electric savings, total natural gas savings, and total oil savings.

\subsubsection{Equipment Project Approach}

This section addresses projects that target equipment other than lighting. Equipment projects are characterized using new equipment efficiency.

Calculating the energy savings associated with an equipment project involves the following steps, which are discussed in the next subsections:

- Determine the size of the potential market and the number of units affected by the buildings-related project.

- Calculate adjustments to the potential market and units affected.

- Determine the base energy consumption of impacted units.

- Determine the energy consumption of impacted units after project implementation.

- Calculate the energy savings. 


\subsubsection{Determine Size of Potential Market and Number of Units Affected by the Buildings-Related Project}

Estimates of building stock, base equipment market share and life, project equipment life, and penetration rates all play a role in determining the potential market and the number of units affected by equipment projects. Unlike the relatively straightforward calculations for the envelope and whole-building projects, equipment calculations are much more complicated. The primary driver behind this is the fact that equipment projects involve devices that fail within a shorter time-frame, relative to the envelope and whole-building projects, and must be replaced during the analysis period. Despite the additional level of complexity, the initial steps are similar.

Each equipment project has a specified target market—residential and/or commercial (and their subsets), new and/or existing vintages, and north and/or south regions.

For the initial calculation, the potential market for any equipment project is, for the targeted building set, the product of the equipment stock and the base equipment replacement factor. The equipment stock is derived through multiplication of the building stock and the equipment market shares. A replacement factor is calculated as the inverse of base equipment life, and indicates the frequency of required replacements. The derivations of equipment stock and the potential market are shown in Equations 2-9 and $2-10$, respectively.

$$
S E_{e, f, q, t}=S_{t} \times M_{e, f, q, t}
$$

Where $\quad \mathrm{SE}_{\mathrm{e}, \mathrm{f}, \mathrm{q}, \mathrm{t}}=$ equipment stock in year $t$ for end-use $e$, fuel type $f$, and equipment type $q$ (billions $\mathrm{ft}^{2}$ or million households)

$\mathrm{S}_{\mathrm{t}} \quad=$ building stock in year $t$ (billion $\mathrm{ft}^{2}$ or million households)

$\mathrm{M}_{\mathrm{e}, \mathrm{f}, \mathrm{q}, \mathrm{t}}=$ equipment market share in year $t$ for end-use $e$, fuel type $f$, and equipment type $q$.

$$
P M_{e, f, q, t}=S E_{e, f, q, t} \times \frac{1}{B L i f e_{e, f, q}}=S E_{e, f, q, t} \times B R_{e, f, q}
$$

Where $\quad \mathrm{PM}_{\mathrm{e}, \mathrm{f}, \mathrm{q}, \mathrm{t}}=$ potential market in year $t$ for end-use $e$, fuel type $f$, and equipment type $q$ (billion $\mathrm{ft}^{2}$ or million households)

$\mathrm{SE}_{\mathrm{e}, \mathrm{f}, \mathrm{q}, \mathrm{t}}=$ equipment stock in year $t$ for end-use $e$, fuel type $f$, and equipment type $q$ (billion $\mathrm{ft}^{2}$ or million households)

BLife $_{\mathrm{e}, \mathrm{f}, \mathrm{q}}=$ base equipment life expectancy for end-use $e$, fuel type $f$, and equipment type $q$ (years)

$\mathrm{BR}_{\mathrm{e}, \mathrm{f}, \mathrm{q}}=$ base equipment replacement factor for end-use $e$, fuel type $f$, and equipment type $q$.

To initially calculate the number of units affected by the buildings-related project, the penetration rate, or fraction of sales, is applied to the potential market, as follows:

$$
u_{e, f, q, n f, t}=P_{e, f, q, n f, t} \times P M_{e, f, q, t}
$$


Where $\quad \mathrm{u}_{\mathrm{e}, \mathrm{f}, \mathrm{q}, \mathrm{nf}, \mathrm{t}} \quad=$ number of units affected in year $t$ for end-use $e$, existing fuel type $f$, equipment type $q$, and new fuel $n f$ (billion $\mathrm{ft}^{2}$ or million households)

$\mathrm{P}_{\mathrm{e}, \mathrm{f}, \mathrm{q}, \mathrm{ff}, \mathrm{t}}=$ penetration rate in year $t$ for end-use $e$, existing fuel type $f$, equipment type $q$, and new fuel $n f$ (provided in the project characterization)

$\mathrm{PM}_{\mathrm{e}, \mathrm{f}, \mathrm{q}, \mathrm{t}}=$ potential market in year $t$ for end-use $e$, fuel type $f$, and equipment type $q$ (billion $\mathrm{ft}^{2}$ or million households).

In reality, $f$ sufficiently represents the various possible fuel types. However, to illuminate the significant probability of fuel switching under equipment projects, $n f$ is used here to represent the fuel type of project-installed equipment. Where there is no fuel switching, $n f=f$.

In contrast to the case for envelope and whole-building projects, the basic units calculation for equipment illustrated here does not require any special handling of existing buildings. With envelope and wholebuilding projects, penetration occurs against the entire building stock. For equipment projects, penetration occurs against only a portion of the building stock because of the use of a replacement factor. As a result, the existing vintage cumulative problem described in the envelope and whole-building approach does not exist here.

\subsubsection{Calculate Adjustments to Potential Market and Units Affected}

While this initial calculation of potential market and impacted units outlined above is fairly simple, the following steps are much more involved. Because base equipment life and project equipment life may differ, a project installation (unit impacted) in year $t$ may impact the potential market in future years, which in turn affects project installations in future years. Handling this issue requires an iterative process. The results of the calculations of the previous section serve as inputs to this process.

The issue of differing base and project-sponsored equipment lives is not the only complicating factor. The annual (rather than cumulative) nature of new building stock numbers requires unique coding to ensure recompetition of new vintage installations upon failure. This treatment renders new vintage handling consistent with that for existing buildings. Without this added treatment, new vintage installations (whether base equipment or project equipment) would always be replaced with like equipment upon failure, ignoring a valid possibility of additional project penetration.

Beginning with the existing vintage case for the potential market, the calculations of this iterative updating process are outlined below as a series of conditional statements: 


$$
\begin{aligned}
& P M_{e, f, q, t}= \\
& \left(\text { If }(t-1) \geq B \text { Life } e_{e, f, q} \text { then } \frac{P M_{e, f, q,\left(t-B L i f e_{e, f, q}\right)}}{S E_{e, f, q,\left(t-B L i f e_{e, f, q}\right)}} \times S E_{e, f, q, t} \text {, else } P M_{e, f, q, t}\right) \\
& -\left(\text { If }(t-1) \geq \text { BLife }_{e, f, q} \text { then } \frac{u_{e, f, q, n f,\left(t-B L i f e_{e, f, q}\right)}}{\left.S E_{e, f, q,\left(t-B L i f e_{e}, f, q\right.}\right)} \times S E_{e, f, q, t}, \text { else } 0\right) \\
& +\left(\text { If }(t-1) \geq \text { PLife }_{e, f, q} \text { then } \frac{u_{e, f, q, n f,\left(t-P L i f e_{e, f, q}\right)}}{S E_{e, f, q,\left(t-P L i f e_{e, f, q}\right)}} \times S E_{e, f, q, t}, \text { else } 0\right)
\end{aligned}
$$

Where $\quad \mathrm{PM}_{\mathrm{e}, \mathrm{f}, \mathrm{q}, \mathrm{t}}=$ potential market in year $t$ for end-use $e$, fuel type $f$, and equipment type $q$

BLife $_{\mathrm{e}, \mathrm{f}, \mathrm{q}}=$ base equipment life expectancy for end-use $e$, fuel type $f$, and equipment type $q$ (years)

PLife $_{\mathrm{e}, \mathrm{f}, \mathrm{q}}=$ project equipment life expectancy for end-use $e$, fuel type $f$, and equipment type $q$ (years)

$\mathrm{SE}_{\mathrm{e}, \mathrm{f}, \mathrm{q}, \mathrm{t}}=$ equipment stock in year $t$ for end-use $e$, fuel type $f$, and equipment type $q$

$\mathrm{u}_{\mathrm{e}, \mathrm{f}, \mathrm{q}, \mathrm{nf}, \mathrm{t}}=$ number of units affected in year $t$ for end-use $e$, existing fuel type $f$, equipment type $q$, and new fuel $n f$.

For new buildings:

$$
\begin{aligned}
& P M_{e, f, q, t}=\left(S E_{e, f, q, t}\right)+\left(\text { If }(t-1) \geq B \text { Bife } e_{e, f, q} \text { then } P M_{e, f, q,\left(t-B L i f e_{e, f, q}\right)} \times\left(1-P_{e, f, q, n f,\left(t-B L i f e_{e, f, q}\right)}\right), \text { else } 0\right) \\
& +\left(\text { If }(t-1) \geq P \text { Life } e_{e, f, q} \text { then } u_{e, f, q, n f,\left(t-P L i f e_{e, f, q}\right)} \text { else 0 }\right)
\end{aligned}
$$

Where $\quad \mathrm{PM}_{\mathrm{e}, \mathrm{f}, \mathrm{q}, \mathrm{t}}=$ potential market in year $t$ for end-use $e$, fuel type $f$, and equipment type $q$

BLife $_{\mathrm{e}, \mathrm{f}, \mathrm{q}}=$ base equipment life expectancy for end-use $e$, fuel type $f$, and equipment type $q$ (years)

PLife $_{\mathrm{e}, \mathrm{f}, \mathrm{q}}=$ project equipment life expectancy for end-use $e$, fuel type $f$, and equipment type $q$ (years)

$\mathrm{SE}_{\mathrm{e}, \mathrm{f}, \mathrm{q}, \mathrm{t}}=$ equipment stock in year $t$ for end-use $e$, fuel type $f$, and equipment type $q$

$\mathrm{P}_{\mathrm{e}, \mathrm{f}, \mathrm{q}, \mathrm{nf}, \mathrm{t}}=$ penetration rate in year $t$ for end-use $e$, existing fuel type $f$, equipment type $q$, and new fuel $n f$

$\mathrm{u}_{\mathrm{e}, \mathrm{f}, \mathrm{q}, \mathrm{nf}, \mathrm{t}}=$ number of units affected in year $t$ for end-use $e$, existing fuel type $f$, equipment type $q$, and new fuel $n f$.

These calculations are carried out for all years sequentially for each market segment, beginning with the first year. After the potential market is recalculated for a given year, the impacted units for that year must be recalculated, using Equation 2-11. 


\subsubsection{Determine Base Energy Consumption of Impacted Units}

Building-level base energy consumption is calculated by dividing end-use loads by base equipment efficiencies. These efficiencies represent the sales, or current-year, efficiencies of equipment that would be installed absent a buildings-related project. End-use loads represent the baseline service requirements per square foot (commercial) or per household (residential) for heating, cooling, and water heating. As such, they must be divided by an efficiency to determine energy consumption:

$$
b c_{e, f, q, t}=\frac{L_{e, t}}{e_{e, f, q, t}}
$$

Where $\quad \mathrm{bc}_{\mathrm{e}, \mathrm{f}, \mathrm{q}, \mathrm{t}}=$ building-level base consumption in year $t$ for end-use $e$, fuel type $f$, and equipment type $q\left(\mathrm{kBtu} / \mathrm{ft}^{2}\right.$ or MMBtu/household)

$\mathrm{L}_{\mathrm{e}, \mathrm{t}} \quad=$ end-use load in year $t$ for end-use $e\left(\mathrm{kBtu} / \mathrm{ft}^{2}\right.$ or MMBtu/household $)$

$\mathrm{e}_{\mathrm{e}, \mathrm{f}, \mathrm{q}, \mathrm{t}}=$ base equipment efficiency in year $t$ for end-use $e$, fuel type $f$, and equipment type $q$ (AFUE, COP, SCOP, or EF).

Multiplying this result by the number of impacted units yields regional base consumption:

$$
B C_{e, f, q, t}=b c_{e, f, q, t} \times u_{e, f, q, t}
$$

Where $\quad \mathrm{BC}_{\mathrm{e}, \mathrm{f}, \mathrm{q}, \mathrm{t}}=$ regional base consumption of impacted units in year $t$ for end-use $e$, fuel type $f$, and equipment type $q$ (TBtu)

$\mathrm{bc}_{\mathrm{e}, \mathrm{f}, \mathrm{q}, \mathrm{t}}=$ building-level base consumption in year $t$ for end-use $e$, fuel type $f$, and equipment type $q\left(\mathrm{kBtu} / \mathrm{ft}^{2}\right.$ or MMBtu/household)

$\mathrm{u}_{\mathrm{e}, \mathrm{f}, \mathrm{q}, \mathrm{t}}=$ total number of units impacted in year $t$ for end-use $e$, fuel type $f$, and equipment type $q$ (billion $\mathrm{ft}^{2}$ or million households).

Because the final goal is calculating energy savings associated with impacted units, deriving total base consumption is not necessary; rather base consumption associated with impacted units only suffices.

At this point, the consumption figures are cumulated across years of the analysis. Each piece of equipment continues to consume energy throughout its lifetime. Therefore, in a given year, consumption may result from equipment installed in several previous years as well. The calculations, as shown in the equations below, provide aggregate energy consumption in each year, while taking into account the effect of declining building stock for existing buildings. This declining building stock acts to reduce consumption somewhat over time. To compare the base and project equipment's energy usage appropriately, the base consumption is cumulated over the lifetime of the project equipment. For existing buildings:

$$
C B C_{e, f, q, t}=\sum_{i=\left(t-P L i f e_{e, f, q}\right)}^{t} B C_{e, f, q, i} \times \frac{S_{t}}{S_{i}}, \text { for } \mathrm{t}>\text { PLife }
$$




$$
C B C_{e, f, q, t}=\sum_{i=1}^{t} B C_{e, f, q, i} * \frac{S_{t}}{S_{i}}, \text { for } \mathrm{t} \leq \text { PLife }
$$

Where $\quad \mathrm{CBC}_{\mathrm{e}, \mathrm{f}, \mathrm{q}, \mathrm{t}}=$ cumulative regional base energy consumption in year $t$ for end-use $e$, fuel type $f$, and equipment type $q$ (TBtu)

$\mathrm{BC}_{\mathrm{e}, \mathrm{f}, \mathrm{q}, \mathrm{i}}=$ regional base energy consumption in year $i$ for end-use $e$, fuel type $f$, and equipment type $q$

$\mathrm{S}_{\mathrm{t}} \quad=$ building stock in year $t$

$\mathrm{S}_{\mathrm{i}} \quad=$ building stock in year $i$

PLife $_{e, f, q}=$ project equipment life expectancy for end-use $e$, fuel type $f$, and equipment type $q$ (years).

For new buildings:

$$
\begin{aligned}
& C B C_{e, f, q, t}=\sum_{i=\left(t-P L i f e_{e, f, q}\right)}^{t} B C_{e, f, q, i}, \text { for } \mathrm{t}>\text { PLife } \\
& C B C_{e, f, q, t}=\sum_{i=1}^{t} B C_{e, f, q, i}, \text { for } \mathrm{t} \leq \text { PLife }
\end{aligned}
$$

Where $\quad \mathrm{CBC}_{\mathrm{e}, \mathrm{f}, \mathrm{q}, \mathrm{t}}=$ cumulative regional base energy consumption in year $t$ for end-use $e$, fuel type $f$, and equipment type $q$ (TBtu)

$\mathrm{BC}_{\mathrm{e}, \mathrm{f}, \mathrm{q}, \mathrm{i}}=$ regional base energy consumption in year $i$ for end-use $e$, fuel type $f$, and equipment type $q$

PLife $_{\mathrm{e}, \mathrm{f}, \mathrm{q}}=$ project equipment life expectancy for end-use $e$, fuel type $f$, and equipment type $q$ (years).

\subsubsection{Determine Energy Consumption of Impacted Units After Project Implementation}

The performance inputs for equipment projects are defined in terms of new equipment efficiencies. A directly parallel process to that described in the previous section (Determine Base Energy Consumption of Impacted Units) is used to calculate consumption associated with the project equipment. In this case, the initial step uses the performance inputs for the project equipment, rather than the base equipment efficiency:

$$
p c_{e, n f, q, t}=\frac{L_{e, t}}{p_{e, n f, q, t}}
$$

Where $\quad \mathrm{pc}_{\mathrm{e}, \mathrm{nf}, \mathrm{q}, \mathrm{t}}=$ building-level project consumption in year $t$ for end-use $e$, new fuel $n f$, and equipment type $q\left(\mathrm{kBtu} / \mathrm{ft}^{2}\right.$ or MMBtu/household)

$\mathrm{L}_{\mathrm{e}, \mathrm{t}} \quad=$ load in year $t$ for end-use $e\left(\mathrm{kBtu} / \mathrm{ft}^{2}\right.$ or MMBtu/household $)$

$\mathrm{p}_{\mathrm{e}, \mathrm{nf}, \mathrm{q}, \mathrm{t}}=$ project equipment efficiency in year $t$ for end-use $e$, new fuel $n f$, and equipment type $q$ (AFUE, COP, SCOP, or EF).

All other steps toward deriving cumulative regional project energy consumption, $\mathrm{CPC}$, are identical to those described in the previous section. 


\subsubsection{Calculate Energy Savings}

With equipment projects, a significant probability of fuel switching exists. To calculate energy savings where the base fuel type is the same as the buildings-related project fuel type, project consumption is subtracted from base consumption:

$$
C E S_{e, f, q, t}=C B C_{e, f, q, t}-C P C_{e, n f, q, t}
$$

Base fuel savings where the base fuel type is different from the project fuel type are simply the entire base fuel use:

$$
C E S_{e, f, q, t}=C B C_{e, f, q, t}
$$

Project fuel savings where the base fuel type is different from the project fuel type are recorded as the negative of project consumption:

$$
C E S_{e, n f, q, t}=-C P C_{e, n f, q, t}
$$

Where $\quad \mathrm{CES}_{\mathrm{e}, \mathrm{f}, \mathrm{q}, \mathrm{t}}=$ cumulative regional energy savings in year $t$ for end-use $e$, fuel type $f$, and equipment type $q(\mathrm{TBtu})$

$\mathrm{CBC}_{\mathrm{e}, \mathrm{f}, \mathrm{q}, \mathrm{t}}=$ cumulative regional base energy consumption in year $t$ for end-use $e$, fuel type $f$, and equipment type $q$ (TBtu)

$\mathrm{CPC}_{\mathrm{e}, \mathrm{nf}, \mathrm{q}, \mathrm{t}}=$ cumulative regional project energy consumption in year $t$ for end-use $e$, new fuel $n f$, and equipment type $q$ (TBtu).

These savings (with some being negative) are combined and summed over end uses and equipment to provide the final net energy savings. The final net energy savings are aggregated by building sector, type, vintage, region, and fuel type to determine the total site electric savings, total natural gas savings, and total oil savings.

\subsubsection{Lighting Project Approach}

This section addresses projects targeting lighting that are modeled using BEAMS. Lighting projects are characterized by a change in the measure of light output per unit of power, or lumens per watt.

Calculating the energy savings associated with a lighting project involves the following steps, which are discussed in the next subsections:

- Determine the size of the potential market and the number of units affected by the buildings-related project.

- Calculate adjustments to the potential market and units affected.

- Determine the base energy consumption of impacted units.

- Determine the energy consumption of impacted units after project implementation.

- Calculate the lighting energy savings. 
- Calculate the heating and cooling interactive effects factors.

- Calculate the change in space conditioning energy use due to interactive effects.

- Derive the final energy savings.

\subsubsection{Determine Size of Potential Market and Number of Units Affected by the Buildings-Related Project}

Unlike envelope and whole-building projects, lighting projects involve equipment that fails and must be replaced during the analysis period. Despite this additional level of complexity, the initial steps are similar.

Each lighting project has a specified target market: residential and/or commercial (and their subsets), new and/or existing vintages, and north and/or south regions.

For the initial calculation, the potential market for any lighting project is, for the targeted building set, the product of the equipment stock and the base equipment replacement factor. The equipment stock is derived by multiplying the building stock and the equipment market shares. A replacement factor is calculated as the inverse of base equipment life and indicates the frequency of required replacements. The derivations of equipment stock and the potential market are shown in Equations 2-24 and 2-25, respectively.

$$
S E_{e, f, q, t}=S_{t} \times M_{e, f, q, t}
$$

Where $\quad \mathrm{SE}_{\mathrm{e}, \mathrm{f}, \mathrm{q}, \mathrm{t}}=$ equipment stock in year $t$ for end-use $e$, fuel type $f$, and equipment type $q$ (billion $\mathrm{ft}^{2}$ or million households)

$\mathrm{S}_{\mathrm{t}} \quad=$ building stock in year $t$ (billion $\mathrm{ft}^{2}$ or million households)

$\mathrm{M}_{\mathrm{e}, \mathrm{f}, \mathrm{q}, \mathrm{t}}=$ equipment market share in year $t$ for end-use $e$, fuel type $f$, and equipment type $q$.

$$
P M_{e, f, q, t}=S E_{e, f, q, t} \times \frac{1}{B L i f e_{e, f, q}}=S E_{e, f, q, t} \times B R_{e, f, q}
$$

Where $\quad \mathrm{PM}_{\mathrm{e}, \mathrm{f}, \mathrm{q}, \mathrm{t}}=$ potential market in year $t$ for end-use $e$, fuel type $f$, and equipment type $q$ (billion $\mathrm{ft}^{2}$ or million households)

$\mathrm{SE}_{\mathrm{e}, \mathrm{f}, \mathrm{q}, \mathrm{t}}=$ equipment stock in year $t$ for end-use $e$, fuel type $f$, and equipment type $q$ (billion $\mathrm{ft}^{2}$ or million households)

BLife $_{\mathrm{e}, \mathrm{f}, \mathrm{q}}=$ base equipment life expectancy for end-use $e$, fuel type $f$, and equipment type $q$ (years)

$\mathrm{BR}_{\mathrm{e}, \mathrm{f}, \mathrm{q}}=$ base equipment replacement factor for end-use $e$, fuel type $f$, and equipment type $q$.

To initially calculate the number of units affected by the BT/WIP project, the penetration rate, or fraction of sales, is applied to the potential market, as follows:

$$
u_{e, f, q, t}=P_{e, f, q, t} \times P M_{e, f, q, t}
$$


Where $\quad \mathrm{u}_{\mathrm{e}, \mathrm{f}, \mathrm{q}, \mathrm{t}}=$ number of units affected in year $t$ for end-use $e$, fuel type $f$, and equipment type $q$ (billion $\mathrm{ft}^{2}$ or million households)

$\mathrm{P}_{\mathrm{e}, \mathrm{f}, \mathrm{q}, \mathrm{t}}=$ penetration rate in year $t$ for end-use $e$, fuel type $f$, and equipment type $q$ (provided in the project characterization)

$\mathrm{PM}_{\mathrm{e}, \mathrm{f}, \mathrm{q}, \mathrm{t}}=$ potential market in year $t$ for end-use $e$, fuel type $f$, and equipment type $q$ (billion $\mathrm{ft}^{2}$ or million households).

In contrast to envelope and whole-building projects, the basic units calculation for lighting illustrated here does not require any special handling of existing buildings. With envelope and whole-building projects, penetration occurs against the entire building stock. For lighting, penetration occurs against only a portion of the building stock because a replacement factor is used. As a result, the existing vintage cumulative problem described in the envelope and whole-building approach does not exist here.

\subsubsection{Calculate Adjustments to the Potential Market and Units Affected}

While this initial calculation of potential market and impacted units outlined above is fairly simple, the following steps are much more involved. Because base equipment life and project equipment life may differ (e.g., lives of CFLs and incandescents), a project installation (unit impacted) in year $t$ may impact the potential market in future years, which in turn affects project installations in future years. Handling this issue requires an iterative process. The results of the calculations of the previous section serve as inputs to this process.

The issue of differing base and buildings-related project lives is not the only complicating factor. The annual (rather than cumulative) nature of new building stock numbers requires unique coding to ensure recompetition of new vintage installations upon failure. This treatment renders new vintage handling consistent with that for existing buildings. Without this added treatment, new vintage installations (whether base equipment or project equipment) would always be replaced with like equipment upon failure, ignoring a valid possibility of additional project penetration.

Beginning with the existing vintage case for the potential market, the calculations of this iterative updating process are outlined below as a series of conditional statements:

$$
\begin{aligned}
& P M_{e, f, q, t}= \\
& \left(\text { If }(t-1) \geq B \text { Life } e_{e, f, q} \text { then } \frac{P M_{e, f, q,\left(t-B L i f e_{e, f, q}\right)}}{S E_{e, f, q,\left(t-B L i f e_{e, f, q}\right)}} \times S E_{e, f, q, t} \text {, else } P M_{e, f, q, t}\right) \\
& -\left(\text { If }(t-1) \geq B \text { Bife } e_{e, f, q} \text { then } \frac{u_{e, f, q,\left(t-B L i f e_{e, f, q}\right)}}{S E_{e, f, q,\left(t-B L i f e_{e, f, q}\right)}} \times S E_{e, f, q, t}, \text { else } 0\right) \\
& +\left(\text { If }(t-1) \geq \text { PLife }_{e, f, q} \text { then } \frac{u_{e, f, q,\left(t-P L i f e_{e, f, q}\right)}}{S E_{e, f, q,\left(t-P L i f e_{e, f, q}\right)}} \times S E_{e, f, q, t}, \text { else } 0\right)
\end{aligned}
$$

Where $\quad \mathrm{PM}_{\mathrm{e}, \mathrm{f}, \mathrm{q}, \mathrm{t}}=$ potential market in year $t$ for end-use $e$, fuel type $f$, and equipment type $q$ 


$$
\begin{aligned}
\text { BLife }_{\mathrm{e}, \mathrm{f}, \mathrm{q}}= & \text { base equipment life expectancy for end-use } e \text {, fuel type } f \text {, and equipment type } q \\
& \text { (years) } \\
\mathrm{PLife}_{\mathrm{e}, \mathrm{f}, \mathrm{q}}= & \begin{array}{l}
\text { project equipment life expectancy for end-use } e \text {, fuel type } f \text {, and equipment type } q \\
\text { (years) }
\end{array} \\
\mathrm{SE}_{\mathrm{e}, \mathrm{f}, \mathrm{q}, \mathrm{t}}= & \text { equipment stock in year } t \text { for end-use } e \text {, fuel type } f \text {, and equipment type } q \\
\mathrm{u}_{\mathrm{e}, \mathrm{f}, \mathrm{q}, \mathrm{t}}= & \text { number of units affected in year } t \text { for end-use } e, \text { fuel type } f \text {, and equipment type } q .
\end{aligned}
$$

For new buildings:

$$
\begin{aligned}
& P M_{e, f, q, t}=\left(S E_{e, f, q, t}\right)+\left(\text { If }(t-1) \geq B \text { Bife } e_{e, f, q} \text { then } P M_{e, f, q,\left(t-B L i f e_{e, f, q}\right)} \times\left(1-P_{e, f, q,\left(t-B L i f e_{e, f, q}\right)}\right), \text { else } 0\right) \\
& +\left(\text { If }(t-1) \geq P \text { Life } e_{e, f, q} \text { then } u_{e, f, q,\left(t-P L i f e_{e, f, q}\right)} \text {, else } 0\right)
\end{aligned}
$$

Where $\quad \mathrm{PM}_{\mathrm{e}, \mathrm{f}, \mathrm{q}, \mathrm{t}}=$ potential market in year $t$ for end-use $e$, fuel type $f$, and equipment type $q$

BLife $_{\mathrm{e}, \mathrm{f}, \mathrm{q}}=$ base equipment life expectancy for end-use $e$, fuel type $f$, and equipment type $q$ (years)

PLife $_{\mathrm{e}, \mathrm{f}, \mathrm{q}}=$ project equipment life expectancy for end-use $e$, fuel type $f$, and equipment type $q$ (years)

$\mathrm{SE}_{\mathrm{e}, \mathrm{f}, \mathrm{q}, \mathrm{t}}=$ equipment stock in year $t$ for end-use $e$, fuel type $f$, and equipment type $q$

$\mathrm{P}_{\mathrm{e}, \mathrm{f}, \mathrm{q}, \mathrm{t}}=$ penetration rate in year $t$ for end-use $e$, fuel type $f$, and equipment type $q$

$\mathrm{u}_{\mathrm{e}, \mathrm{f}, \mathrm{q}, \mathrm{t}}=$ number of units affected in year $t$ for end-use $e$, fuel type $f$, and equipment type $q$.

These calculations are carried out for all years sequentially for each market segment, beginning with the first year. After the potential market is recalculated for a given year, the impacted units for that year must be recalculated, using Equation 2-26 above.

\subsubsection{Determine Base Energy Consumption of Impacted Units}

Building-level base energy consumption is calculated by dividing end-use loads by base equipment efficiencies. These efficiencies represent the sales, or current-year, efficiencies of equipment that would be installed absent a buildings-related project. End-use loads represent the baseline service requirements per square foot (commercial) or per household (residential) for lighting. As such, they must be divided by an efficiency to determine energy consumption:

$$
b c_{e, f, q, t}=\frac{L_{e, t}}{e_{e, f, q, t}}
$$

Where $\quad \mathrm{bc}_{\mathrm{e}, \mathrm{f}, \mathrm{q}, \mathrm{t}}=$ building-level base consumption in year $t$ for end-use $e$, fuel type $f$, and equipment type $q\left(\mathrm{kWh} / \mathrm{ft}^{2}\right.$ or $\mathrm{MWh} /$ household $)$

$\mathrm{L}_{\mathrm{e}, \mathrm{t}} \quad=$ end-use load in year $t$ for end-use $e$ (thousand lumen-hours/ $\mathrm{ft}^{2}$ or million lumenhours/household)

$\mathrm{e}_{\mathrm{e}, \mathrm{f}, \mathrm{q}, \mathrm{t}}=$ base equipment efficiency in year $t$ for end-use $e$, fuel type $f$, and equipment type $q$ (lumens/watt). 
Multiplying this result by the number of impacted units yields regional base consumption:

$$
B C_{e, f, q, t}=b c_{e, f, q, t} \times u_{e, f, q, t}
$$

Where $\quad \mathrm{BC}_{\mathrm{e}, \mathrm{f}, \mathrm{q}, \mathrm{t}}=$ regional base consumption of impacted units in year $t$ for end-use $e$, fuel type $f$, and equipment type $q$ (billion $\mathrm{kWh}$ )

$\mathrm{bc}_{\mathrm{e}, \mathrm{f}, \mathrm{q}, \mathrm{t}}=$ building-level base consumption in year $t$ for end-use $e$, fuel type $f$, and equipment type $q\left(\mathrm{kWh} / \mathrm{ft}^{2}\right.$ or $\mathrm{MWh} /$ household $)$

$\mathrm{u}_{\mathrm{e}, \mathrm{f}, \mathrm{q}, \mathrm{t}}=$ total number of units impacted in year $t$ for end-use $e$, fuel type $f$, and equipment type $q$ (billion $\mathrm{ft}^{2}$ or million households).

This result is converted from billion $\mathrm{kWh}$ to TBtu, using a standard conversion of $3412 \mathrm{BTU} / \mathrm{kWh}$.

Because the final goal is to calculate energy savings associated with impacted units, deriving total base consumption is not necessary; rather base consumption associated with impacted units only suffices.

At this point, the consumption figures are cumulated across years of the analysis. Each piece of equipment continues to consume energy throughout its lifetime. Therefore, in a given year, consumption may result from equipment installed in several previous years as well. The calculations, as shown in the equations below, provide aggregate energy consumption in each year, while taking into account the effect of declining building stock for existing buildings. This declining building stock acts to reduce consumption somewhat over time. To compare the base and project equipment's energy usage appropriately, the base consumption is cumulated over the lifetime of the project equipment. For existing buildings:

$$
\begin{aligned}
& C B C_{e, f, q, t}=\sum_{i=\left(t-P L i f e_{e, f, q}\right)}^{t} B C_{e, f, q, i} \times \frac{S_{t}}{S_{i}}, \text { for } \mathrm{t}>\text { PLife } \\
& C B C_{e, f, q, t}=\sum_{i=1}^{t} B C_{e, f, q, i} \times \frac{S_{t}}{S_{i}}, \text { for } \mathrm{t} \leq \text { PLife }
\end{aligned}
$$

Where $\quad \mathrm{CBC}_{\mathrm{e}, \mathrm{f}, \mathrm{q}, \mathrm{t}}=$ cumulative regional base energy consumption in year $t$ for end-use $e$, fuel type $f$, and equipment type $q$ (TBtu)

$\mathrm{BC}_{\mathrm{e}, \mathrm{f}, \mathrm{q}, \mathrm{i}}=$ regional base energy consumption in year $i$ for end-use $e$, fuel type $f$, and equipment type $q$

$\mathrm{S}_{\mathrm{t}} \quad=$ building stock in year $t$

$\mathrm{S}_{\mathrm{i}} \quad=$ building stock in year $i$

PLife $_{\mathrm{e}, \mathrm{f}, \mathrm{q}}=$ project equipment life expectancy for end-use $e$, fuel type $f$, and equipment type $q$ (years).

For new buildings:

$$
C B C_{e, f, q, t}=\sum_{i=\left(t-P L i f e_{e, f, q}\right)}^{t} B C_{e, f, q, i} \text {, for } \mathrm{t}>\text { PLife }
$$




$$
C B C_{e, f, q, t}=\sum_{i=1}^{t} B C_{e, f, q, i}, \text { for } \mathrm{t} \leq \text { PLife }
$$

Where $\quad \mathrm{CBC}_{\mathrm{e}, \mathrm{f}, \mathrm{q}, \mathrm{t}}=$ cumulative regional base energy consumption in year $t$ for end-use $e$, fuel type $f$, and equipment type $q$ (TBtu)

$\mathrm{BC}_{\mathrm{e}, \mathrm{f}, \mathrm{q}, \mathrm{i}}=$ regional base energy consumption in year $i$ for end-use $e$, fuel type $f$, and equipment type $q$

PLife $_{\mathrm{e}, \mathrm{f}, \mathrm{q}}=$ project equipment life expectancy for end-use $e$, fuel type $f$, and equipment type $q$ (years).

\subsubsection{Determine Energy Consumption of Impacted Units After Project Implementation}

The performance inputs for lighting projects are defined in terms of new equipment efficiencies. A directly parallel process to that described in the previous section (Determine Base Energy Consumption of Impacted Units) is used to calculate consumption associated with the project equipment. In this case, the initial step uses the performance inputs for the project equipment, rather than the base equipment efficiency:

$$
p c_{e, f, q, t}=\frac{L_{e, t}}{p_{e, f, q, t}}
$$

Where $\quad \mathrm{pc}_{\mathrm{e}, \mathrm{f}, \mathrm{q}, \mathrm{t}}=$ building-level project consumption in year $t$ for end-use $e$, fuel $f$, and equipment type $q\left(\mathrm{kWh} / \mathrm{ft}^{2}\right.$ or $\mathrm{MWh} /$ household $)$

$\mathrm{L}_{\mathrm{e}, \mathrm{t}} \quad=$ load in year $t$ for end-use $e$ (thousand lumen-hours $/ \mathrm{ft}^{2}$ or million lumenhours/household)

$\mathrm{p}_{\mathrm{e}, \mathrm{f}, \mathrm{q}, \mathrm{t}}=$ project equipment efficiency in year $t$ for end-use $e$, fuel $f$, and equipment type $q$ (lumens/watt).

All other steps toward deriving cumulative regional project energy consumption, $\mathrm{CPC}$, are identical to those described in the previous section.

\subsubsection{Calculate Lighting Energy Savings}

Unlike equipment projects, where a significant probability of fuel switching exists, the lighting case is more straightforward. To calculate lighting energy savings, project consumption is subtracted from base consumption:

$$
C E S_{e, f, q, t}=C B C_{e, f, q, t}-C P C_{e, f, q, t}
$$

Where $\quad \mathrm{CES}_{\mathrm{e}, \mathrm{f}, \mathrm{q}, \mathrm{t}}=$ cumulative regional energy savings in year $t$ for end-use $e$, fuel type $f$, and equipment type $q$ (TBtu)

$\mathrm{CBC}_{\mathrm{e}, \mathrm{f}, \mathrm{q}, \mathrm{t}}=$ cumulative regional base energy consumption in year $t$ for end-use $e$, fuel type $f$, and equipment type $q(\mathrm{TBtu})$ 


$$
\begin{aligned}
\mathrm{CPC}_{\mathrm{e}, \mathrm{f}, \mathrm{q}, \mathrm{t}}= & \text { cumulative regional project energy consumption in year } t \text { for end-use } e \text {, fuel } f \text {, and } \\
& \text { equipment type } q(\mathrm{TBtu})
\end{aligned}
$$

\subsubsection{Calculate Heating and Cooling Interactive Effects Factors}

A change in lighting consumption significantly impacts other end uses as well. As more efficient lighting is incorporated in buildings, heating loads can be expected to increase, while cooling loads should be reduced. These interactions are accounted for through the development and use of lighting interaction factors. BEAMS incorporates interactive effects coefficients as inputs, which are used to derive heating and cooling load change factors.

\subsection{Derivation of the interactive effects coefficients-Baseline}

Baseline loads were determined using NEMSFEDS, an iteration tool based on FEDS that allows a single case to be modified and run (loads only) by altering inputs to a [casename].ini file. In this manner a single case can be used to run a multi-dimensional matrix of all combinations of building type, size, vintage, location, occupancy, and lighting configurations. Statistical data of actual building size and vintage information were then used to combine the NEMSFEDS results into a location by building type results matrix where each building type is of the weighted average size and weighted average vintage (for existing) or 2000 vintage for new buildings.

Values were determined for all combinations of the following:

- Commercial, residential, and industrial building types

- New and existing buildings

- Nine census regions (and north and south for BEAMS).

\subsection{Derivation of the interactive effects coefficients-Variation from Baseline}

Lighting consumption was decreased from $100 \%$ to $0 \%$ with $10 \%$ steps. As a result of the decrease in lighting consumption, the heating load increased and the cooling load decreased. The fractional increases in the heating load and fractional decreases in the cooling load were then determined at each of the steps. Lastly, the results were converted via regression to equations (one for heat and one for cooling for each combination of building type, new/existing, and location) where the only input is the percentage reduction in the lighting consumption. The regression equations are of the form:

$$
\begin{aligned}
& \text { sheat }=a \times \Delta L^{b} \\
& \Delta \text { cool }=c \times \Delta L^{2}+d \times \Delta L
\end{aligned}
$$

Where $a, b, c$, and $d$ are the interactive effects coefficients

$\Delta$ heat $=$ the fractional change in heating load

$\Delta \mathrm{cool}=$ the fractional change in cooling load

$\Delta \mathrm{L}=$ the percentage reduction in lighting consumption. 


\subsection{Specification}

Because of the way this was modeled the implicit assumption is that a $20 \%$ penetration rate means that $20 \%$ of the lighting within all buildings of a certain type, vintage, and region get the buildings-related technology. Hence the $20 \%$ value can be used directly. The alternative, which could also be easily modeled using the data generated in this activity, is that $20 \%$ of the buildings within a certain type, vintage, and region have $100 \%$ of the buildings-related technology. This would require that a weighted average be developed (20\% with $100 \%$ penetration and $80 \%$ with $0 \%$ penetration).

\subsection{Calculation of Interactive Effects Factors}

To calculate the necessary input, $\Delta \mathrm{L}$, the previously calculated cumulative regional base consumption and energy savings are first aggregated across equipment types, as the lighting source does not affect the interactive effects. The percentage reduction in lighting consumption is calculated as:

$$
\Delta L=\left(\frac{C E S_{t}}{C B C_{t}}\right) \times 100
$$

Where $\Delta \mathrm{L} \quad=$ the percentage reduction in lighting consumption

$\mathrm{CES}_{\mathrm{t}}=$ cumulative regional lighting energy savings in year $t$ (TBtu)

$\mathrm{CBC}_{\mathrm{t}}=$ cumulative regional base lighting consumption in year $t(\mathrm{TBtu})$.

At this point, the required components for calculating the interactive effects factors are available. Using Equations 2-37 and 2-38, $\Delta$ heat and $\Delta$ cool are computed.

\subsubsection{Calculate Change in Space Conditioning Energy Use Due to Interactive Effects}

The load changes from interactive effects are calculated by applying the interactive effects factors to the cumulative regional lighting energy savings (calculated previously in equations 2-36). As noted earlier, as lighting efficiency increases, cooling loads decrease and heating loads increase. As a result, the calculated values for $\Delta$ heat are positive, and those for $\Delta$ cool are negative. Because the load reduction, rather than the change in load, is the desired output, a sign change is applied in the following calculation:

For heating:

$$
I L R_{e, f, q, t}=C E S_{e, f, q, t} \times(-\Delta h e a t)
$$

For cooling:

$$
I L R_{e, f, q, t}=C E S_{e, f, q, t} \times(-\Delta c o o l)
$$

Where $\quad \operatorname{ILR}_{\mathrm{e}, \mathrm{f}, \mathrm{q}, \mathrm{t}}=$ load reductions in year $t$ due to interactive effects for end-use $e$, fuel type $f$, and equipment type $q$ (TBtu) 


$$
\begin{aligned}
\mathrm{CES}_{\mathrm{e}, \mathrm{f}, \mathrm{q}, \mathrm{t}}= & \text { cumulative regional energy savings for end-use } e, \text { fuel type } f, \text { and equipment type } \\
& q(\mathrm{TBtu}) \\
\Delta \text { heat }= & \text { the fractional change in heating load } \\
\Delta \mathrm{cool}= & \text { the fractional change in cooling load. }
\end{aligned}
$$

These load reductions must be translated into energy savings. To do this, baseline assumptions regarding existing equipment efficiencies and existing equipment market shares are used. First, the load reductions resulting from interactive effects are divided by the baseline existing equipment efficiencies, which yields potential energy savings by equipment type and end use. The potential energy savings assume that each equipment type has $100 \%$ of the market, so the actual equipment market shares must then be applied. The market share for each equipment type is multiplied by the potential energy savings to determine the actual energy savings. Equation 2-42 illustrates the energy savings by equipment type and end use calculations:

$$
I E S_{e, f, q, t}=\frac{I L R_{e, f, q, t}}{e_{e, f, q, t}} \times M_{e, f, q, t}
$$

Where $\quad \operatorname{IES}_{\mathrm{e}, \mathrm{f}, \mathrm{q}, \mathrm{t}}=$ energy savings in year $t$ due to interactive effects for end-use $e$, fuel type $f$, and equipment type $q$ (TBtu)

$\mathrm{ILR}_{\mathrm{e}, \mathrm{f}, \mathrm{q}, \mathrm{t}}=$ load reductions in year $t$ due to interactive effects for end-use $e$, fuel type $f$, and equipment type $q$ (TBtu)

$\mathrm{e}_{\mathrm{e}, \mathrm{f}, \mathrm{q}, \mathrm{t}}=$ equipment efficiency in year $t$ for end-use $e$, fuel type $f$, and equipment type $q$ (AFUE, COP, or SCOP)

$\mathrm{M}_{\mathrm{e}, \mathrm{f}, \mathrm{q}, \mathrm{t}}=$ equipment market share in year $t$ for end-use $e$, fuel type $f$, and equipment type $q$.

\subsubsection{Derive Final Energy Savings}

The lighting energy savings and the space-conditioning energy savings are combined and summed over end uses and equipment to provide the final net energy savings. The final net energy savings are aggregated by building sector, type, vintage, region, and fuel type to determine the total site electric savings, total natural gas savings, and total oil savings.

\subsubsection{Other Components}

This section addresses calculations made within BEAMS that occur after the individual energy algorithms described above. Each of the following computations applies not only to BEAMS-estimated projects but also to projects with savings estimated by NEMS-PNNL or spreadsheets models. For projects estimated by methods other than BEAMS, site energy savings (electric, gas, and oil), investment, and any nonenergy costs are first imported into BEAMS. These inputs are broken out by building sector, type, vintage, region, and year, as are all final outputs of the calculations described below. 


\subsubsection{Calculate Primary Energy Savings}

For BEAMS-estimated projects, site energy savings are calculated within the algorithms already discussed above. For other projects, site energy savings are provided to BEAMS as an input. Total site energy consists of site electric, natural gas, and fuel oil savings. To derive primary electric savings, the external site electricity savings are multiplied by a year-specific electricity conversion factor within BEAMS. Primary non-electric savings consists of the sum of natural gas and oil savings. Summation of primary electricity and primary non-electric savings yields the total net primary energy savings. The units for all of these data are TBtu.

\subsubsection{Calculate Emissions Reductions and Energy Cost Savings}

BEAMS input data include energy prices and site-energy emission factors, both of which are building sector-, fuel- (electric, gas, and oil), and year-specific. Emission factors are included for carbon equivalent emissions, sulfur dioxide, nitrous oxides, volatile organic compounds, particulate matter, and carbon monoxide. EERE's GPRA guidance provided the various factors used ((Draft letter, Office of Energy Efficiency and Renewable Energy. April 1, 2002. "Performance Planning Guidance (GPRA Data Call) FY 2004-FY 2008 Budget Cycle.” US Department of Energy, Washington, D.C.). Factors are multiplied by site energy savings, and prices are multiplied by the respective fuel savings. The resulting energy cost savings are reported in millions of dollars, and the emissions reductions are represented as millions of metric tons (MMton) avoided.

\subsubsection{Determine Required Investment and Non-energy Costs}

For projects estimated outside of BEAMS, investment and non-energy costs are provided as an input to BEAMS. For BEAMS-estimated projects, investment and non-energy costs are output as part of the process, and their estimation relies on the installed units calculated in the above algorithms. These units are in terms of either million households (residential), or billion square feet (commercial) building sectors. Per-unit equipment costs (dollars per square foot or dollars per household) are multiplied by installed units, as Equation 2-43 shows:

$$
I_{t}=c_{t} \times u_{t}
$$

Where $\quad \mathrm{I}_{\mathrm{t}} \quad=$ investment in year $t$

$\mathrm{c}_{\mathrm{t}} \quad=$ per-unit installed cost in year $t$

$\mathrm{u}_{\mathrm{t}} \quad=$ number of units impacted in year $t$.

Similarly, non-energy costs are calculated as follows:

$$
N E_{t}=n e_{t} \times u_{t}
$$

Where $\quad \begin{array}{ll}\mathrm{NE}_{\mathrm{t}} & =\text { non-energy cost in year } t \\ \mathrm{ne}_{\mathrm{t}} & =\text { per-unit non-energy cost in year } t \\ \mathrm{u}_{\mathrm{t}} & =\text { number of units impacted in year } t .\end{array}$ 
Each of these calculations is performed for base costs, project costs, and the incremental costs. After necessary conversions, the resulting investment and non-energy costs are reported in millions of dollars.

\subsection{General Methodology Using NEMS-PNNL}

Many of the buildings-related projects target specific types of equipment. Equipment projects are characterized by new equipment efficiencies and are compared with "baseline" efficiencies to calculate energy savings. To determine the penetration of the project-sponsored equipment relative to the more conventional equipment, a modified version of the NEMS model (NEMS-PNNL) employed for EIA's Annual Energy Outlook (EIA 1999) was used.

NEMS-PNNL selects specific technologies to meet the energy services demands by choosing among a discrete set of technologies that are externally characterized by commercial availability, capital costs, operating and maintenance costs, efficiencies, and lifetime. NEMS-PNNL is coded to allow several possible assumptions to be used about consumer behavior to model this selection process. For the GPRA effort, the menu of equipment was changed to include relevant project equipment, technological innovations, and standards.

The NEMS-PNNL design can accommodate various technology choices. For the GPRA effort, the NEMS-PNNL data input were adjusted to reflect DOE technology choices. For buildings-related projects that target efficiency of the building envelope (or shell), specific shell-efficiency indices were read into the model.

The NEMS-PNNL commercial and residential demand modules generate forecasts of energy demand (energy consumption) for the commercial and residential sectors. The commercial demand module generates fuel consumption forecasts for electricity, natural gas, and distillate fuel oil. These forecasts are based on energy prices and macroeconomic variables from the NEMS system, combined with external data sources. The residential model uses energy prices and macroeconomic indicators to generate energy consumption by fuel type and census division in the residential sector. The commercial and residential demand modules are described in the following subsections.

\subsubsection{Commercial Demand}

This module develops projects of energy consumption by major types of commercial buildings, including assembly, education, food service, food sales, health care, lodging, mercantile and service, office buildings, and warehouses. Commercial energy demand within NEMS-PNNL is calculated in four basic steps:

1. Forecast commercial sector floorspace.

2. Forecast energy services such as space conditioning equipment, lighting, water heating, and refrigeration.

3. Select specific technologies to meet the demand of energy services, which involves modeling consumer behavior and capturing the decision between such equipment as incandescent lights and fluorescent lights.

4. Determine how much energy will be consumed by the equipment chosen to meet the demand for energy services. 
The third step is a key element in calculating the estimated energy savings of a given technology promoted by a particular buildings-related project. Within this step, consumers are assumed to purchase energy-using equipment to meet three types of service demands: services for new buildings, replacement of old equipment that is at the end of its technical life, and replacement of old equipment that is at the end of its economic life (although it still may be technically viable). The NEMS-PNNL commercial model is structured to allow the use of several possible assumptions about consumer behavior to model this decision process. The assumptions are designed to represent empirically the range of economic factors that most influence the consumer's decision and include the following:

- Consumer buys the equipment with the minimum life-cycle cost.

- Consumer buys equipment that uses the same fuel as existing and retiring equipment but minimizes costs across technologies using that fuel.

- Consumer buys (or keeps) the same technology as the existing and retiring equipment but chooses among different efficiency levels based on minimum life-cycle cost.

The model is designed to choose among a discrete set of technologies that are externally characterized by commercial availability, capital costs, operating and maintenance costs, efficiencies, and lifetime. For GPRA metrics, the menu of equipment may be altered to include relevant DOE project equipment, technological innovations, and standards. The NEMS-PNNL design can accommodate a changing menu of technology choices, recognizing that changes in energy prices and consumer demand may significantly change the set of relevant technologies that the model user wishes to consider.

\subsubsection{Residential Demand}

The residential sector demand module includes single-family, multifamily, and mobile home dwellings. Residential energy demand is modeled using a sequence of five steps:

1. Forecast housing stock.

2. Select the specific technologies to meet the demand for each energy service (e.g. furnaces and heat pumps).

3. Forecast appliance stocks that are required by each end-use service.

4. Forecast changes in building-shell integrity; building-shell efficiency in new construction is assumed to improve over the forecast period because of stricter building codes and other efficiency projects and may fluctuate in response to fuel price changes from the base year.

5. Calculate the energy consumed by the equipment chosen to meet the demand for energy services.

As with the commercial model, the GPRA metrics methodology involves modifying the technology performance and cost inputs to reflect the DOE project-developed equipment. The technology and equipment selection simulates the behavior of residential consumers based on the relative importance of life-cycle costs, capital costs, and operating costs of competing technologies within a service. Decisions on new and replacement equipment reflect additional factors beyond the traditional life-cycle cost methodology, including space heating fuel choice and previous equipment choices. The technology and equipment selection allocates end-use services based on a defined equipment menu of the various technologies and fuels that compete in the market. 


\subsubsection{Methodology for Market Transformation-Type Projects}

This section discusses the methodological approach to calculating energy savings for projects that attempt to increase sales by modifying consumer behavior.

For a few appliances, some changes were made in the baseline assumptions made by EIA. The reasons for these changes are briefly discussed.

EIA labeled the two modeling parameters as Beta1 and Beta2. Beta1 is used as multiplicative factor with the initial cost of the appliance, and Beta2 is used to multiply the annual energy cost. The sum of the two products (i.e., Beta $1 \times$ initial cost + Beta $2 \times$ operating cost) is used in the logit specification to yield market shares for each technology. These coefficients are specific to each equipment type and fuel type. As a rough approximation, the ratio of Beta1/Beta2 can be interpreted as the consumer discount rate for the specific appliance. The Beta1 and Beta2 coefficients are contained with the cost and efficiency data inputs in the file RTEKTY. In the residential NEMS module, the Beta1 and Beta 2 coefficients vary among appliances, as do the resulting discount rates. For example, the implied discount rate for refrigerators is $16 \%$. On the other hand, the discount rate is estimated to be over $80 \%$ for electric water heaters.

\subsubsection{Methodology for Equipment Projects}

NEMS-PNNL was used to estimate the energy savings associated with equipment products being developed under buildings-related projects by modifying the NEMS-PNNL input files (RTEKTY.txt for residential, KTECH.wk1 for commercial) for each type of equipment.

For a few appliances, some changes were made in EIA's baseline assumptions. Where the original Annual Energy Outlook input file does not reflect pending standards that are scheduled to take effect during the analysis period, modifications were made to crudely account for these standards.

One issue related to assessing benefits with the NEMS-PNNL model is the appropriate discount rate to use. If the implied discount rate is too high, discouraging most consumers from choosing the technology, then the logit parameters, Beta1 and Beta2, may be modified. Energy Star or other market transformation projects provide impetus for increased market acceptance of selected technologies. Therefore, when appropriate, parameters are modified to decrease the implied discount rate (i.e., encourage consumers to choose this technology earlier) for the technologies targeted by these projects.

The project's energy savings are therefore calculated as the difference between NEMS-PNNL model runs that 1) include the technology assumed in the Annual Energy Outlook base case and 2) substitute the lower-cost units assumed to stem from the buildings-related project.

\subsubsection{GPRA Envelope Calculations Using NEMS-PNNL}

The general approach for GPRA envelope calculations using NEMS-PNNL was to simulate the effect of an envelope technology using the FEDS model for many different building types, sizes, vintages, and locations. The heating and cooling loads were calculated for each building with and without the envelope technology being evaluated. The changes in the heating and cooling loads were then used to modify the 
heating and cooling envelope factors in NEMS-PNNL. These factors were input as a vector for each building type and census region; these vectors captured both the thermal impact and the expected market penetration by year. Market penetration estimates were based on input from the DOE project manager or their representatives.

\subsubsection{FEDS Modeling}

To estimate the national impact of introducing a new envelope technology, the impact of that technology must be accurately captured within the buildings where it is likely to be employed. For each technology, the impact was simulated in 3,960 commercial buildings and 1,188 residential buildings representing all combinations of building type, size, vintage, and location (see Table 2.1).

\subsubsection{Aggregating FEDS Results for NEMS-PNNL}

Because NEMS-PNNL only models one of each building type in each of the nine census regions, the FEDS results needed to be aggregated for input into NEMS-PNNL.

City Weights. The cities shown in Table 2.1 were selected for the FEDS analysis because the weather is characteristic of the climate in the different portions of the census regions. Because NEMS operates on a census region basis, weighted averages of the FEDS results for individual weather cities were produced to represent the loads within a census region. Table 2.2 shows the weights given to each city for each census region. 
Table 2.1. Building Simulation Parameters

\begin{tabular}{|c|c|c|c|}
\hline Building Type & Building Size $\left(\mathbf{f t}^{2}\right)$ & $\begin{array}{l}\text { Vintage (Year } \\
\text { Built) }\end{array}$ & Location \\
\hline Assembly & \multirow{10}{*}{$\begin{array}{l}4000 \\
7500 \\
17500 \\
37500 \\
75000 \\
125000\end{array}$} & \multirow{22}{*}{$\begin{array}{l}1940 \\
1953 \\
1967 \\
1976 \\
1983 \\
2000\end{array}$} & \multirow{22}{*}{$\begin{array}{l}\text { Denver, Colorado } \\
\text { Detroit, Michigan } \\
\text { Fresno, California } \\
\text { Knoxville, Tennessee } \\
\text { Los Angeles, California } \\
\text { Minneapolis, Minnesota } \\
\text { Phoenix, Arizona } \\
\text { Providence, Rhode Island } \\
\text { Seattle, Washington } \\
\text { Shreveport, Louisiana } \\
\text { Tampa, Florida }\end{array}$} \\
\hline Education & & & \\
\hline Food Sales & & & \\
\hline Food Service & & & \\
\hline Healthcare & & & \\
\hline Lodging & & & \\
\hline Mercantile and Service & & & \\
\hline Office & & & \\
\hline Warehouse & & & \\
\hline $\begin{array}{l}\text { Other Commercial } \\
\text { Buildings }\end{array}$ & & & \\
\hline Single Family & \multirow{6}{*}{$\begin{array}{c}600 \\
800 \\
1300 \\
1800 \\
2200 \\
3000^{*}\end{array}$} & & \\
\hline Mobile Home & & & \\
\hline & & & \\
\hline & & & \\
\hline & & & \\
\hline & & & \\
\hline \multirow[t]{6}{*}{ Multifamily } & 14309 & & \\
\hline & 19079 & & \\
\hline & 31003 & & \\
\hline & 42927 & & \\
\hline & 52466 & & \\
\hline & 71545 & & \\
\hline
\end{tabular}


Table 2.2. Weights Given to Each City for Each Census Region (\%)

\begin{tabular}{||l|c|c|c|c|c|c|c|c|c||}
\hline \multicolumn{1}{|c|}{ City } & $\begin{array}{c}\text { New } \\
\text { England }\end{array}$ & $\begin{array}{c}\text { Mid } \\
\text { Atlantic }\end{array}$ & $\begin{array}{c}\text { East } \\
\text { North } \\
\text { Central }\end{array}$ & $\begin{array}{c}\text { West } \\
\text { North } \\
\text { Central }\end{array}$ & $\begin{array}{c}\text { East } \\
\text { South } \\
\text { Atlantic }\end{array}$ & $\begin{array}{c}\text { West } \\
\text { South } \\
\text { Central }\end{array}$ & $\begin{array}{c}\text { South } \\
\text { Central }\end{array}$ & Mountain & Pacific \\
\hline Denver & 0.0 & 0.0 & 0.0 & 0.0 & 0.0 & 0.0 & 0.0 & 64.0 & 2.2 \\
\hline Detroit & 0.0 & 0.0 & 99.3 & 60.0 & 0.0 & 0.0 & 0.0 & 0.0 & 0.0 \\
\hline Fresno & 0.0 & 0.0 & 0.0 & 0.0 & 0.0 & 0.0 & 0.0 & 0.0 & 13.3 \\
\hline Knoxville & 0.0 & 0.0 & 0.0 & 0.0 & 50.7 & 67.4 & 13.4 & 0.0 & 0.0 \\
\hline Los Angeles & 0.0 & 0.0 & 0.0 & 0.0 & 0.0 & 0.0 & 0.0 & 0.0 & 71.2 \\
\hline Minneapolis & 0.0 & 0.0 & 0.7 & 40.0 & 0.0 & 0.0 & 0.0 & 0.0 & 0.0 \\
\hline Phoenix & 0.0 & 0.0 & 0.0 & 0.0 & 0.0 & 0.0 & 0.0 & 36.0 & 0.0 \\
\hline Providence & 100.0 & 100.0 & 0.0 & 0.0 & 0.0 & 0.0 & 0.0 & 0.0 & 0.0 \\
\hline Seattle & 0.0 & 0.0 & 0.0 & 0.0 & 0.0 & 0.0 & 0.0 & 0.0 & 13.2 \\
\hline Shreveport & 0.0 & 0.0 & 0.0 & 0.0 & 17.7 & 32.6 & 80.6 & 0.0 & 0.0 \\
\hline Tampa & 0.0 & 0.0 & 0.0 & 0.0 & 31.6 & 0.0 & 6.0 & 0.0 & 0.0 \\
\hline
\end{tabular}

Floor Area Weights. The fraction of floor space within each size category for each commercial building type was determined using data from 1995 "Commercial Buildings Energy Consumption Survey"c (EIA 1995) and is shown in Table 2.3.

Table 2.4 shows the fraction of floor space within each size category for each residential building type (single family, mobile homes, and multifamily). The data for single-family and mobile homes were determined using data from the 1997 "Residential Energy Consumption Survey"d (EIA 1997) and the data for multifamily homes were determined using data from survey and apartment stock data from the National Multi-Housing Council. ${ }^{\mathrm{e}}$

Vintage Weights. For simplicity, all vintages were given equal weighting.

Market Penetration. The DOE project manager or representative provided market penetration point estimates. These estimates were then used in the previously developed and documented market penetration model (see Section 3.3, "Bass Diffusion Model") to estimate the market penetration by year.

\footnotetext{
${ }^{\mathrm{c}}$ Table 9. Where no data were available, expert judgment was used.

d Table HC1-4b, single-family, and Table HC1-4b, five or more units.

${ }^{\mathrm{e}} \mathrm{http}: / /$ www.nmhc.org/content/ServeContent.cfm?IssueID=253\&ContentItemId=141\#size.
} 
Table 2.3. Percentage of Floor Space in Each Size Category for Each Commercial Building Type (\%)

\begin{tabular}{|c|c|c|c|c|c|c|c|}
\hline \multirow[b]{2}{*}{ Building Type } & \multicolumn{7}{|c|}{ Floor Space Size Category-Range and [Modeled Size] $\mathrm{ft}^{2}$} \\
\hline & $\begin{array}{l}\leq 5,000 \\
{[4,000]}\end{array}$ & $\begin{array}{l}5,001- \\
10,000 \\
{[7,500]}\end{array}$ & $\begin{array}{c}10,000- \\
25,000 \\
{[17,500]}\end{array}$ & $\begin{array}{c}25,001- \\
50,000 \\
{[37,500]}\end{array}$ & $\begin{array}{c}50,001- \\
100,000 \\
{[75,000]}\end{array}$ & $\begin{array}{l}>100,000 \\
{[125,000]}\end{array}$ & Total \\
\hline Assembly & 7.9 & 19.9 & 23.8 & 12.3 & 12.6 & 23.5 & 100.0 \\
\hline Education & 3.2 & 5.2 & 13.5 & 23.6 & 22.6 & 31.8 & 100.0 \\
\hline Food Sales & 36.4 & 6.4 & 31.8 & 19.1 & 5.1 & 1.3 & 100.0 \\
\hline Food Service & 40.7 & 28.8 & 24.4 & 5.2 & 0.6 & 0.3 & 100.0 \\
\hline Healthcare & 6.5 & 6.5 & 10.4 & 7.5 & 5.5 & 63.6 & 100.0 \\
\hline Lodging & 4.1 & 7.4 & 20.7 & 14.2 & 16.9 & 36.7 & 100.0 \\
\hline Mercantile and Service & 14.5 & 17.3 & 23.1 & 9.3 & 10.0 & 25.7 & 100.0 \\
\hline Large Office & 0.0 & 0.0 & 0.0 & 0.0 & 27.5 & 72.5 & 100.0 \\
\hline Small Office & 21.7 & 18.9 & 32.7 & 26.7 & 0.0 & 0.0 & 100.0 \\
\hline Other Buildings & 10.8 & 12.8 & 19.7 & 13.0 & 13.5 & 30.1 & 100.0 \\
\hline Warehouse & 9.5 & 11.7 & 18.0 & 13.7 & 13.5 & 33.5 & 100.0 \\
\hline
\end{tabular}

Table 2.4. Fraction of Floor Space in Each Size Category for Each Residential Type (\%)

\begin{tabular}{|c|c|c|c|c|c|c|}
\hline \multirow[b]{2}{*}{ Building Type } & \multicolumn{6}{|c|}{$\begin{array}{c}\text { Single-Family Residential Floor Space Size Category- } \\
\text { Range and [Modeled Size] } \mathrm{ft}^{2}\end{array}$} \\
\hline & $\begin{array}{l}\leq 600 \\
{[600]}\end{array}$ & $\begin{array}{c}601-999 \\
{[800]}\end{array}$ & $\begin{array}{c}1,000-1,599 \\
{[1,300]}\end{array}$ & $\begin{array}{c}1,600-1,999 \\
{[1,800]}\end{array}$ & $\begin{array}{c}2,000-2,399 \\
{[2,200]}\end{array}$ & $\begin{array}{l}>2,400 \\
{[3,000]}\end{array}$ \\
\hline Single Family & 2.8 & 14.0 & 37.0 & 21.2 & 11.3 & 13.7 \\
\hline Mobile Home & 15.7 & 43.8 & 31.6 & 7.2 & 2.2 & 0.7 \\
\hline \multirow[b]{2}{*}{ Building Type } & \multicolumn{6}{|c|}{$\begin{array}{c}\text { Multifamily Residential Floor Space Size Category- } \\
\text { Range and [Modeled Size] } \mathrm{ft}^{2}\end{array}$} \\
\hline & $\begin{array}{l}\leq 14,309 \\
{[14,309]}\end{array}$ & $\begin{array}{c}14,310- \\
23,848 \\
{[19,079]}\end{array}$ & $\begin{array}{c}23,849- \\
38157 \\
{[31,003]}\end{array}$ & $\begin{array}{c}38,158- \\
47,696 \\
{[42,927]}\end{array}$ & $\begin{array}{c}47,697- \\
57,236 \\
{[52,466]}\end{array}$ & $\begin{array}{c}>57,236 \\
{[71,545]}\end{array}$ \\
\hline Multifamily & 25.4 & 49.3 & 17.9 & 2.4 & 0.7 & 0.2 \\
\hline
\end{tabular}

\subsubsection{Baseline Assumptions}

Consistent with the NEMS-PNNL model, the heating and cooling envelope factors were assumed to be decreasing over time. These changes account for technological improvements over time that would occur without the DOE project. The baseline envelope factors in NEMS-PNNL were modified annually to 
account for the technological improvements, and the modifiers are calculated using the following equation with 1995 being the base year:

$$
\begin{aligned}
& \text { BaselineModifier }_{\text {new buildings }}=0.94\left(\frac{\text { Current Year }-1995}{25}\right) \\
& \text { BaselineModifier }_{\text {existing buildings }}=0.96\left(\frac{\text { Current Year }-1995}{25}\right)
\end{aligned}
$$

The constants 0.94 and 0.96 (EIA 2003b, EIA 2003c) represent a 25-year improvement of 6 percent and 4 percent, respectively. The project benefits are in addition to the baseline modifier.

\subsubsection{Output}

The FEDS output for each technology is processed into the following information for direct use by NEMS:

- census division

- building type

- year

- total heating envelope factor adjustment for new buildings

- total cooling envelope factor adjustment for new buildings

- total heating envelope factor adjustment for existing buildings

- total cooling envelope factor adjustment for existing buildings

- lighting load adjustment for new buildings

- lighting load adjustment for existing buildings.

\subsection{Spreadsheet Models}

Whenever possible, PNNL modeled projects within BEAMS or NEMS-PNNL to help ensure consistency in baseline inputs and methodology. However, we modeled several projects in spreadsheets because of their unique characteristics. The estimated savings generated by the spreadsheet models are entered by fuel type into "fixed" tables within BEAMS so that the environmental and energy cost-savings benefits can be calculated using the same data set as the other projects.

Energy savings estimates developed in spreadsheets require similar types of information as their BEAMS and NEMS-PNNL counterparts. An estimated savings per unit (e.g., energy savings per budget dollar or per household) is applied to an estimated annual forecast of unit sales or installations during the analysis period. Investment costs are also developed. Where possible, baseline data are taken from BEAMS and/or NEMS-PNNL in order to maintain a consistent baseline across projects. 


\subsection{Technology Diffusion Models - Application to Selected Energy-Efficient Products for Buildings}

Diffusion models represent the principal forecasting method for determining potential market penetration for products that have not yet been introduced into the marketplace. Because this situation generally applies to the long-term forecasting horizon of technology assessment models, a means to credibly represent price and policy effects in diffusion models is a key factor in improving the usefulness of market assessment studies. The basic diffusion models assume that the cumulative market penetration follows a characteristic time path (usually in the form of an S-shaped curve).

The dominant type of diffusion model is most likely the mixed-influence model introduced by Frank Bass (1969). The Bass model incorporates parameters that reflect both external (e.g., mass media communication) and internal influences (e.g., word of mouth). In 1998, PNNL conducted a study for DOE/BT to estimate the Bass specification for ten selected energy-efficient building products available in the marketplace today. The results of this work are instrumental in helping to project the likely market pathways of advanced building technologies under development by DOE/BT. This section summarizes the results of that study.

\subsection{Scientific and Technical Approach}

PNNL conducted a study examining the historical market penetration for ten energy-efficient products related to the buildings sector. Diffusion models were estimated for each product, based on the specification proposed by Bass (1969). The resulting models were intended to help assess technologies supported by BT. This model development and empirical analysis were designed to generate more credible predictions of the adoption process of important energy-efficiency technologies in the buildings sector.

The basic Bass diffusion model, which is possibly the most widely used specification for analyzing market penetration, assumes that the potential market in which the new technology is penetrating is fixed. In reality, the potential market usually is growing in response to a falling price as the manufacturing process and industry structure behind the new technology evolve. This study developed a simple structural model that incorporates these effects and that can be easily estimated from historical data. Given a suitable conceptual model, its parameters can be estimated from data related to several energy technologies.

Most studies of technology adoption have focused either on defining the market potential of the new technology or on the pace at which the technology is adopted. Models that have integrated both aspects generally have not been subjected to historical validation of their underlying parameters. Therefore, in general, little empirical basis exists to suggest which process - diffusion or expanding market potential due to falling costs - might be more influential in driving the penetration of new technologies. 


\subsection{Background}

A report by the Research Triangle Institute for the Electric Power Research Institute (EPRI) (1991) provides a good overview of market penetration approaches. Although the report has a slant toward utilities, much of the discussion applies to all types of energy-saving technologies. The EPRI report clearly distinguishes between two aspects of the process for forecasting market penetration: forecasting market potential and forecasting the rate of market penetration. Forecasting market potential can involve several different concepts of potential, including maximum, technical, and economic potential.

The EPRI report states that the factors affecting the rate of market penetration are predominantly different from factors affecting market potential. For example, comparative advantage —often determined by economic cost—strongly affects market potential. However, comparative advantage doesn't appear to have as strong an effect on the rate of market penetration.

In trying to distinguish the key factors affecting potential vs. penetration, EPRI suggests that market potential is predominantly influenced by the following:

- the market population and demographic trends

- the needs of the market: customer perceptions, attitudes, and beliefs

- feasibility of the product, which depends on functional characteristics of the product and its economic advantages compared with alternatives.

According to EPRI, the rate of market penetration is predominantly influenced by other factors:

- Marketing effort, such as promotion, advertising, and product positioning

- Product characteristics, such as complexity, compatibility, trialability, and observability

- Characteristics of potential adopters, such as decision-making style, innovativeness, and adoption processes

- Market characteristics, such as macroeconomic conditions, degree of social interaction among potential adopters, and competitive conditions.

Approaches to predicting the diffusion of a new technology generally fall under the category of judgmental methods or model-based methods. Judgmental methods share the common trait that they don't require mathematical models or computations; they rely implicitly on the experience and perceptions of the forecaster. On the other hand, model-based methods use well-specified algorithms to process and analyze data. Therefore, the model-based methods can provide systematic forecasts of market penetration that are reproducible and amenable to being incorporated into broader integrated models.

Model-based methods can be divided into two major categories: extrapolation models and causal models. Extrapolation methods include the following: 1) naive diffusion process models, 2) moving average, 3) exponential smoothing, 4) Census Bureau X-11, 5) Box-Jenkins, and 6) Multivariate Time Series. 
Of the extrapolation methods, the diffusion models represent the principal method for dealing with products that have not yet been introduced. Because this situation generally applies to long-range models, the discussion will be restricted to these models.

Diffusion models assume that the cumulative market penetration follows a characteristic time path (usually in the form of an S-shaped curve). An apt analogy is the spread of contagious disease in a fixed population. Once begun, growth of the disease in the number of infected individuals may follow a stable, predictable path. The time path of the infection in the population depends on the probability of spontaneous infection, the share of infected individuals, and probability of uninfected individuals interacting with individuals already infected. The notion underlying penetration rate models is that information about the new technology—sufficient to induce its adoption—is similar to an infectious disease (although with a much more positive connotation). This model provides the rationale behind the S-shaped ("logistic") penetration curves that are often observed.

\subsection{Bass Diffusion Model}

Perhaps the dominant type of diffusion model is the mixed-influence model introduced by Bass in the late 1960s. This two-parameter model incorporates parameters that reflect both external and internal influences. The external influence (corresponding to the "spontaneous" infection mentioned above) is exemplified by mass media communication, size of sales force, or other structured channels of information. Spontaneous refers to the adopter not being influenced by previous adopters but by advertising or some other external change-agent.

In contrast, the internal influence is intended to capture interpersonal communication or word of mouth (i.e., the contagious aspect of the disease analogy above). This also has been termed the imitative effect; the decision to adopt is made only after being influenced by prior adopters. The basic specification of the Bass model is as follows (Bass 1969):

$$
\frac{d N(t)}{d t}=\left[p+\frac{q}{M} \times N(t)\right] \times[M-N(t)]
$$

Where $\mathrm{N}(\mathrm{t})=$ cumulative number of adoptions at time $t$

$\mathrm{M}=$ market potential, a constant

$\mathrm{p}=$ the coefficient of innovation or external influence

$\mathrm{q}=$ the coefficient of imitation or internal influence.

Equation 3-1 states that the rate of change in the cumulative number of adopters $(\mathrm{dN}(\mathrm{t}) / \mathrm{dt})$ is proportional to the difference between the market potential $\mathrm{M}$ and the number of previous adopters. The proportionality factor $[\mathrm{p}+\mathrm{q} / \mathrm{M} \times \mathrm{N}(\mathrm{t})]$ can be interpreted as the probability of adoption at time $t$. This probability is composed of two components: $p$ is interpreted as the probability of spontaneous adoption. The term $[\mathrm{q} / \mathrm{M} \times \mathrm{N}(\mathrm{t})]$ relates to the probability that adoption will be chosen based on the influence of previous adopters. This probability grows as the number of adopters increases.

To simplify the presentation, Equation 3-1 can be reoriented in terms of the fraction of the market $(F)$ that is being penetrated rather than the absolute number of adopters. In this case, the market potential can be 
defined as 1.0. This simplified expression in Equation 3-2 now relates to the change in relative cumulative adoptions:

$$
\frac{d F(t)}{d t}=[p+q F(t)] \times[1-F(t)]
$$

The number of cumulative adoptions at any time, $F(t)$, can be solved by specifying an initial condition that the number of adopters at $t=0$ is 0 . This solution is as follows (Bass 1969):

$$
F(t)=\frac{1-\exp (-(p+q) t)}{1+(q / p) \exp (-(p+q) t)}
$$

The basic diffusion models therefore separate the issue of market penetration rate from market potential. That is why the model in Equation 3-3 can be compared across technologies - the percentage change in the total penetration does not depend on the size of the market but only on the parameters $p$ and $q$. This overcomes the limiting assumption mentioned above that the market segments, in unit terms, are fixed through time.

\subsection{Estimation Issues}

Issues related to the appropriate estimation procedures for the Bass diffusion model spawned a considerable literature. At least four estimation procedures were proposed by various researchers: 1) ordinary least squares (Bass 1969), 2) maximum likelihood estimators (Schmittlein and Mahajan 1982), 3) nonlinear least squares (Srinivasan and Mason 1986); Jain and Rao 1989), and 4) algebraic estimation (Mahajan and Sharma 1986).

Mahajan et al. (1986) performed a comparative study of estimation procedures using penetration data for seven products. They concluded that the maximum likelihood and nonlinear least squares procedures provided the best predictions of the four procedures considered. Between those two procedures, nonlinear least squares provided slightly better predictive performance and more valid estimates of the standard errors for the parameter estimates.

As preliminary analysis, PNNL looked at three variants of the nonlinear least squares model. For the first two variants, the focus is on the number of adopters $(X)$ in each period. Taking the differences of Equation 3-3 above and including a separate parameter reflects the total number of adopters (m) results in the following for the first variant:

$$
X(i)=\frac{m\left(1-\exp \left(-(p+q) t_{i}\right)\right)}{\left.1+(q / p) \times \exp \left(-(p+q) t_{i}\right)\right)}-\frac{m\left(1-\exp \left(-(p+q) t_{i-1}\right)\right)}{\left.1+(q / p) \times \exp \left(-(p+q) t_{i-1}\right)\right)}+u_{i}
$$

where $\mathrm{u}_{\mathrm{i}}$ is the error term. Jain and Rao (1989) suggest that the formulation in Equation 3-4 gives the $e x$ ante value for $\mathrm{X}(\mathrm{i})$ and does not use the ex post information on $\mathrm{X}(1), \mathrm{X}(2), \ldots, \mathrm{X}(\mathrm{I}-1)$. In the Bass model, the probability that an individual who has not purchased the product up to period $\mathrm{t}_{\mathrm{i}-1}$ is given by $\left[\mathrm{F}\left(\mathrm{t}_{\mathrm{i}}\right)-\right.$ $\left.\mathrm{F}\left(\mathrm{t}_{\mathrm{i}-1}\right)\right] /\left(\left(1-\mathrm{F}\left(\mathrm{t}_{\mathrm{i}-1}\right)\right]\right.$. Thus, the number of adopters in the ith time interval is as follows: 


$$
X_{i}=\left(m-N\left(t_{i-1}\right)\right)\left(\frac{F\left(t_{i}\right)-F\left(t_{i-1}\right)}{1-F\left(t_{i-1}\right)}\right)+v_{i}
$$

where $\mathrm{N}\left(\mathrm{t}_{\mathrm{i}-1}\right)$ is the cumulative number of adopters up to time $\mathrm{t}_{\mathrm{i}-1, \mathrm{~V}_{\mathrm{i}}}$ is the error term, and cumulative distribution function is given by Equation 3-3. This ex post estimation procedure proposed by Jain and Rao uses the actual number of cumulative adoptions in the estimation, compared with the predicted number in Equation 3-4. Therefore, it is termed the ex post estimation in contrast to the ex ante estimation.

Mahajan et al. (1986) also point out the possibility of estimating the diffusion curve in level rather than differences form (e.g., cumulative sales rather than annual sales). Thus, the cumulative number of adopters is the dependent variable and the specification becomes the following:

$$
N\left(t_{i}\right)=m F(t)=\frac{m(1-\exp (-(p+q) t))}{1+q / p \times \exp (-(p+q) t)}+w_{i}
$$

where $\mathrm{w}_{\mathrm{i}}$ is the error term. As Mahajan et al. (1986) indicate, the errors in Equation 3-6 are likely to be heteroscedastic (i.e., error variance increasing with i) and autocorrelated. Nevertheless, this formulation is somewhat more stable than the differences form and sometimes yields more plausible estimates.

\subsection{Results}

The results of estimating the Bass (1969) diffusion model for ten energy-related technologies are described below. The technologies were placed into four separate categories: 1) lighting, 2) HVAC and refrigeration (HVAC/R), 3) envelope, and 4) other. Table 3.1 summarizes the technologies for which Bass diffusion models were estimated.

In most of the cases, the technology was not assumed to ultimately capture all of the market, as defined in the fourth column of the table. The maximum market potential was determined judgmentally, on the basis of inspection of the data or from other sources.

Table 3.2 presents the results of the estimation work. The parameter sets labeled in bold are those judged as the most preferred, based on the reasonableness of the estimates and statistical significance. While estimates were developed based on both annual adoptions and cumulative adoptions, at this point, estimates based on annual adoptions have been used. The annual adoption rates are expressed as a fraction of the total potential market and the maximum fraction of the total market potential is expressed exogenously. The first and third groups of estimates reflect an effort to allow the data to suggest the maximum market potential ( $\mathrm{m}$ rather than $\mathrm{m}^{*}$ ). 
Table 3.1. Summaries of Technologies Analyzed

\begin{tabular}{||l|l|l|l||}
\hline \multicolumn{1}{|c|}{ Technology } & Start Year & \multicolumn{1}{|c|}{ End Year } & \multicolumn{1}{|c|}{ Market Definition } \\
\hline \multicolumn{5}{|c|}{ Lighting } \\
\hline Electronic Ballast & 1986 & 1997 & Corrected Power-Factor Ballasts \\
\hline Compact Fluorescent & 1986 & 1994 & Incandescent, 15-150 Watt \\
\hline T-8 Lamps & 1986 & 1994 & Fluorescent lamps, >30 Watt \\
\hline \multicolumn{5}{|c|}{ HVd Refrigeration } \\
\hline Electric Heat Pump & 1970 & 1995 & Residential Furnaces \\
\hline Flame Retention Burner & 1975 & 1987 & All Oil Burners \\
\hline Condensing Gas Furnace & 1982 & 1997 & Gas Furnaces \\
\hline Advanced Compressor & 1982 & 1995 & No. of Supermarkets \\
\hline Room Air Conditioners & 1949 & 1961 & No. of Households \\
\hline \multicolumn{5}{|c|}{ Envelope Technologies } \\
\hline Low-E Window & 1983 & 1996 & Residential Windows \\
\hline \multicolumn{5}{|c|}{ Other } \\
\hline DOE-2 Bldg Model & 1994 & Commercial Buildings Designed \\
\hline
\end{tabular}

Examination of the estimated coefficients indicates that the estimates of the external influence parameter are much more variable than those for the internal influence parameter. One of the lowest values of the internal influence coefficient is found for CFLs; this coefficient reflects the lamps extremely slow initial penetration into the market. In addition to the lamp's high initial price, Haddad (1994) suggests that industrial organization, retail incentives, and social convention are additional reasons for the atypically slow adoption of this technology. On the other extreme is the flame retention oil burner, whose adoption was accelerated by the increase in oil prices during the Iranian revolution in the late 1970s. In spite of these extremes, the simple average internal influence coefficient of 0.38 is the same as the average for 213 technologies as reported by Sultan, Farley, and Lehmann (1990). In that study, the average external influence was 0.03 compared with an average 0.018 for the ten energy-related technologies.

\footnotetext{
${ }^{\mathrm{f}}$ Our diffusion curve work was performed prior to the NRC 2001 report, which raised serious concerns regarding the actual penetration of DOE-2 into the building design marketplace. Although parameters for DOE-2 were developed in the original work, their influence has been removed from the generic diffusion curves developed by PNNL and used in the GPRA process.
} 
Table 3.2. Diffusion Curve Parameter Results

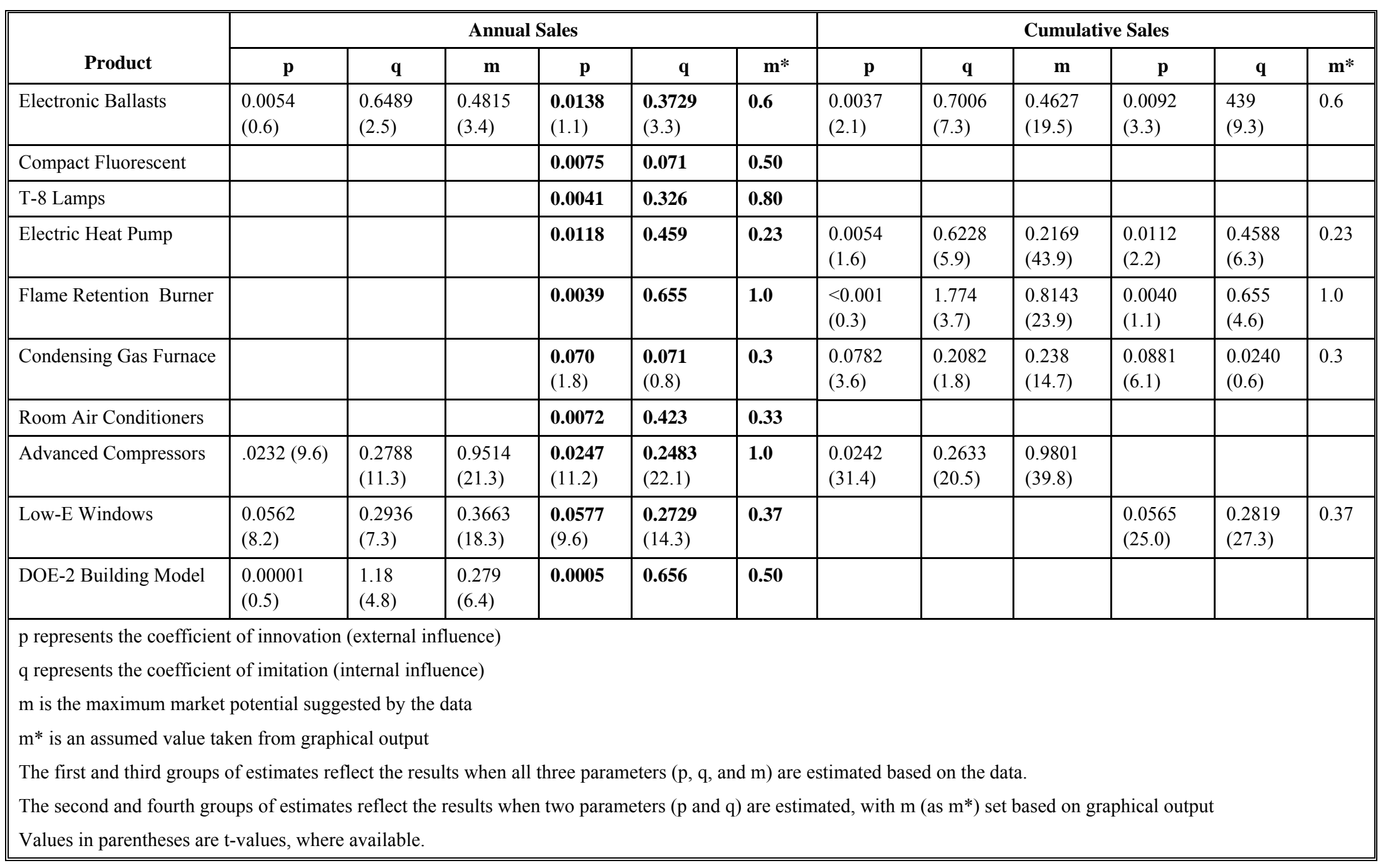




\subsubsection{Lighting Technologies}

As Table 3.1 outlines, the generic lighting diffusion curve is based on the market penetration of the electronic ballast, compact fluorescent, and T-8 lamp technologies. Tables 3.3 through 3.5 and Figures 3.1 through 3.3 detail the penetration of these technologies and chart the predicted penetration rates. To develop a generic lighting curve, the three lighting technology curves were normalized by setting $\mathrm{m}^{*}$ (the maximum market potential) to 1.0. By plotting the three curves using the normalized market potential, a generic curve was specified by visual determination. The resulting parameters for the generic lighting curve are 0.005 (external, or p) and 0.25 (internal, or q). Figure 3.4 charts the diffusion curves for the three technologies and the generic lighting curve.

Table 3.3. Ballast Shipments and Penetration of Electronic Ballasts

\begin{tabular}{||l|c|c|c|c||}
\hline Year & $\begin{array}{c}\text { Corrected Power- } \\
\text { Factor Type (magnetic) } \\
\text { (million) }\end{array}$ & $\begin{array}{c}\text { Electronic Type } \\
\text { (million) }\end{array}$ & $\begin{array}{c}\text { Total Ballast } \\
\text { Shipments } \\
\text { (million) }\end{array}$ & $\begin{array}{c}\text { Penetration of } \\
\text { Electronic type } \\
\text { (fraction) }\end{array}$ \\
\hline 1986 & 52.04 & 0.43 & 52.47 & 0.008 \\
\hline 1987 & 54.75 & 0.65 & 55.40 & 0.012 \\
\hline 1988 & 56.80 & 1.06 & 57.86 & 0.018 \\
\hline 1989 & 58.27 & 1.43 & 59.70 & 0.024 \\
\hline 1990 & 55.81 & 3.00 & 58.81 & 0.051 \\
\hline 1991 & 55.47 & 8.34 & 63.81 & 0.131 \\
\hline 1992 & 55.38 & 13.29 & 68.67 & 0.194 \\
\hline 1993 & 54.79 & 24.49 & 79.28 & 0.309 \\
\hline 1994 & 55.99 & 24.61 & 80.60 & 0.305 \\
\hline 1995 & 47.65 & 32.90 & 80.55 & 0.408 \\
\hline 1996 & 42.84 & 30.34 & 73.18 & 0.415 \\
\hline 1997 & 42.89 & 36.54 & 79.43 & 0.460 \\
\hline 1998 & 42.58 & 39.84 & 82.42 & 0.483 \\
\hline 1999 & 41.44 & 41.63 & 83.07 & 0.501 \\
\hline 2000 & 37.54 & 49.32 & 86.86 & 0.568 \\
\hline Source: Bureau of the Census, Current Industrial Reports (ESA 1997,2002$).$ & \\
\hline
\end{tabular}




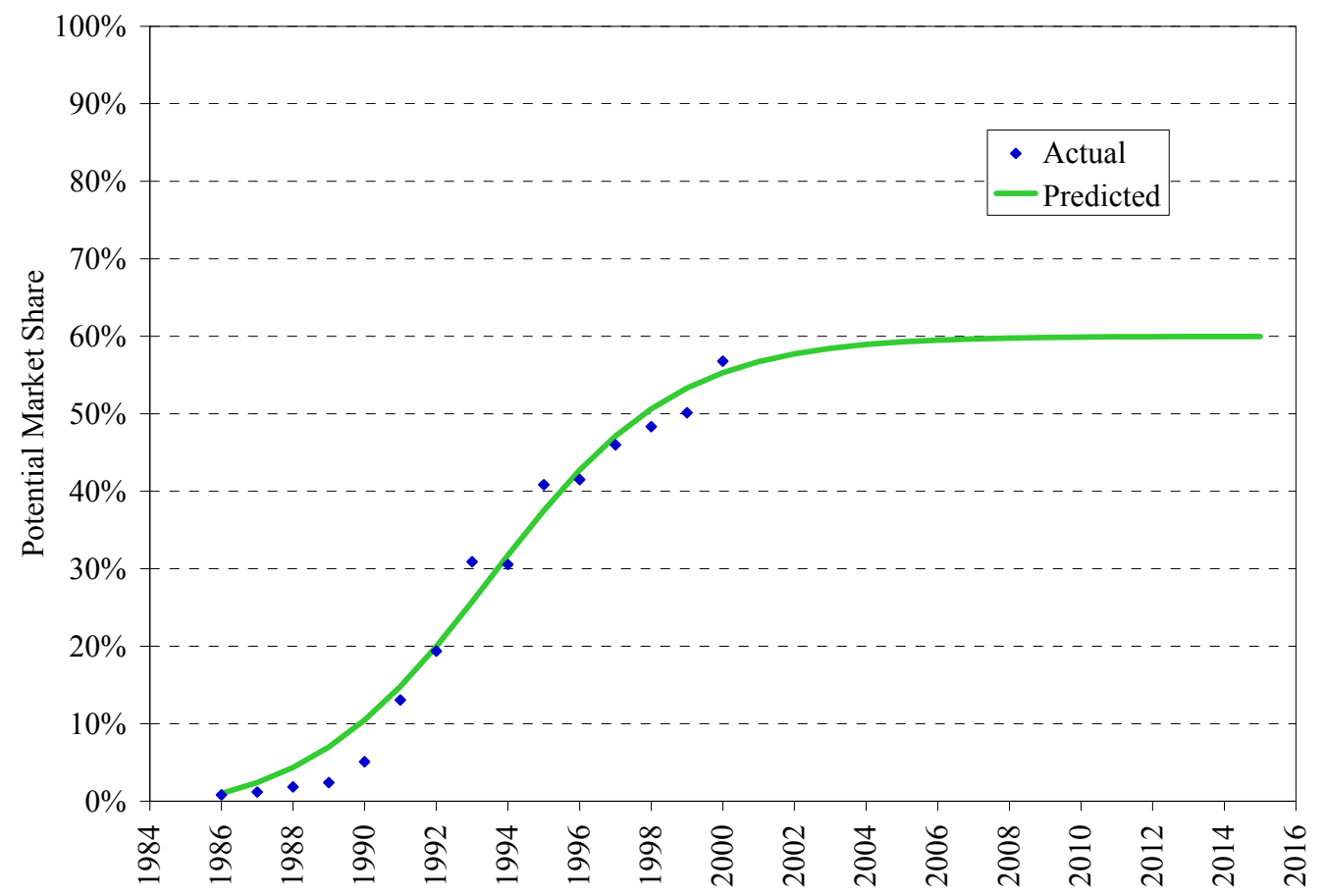

Figure 3.1. Actual and Predicted Penetration Rates: Electronic Ballasts

Table 3.4. Total Fluorescent Tube and T-8 Tube Shipments

\begin{tabular}{|c|c|c|c|c|c|}
\hline \multirow[b]{2}{*}{ Year } & \multicolumn{3}{|c|}{ Conventional Fluorescent (1) } & \multirow[b]{2}{*}{$\begin{array}{l}\text { Linear T-8 } \\
\text { (million) }\end{array}$} & \multirow[b]{2}{*}{$\begin{array}{l}\text { Data Source for } \\
\text { T-8 }\end{array}$} \\
\hline & $\begin{array}{l}\text { Low-Power } \\
\text { (million)(2) }\end{array}$ & $\begin{array}{l}\text { High-Power } \\
\text { (million) }\end{array}$ & $\begin{array}{l}\text { Total } \\
\text { (million)(3) }\end{array}$ & & \\
\hline 1985 & 45 & 255 & 300 & 0 & estimate \\
\hline 1986 & 45 & 270 & 315 & 0.5 & estimate \\
\hline 1987 & 45.7 & 287 & 332.7 & 1 & estimate \\
\hline 1988 & 50 & 300 & 350 & 2 & EPRI (4) \\
\hline 1989 & 55 & 315 & 370 & 3.1 & EPRI \\
\hline 1990 & 62 & 332.8 & 394.8 & 5.7 & EPRI \\
\hline 1991 & 69.3 & 353.1 & 422.4 & 15 & estimate \\
\hline 1992 & 70.3 & 367.4 & 437.7 & 27.7 & CIR (5) \\
\hline 1993 & 71.5 & 389.9 & 461.4 & 43.8 & CIR \\
\hline 1994 & 78.4 & 399.7 & 478.1 & 56.1 & CIR \\
\hline \multicolumn{6}{|c|}{$\begin{array}{l}\text { (1) "Conventional Fluorescent" corresponds to the Census Bureau's category of "Other Fluorescent Lamps"; } \\
\text { excludes slimline, circular, and high-output } 800 \text { milliamp or more. Includes T-8 Lamps. }\end{array}$} \\
\hline \multicolumn{6}{|c|}{$\begin{array}{l}\text { (2) Low-power is defined as } 40 \text { watts or less prior to 1992, } 30 \text { watts from } 1992 \text { through } 1994 \text {. No adjustment } \\
\text { was made to achieve definitional consistency. }\end{array}$} \\
\hline \multicolumn{6}{|c|}{ (3) Values for conventional fluorescent are estimated for 1985, 1986, 1988 and 1989.} \\
\hline \multicolumn{6}{|c|}{ (4) EPRI 1992.} \\
\hline \multicolumn{6}{|c|}{ (5) CIR: Current Industrial Reports, MQ36B series. } \\
\hline
\end{tabular}




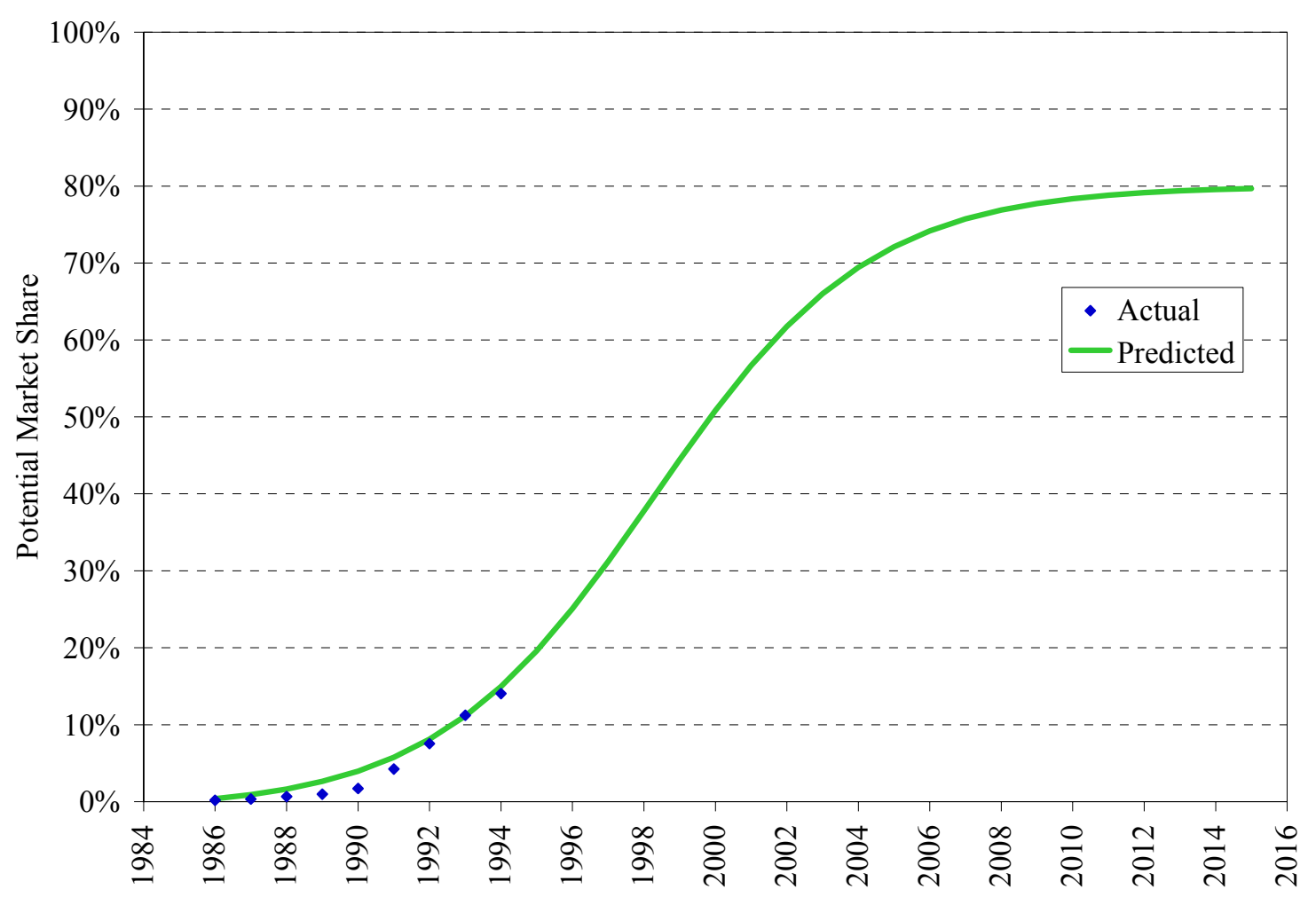

Figure 3.2. Actual and Predicted Penetration Rates: T-8 Lamps

Table 3.5. Shipments and Penetration of CFLs

\begin{tabular}{|c|c|c|c|c|c|c|}
\hline \multirow[b]{2}{*}{ Year } & \multirow{2}{*}{$\begin{array}{l}\text { Incandes. 15- } \\
150 \text { watt } \\
\text { (million) }\end{array}$} & \multirow{2}{*}{$\begin{array}{c}\text { CFLs } \\
\text { (million) }\end{array}$} & \multirow{2}{*}{$\begin{array}{c}\text { Total } \\
\text { (million) }\end{array}$} & \multirow{2}{*}{$\begin{array}{c}\text { Market } \\
\text { Penetration }\end{array}$} & \multicolumn{2}{|c|}{ Data Sources } \\
\hline & & & & & Incandes. & CFL \\
\hline 1986 & 800.0 & 2.0 & 802.0 & 0.0025 & estimate & estimate \\
\hline 1987 & 800.0 & 4.0 & 804.0 & 0.0050 & estimate & estimate \\
\hline 1988 & 800.0 & 9.9 & 809.9 & 0.0122 & estimate & EPRI \\
\hline 1989 & 810.7 & 11.6 & 822.3 & 0.0141 & CIR* & EPRI \\
\hline 1990 & 798.6 & 16.7 & 815.3 & 0.0205 & CIR & EPRI \\
\hline 1991 & 783.0 & 25.2 & 808.2 & 0.0312 & CIR & estimate \\
\hline 1992 & 795.5 & 30.4 & 825.9 & 0.0368 & CIR & CIR \\
\hline 1993 & 847.1 & 33.4 & 880.5 & 0.0379 & CIR & CIR \\
\hline 1994 & 818.8 & 35.8 & 854.6 & 0.0419 & CIR & CIR \\
\hline
\end{tabular}




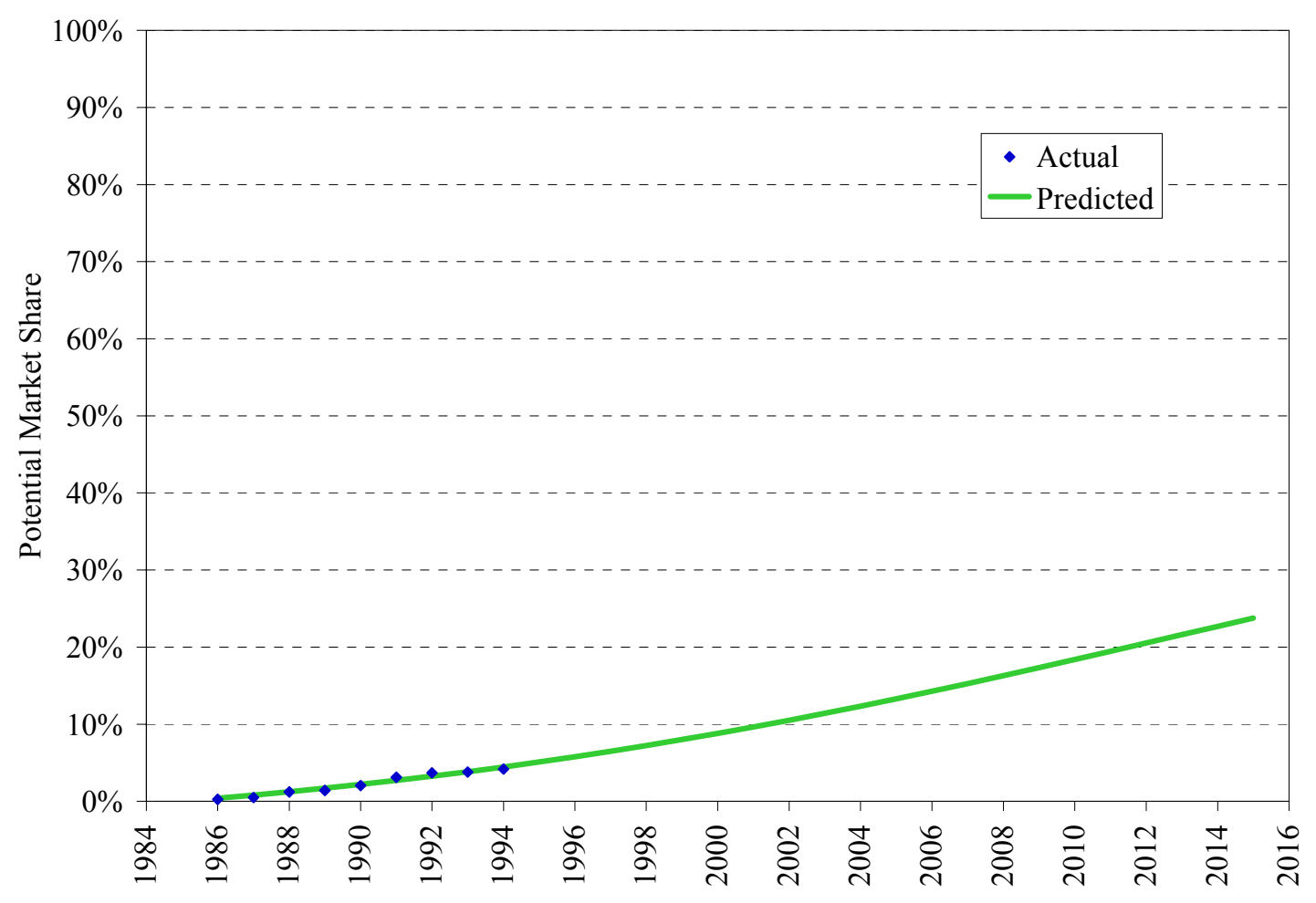

Figure 3.3. Actual and Predicted Penetration Rates: CFLs

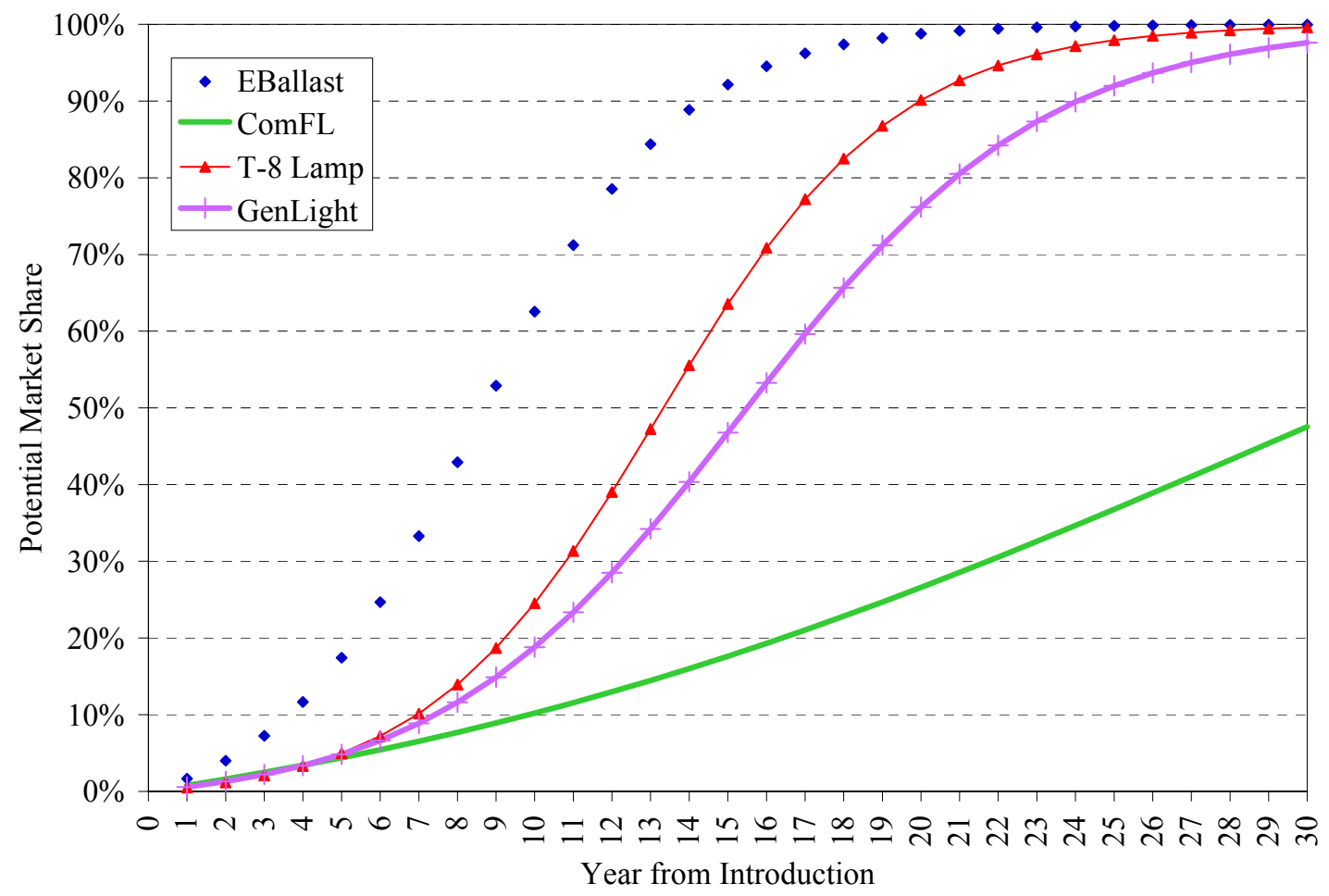

Figure 3.4. Generic Lighting Diffusion Curve Compared With Other Lighting Technology Curves (Normalized to $\mathrm{m}^{*}=1.0$ ) 


\subsubsection{HVAC Technologies}

As Table 3.1 outlines, the generic HVAC diffusion curve is based on the market penetration of the electric heat pump, flame retention burner, condensing gas furnace, and room air conditioners technologies. Tables 3.6 through 3.9 and Figures 3.5 through 3.8 detail the penetration of these technologies and the predicted penetration rates. To develop a generic HVAC curve, the four HVAC technology curves were normalized by setting $\mathrm{m}^{*}$ (the maximum market potential) to 1.0. By plotting the four curves using the normalized market potential, a generic curve was specified by visual determination. The resulting parameters for the generic HVAC curve are 0.02 (external, or $\mathrm{p}$ ) and 0.3 (internal, or q). Figure 3.9 charts the diffusion curves for the four technologies and the generic HVAC curve.

Table 3.6. Advanced Electric Heat Pump Shipments and Penetration

\begin{tabular}{|c|c|c|c|c|c|}
\hline Year & $\begin{array}{c}\text { Gas Furnaces } \\
\text { (thousands) }\end{array}$ & $\begin{array}{l}\text { Electric } \\
\text { Furnaces } \\
\text { (thousands) }\end{array}$ & $\begin{array}{l}\text { Split System } \\
\text { Heat Pumps } \\
\text { (thousands) }\end{array}$ & $\begin{array}{c}\text { Total } \\
\text { (thousands) }\end{array}$ & $\begin{array}{l}\text { HP Market } \\
\text { Penetration } \\
\text { (fraction) }\end{array}$ \\
\hline 1970 & 1471.2 & 105.3 & 33.6 & 1610.1 & 0.021 \\
\hline 1971 & 1795.2 & 193.8 & 26.6 & 2015.6 & 0.013 \\
\hline 1972 & 2066.2 & 288.5 & 32.3 & 2387.0 & 0.014 \\
\hline 1973 & 1719.5 & 370.2 & 43.9 & 2133.6 & 0.021 \\
\hline 1974 & 1476.3 & 406.8 & 56.6 & 1939.7 & 0.029 \\
\hline 1975 & 1185.8 & 252.3 & 92.8 & 1530.9 & 0.061 \\
\hline 1976 & 1544.4 & 338.9 & 202.0 & 2085.3 & 0.097 \\
\hline 1977 & 1508.1 & 283.6 & 356.8 & 2148.5 & 0.166 \\
\hline 1978 & 1636.1 & 360.0 & 420.8 & 2416.9 & 0.174 \\
\hline 1979 & 1862.6 & 360.0 & 407.6 & 2630.2 & 0.155 \\
\hline 1980 & 1445.7 & 360.0 & 323.4 & 2129.1 & 0.152 \\
\hline 1981 & 1416.7 & 360.0 & 390.4 & 2167.1 & 0.180 \\
\hline 1982 & 1155.6 & 300.0 & 300.9 & 1756.5 & 0.171 \\
\hline 1983 & 1661.8 & 360.0 & 509.6 & 2531.4 & 0.201 \\
\hline 1984 & 1849.2 & 360.0 & 603.1 & 2812.3 & 0.214 \\
\hline 1985 & 1822.3 & 370.0 & 665.2 & 2857.5 & 0.233 \\
\hline 1986 & 2104.8 & 382.6 & 728.3 & 3215.7 & 0.226 \\
\hline 1987 & 2072.9 & 375.1 & 754.6 & 3202.6 & 0.236 \\
\hline 1988 & 2092.2 & 293.1 & 680.9 & 3066.2 & 0.222 \\
\hline 1989 & 2162.2 & 298.2 & 690.0 & 3150.4 & 0.219 \\
\hline 1990 & 1950.5 & 280.0 & 667.4 & 2897.9 & 0.230 \\
\hline 1991 & 2056.7 & 245.2 & 637.1 & 2939.0 & 0.217 \\
\hline 1992 & 2106.9 & 290.2 & 670.0 & 3067.1 & 0.218 \\
\hline 1993 & 2584.6 & 348.5 & 747.5 & 3680.6 & 0.203 \\
\hline 1994 & 2696.8 & 400.8 & 857.6 & 3955.2 & 0.217 \\
\hline 1995 & 2601.0 & 402.0 & 866.6 & 3869.6 & 0.224 \\
\hline \multicolumn{6}{|c|}{$\begin{array}{l}\text { Sources: For gas furnaces the source is the Census of Manufactures, } 1972 \text { and } 1977 \text { (DOC 1973, 1978); PNNL estimates } \\
\text { are for the intervening years; and the Gas Appliance Manufacturers Association (GAMA) estimates are for years 1986- } \\
\text { 1995. }\end{array}$} \\
\hline
\end{tabular}




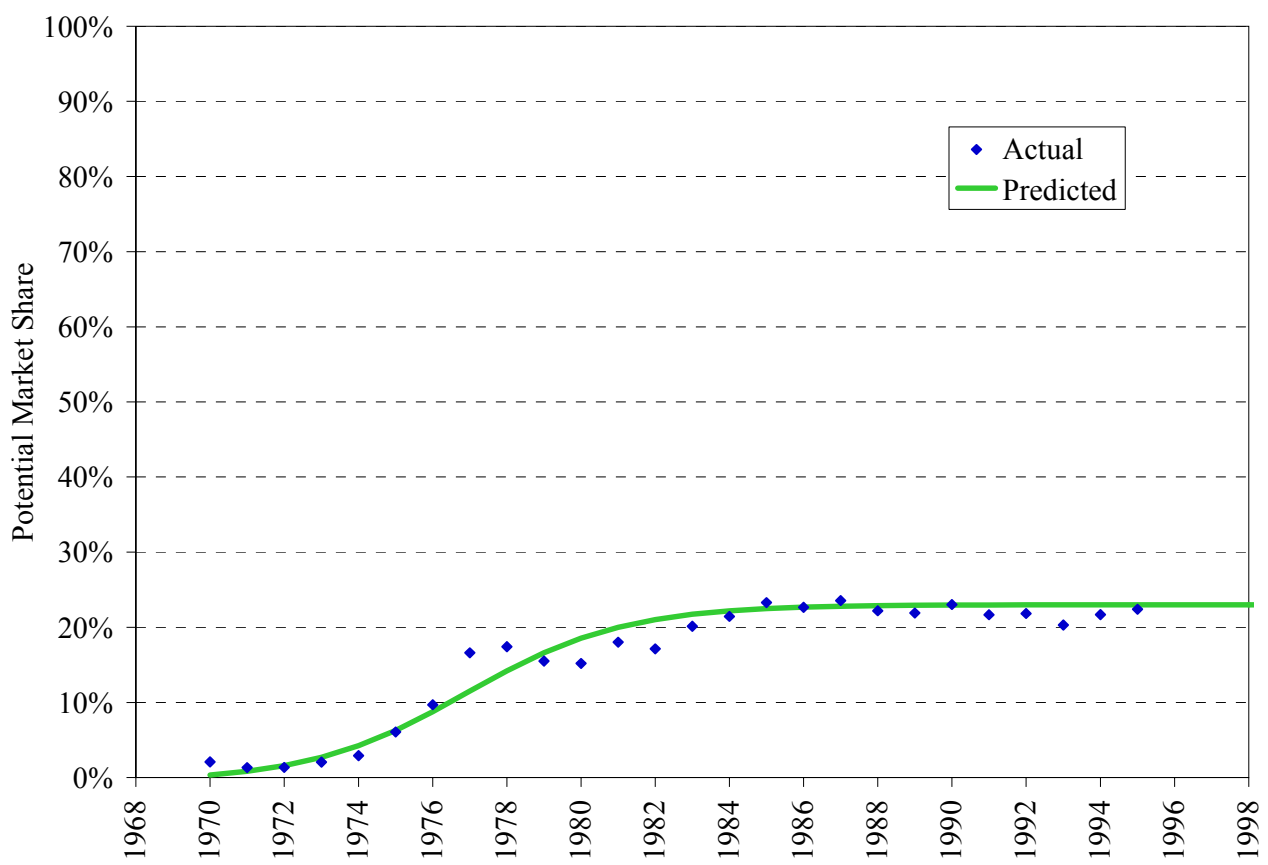

Figure 3.5. Actual and Predicted Market Penetration: Electric Heat Pumps 
Table 3.7. Sales and Market Penetration of Flame Retention Head Oil Burners (FRHOBs)

\begin{tabular}{|c|c|c|c|c|}
\hline & $\begin{array}{l}\text { Annual Oil Burner } \\
\text { Sales(1) (thousand) }\end{array}$ & $\begin{array}{c}\text { Cumulative } \\
\text { FRHOB Sales(2) } \\
\text { (thousand) }\end{array}$ & $\begin{array}{c}\text { Annual FRHOB } \\
\text { Sales(3) (thousand) }\end{array}$ & $\begin{array}{l}\text { FRHOB Market } \\
\text { Share(4) (fraction) }\end{array}$ \\
\hline 1975 & 750 & 20 & 20 & 0.027 \\
\hline 1976 & 750 & 50 & 30 & 0.040 \\
\hline 1977 & 749 & 70 & 20 & 0.027 \\
\hline 1978 & 777 & 100 & 30 & 0.039 \\
\hline 1979 & 735 & 125 & 25 & 0.034 \\
\hline 1980 & 585 & 250 & 125 & 0.214 \\
\hline 1981 & 606 & 400 & 150 & 0.248 \\
\hline 1982 & 522 & 800 & 400 & 0.766 \\
\hline 1983 & 512 & 1200 & 400 & 0.781 \\
\hline 1984 & 510 & 1600 & 400 & 0.784 \\
\hline 1985 & 536 & 2000 & 400 & 0.746 \\
\hline 1986 & 555 & 2450 & 450 & 0.811 \\
\hline 1987 & 577 & 2950 & 500 & 0.867 \\
\hline $\begin{array}{ll}\text { (1) } & \mathrm{A} \\
& \mathrm{fi} \\
\text { (2) } & \mathrm{C} \\
\text { (3) } & \mathrm{A} \\
\text { (4) } & \mathrm{N}\end{array}$ & $\begin{array}{l}1 \text { burner sales data from } 1 \\
\text { tained by Fuel Oil and O } \\
\text { e sales for FRHOBs wer } \\
\text { RHOB sales data were es } \\
\text { are of FRHOB is the rati }\end{array}$ & $\begin{array}{l}-1987 \text { were obtained th } \\
\text { eat Magazine. Data for } \\
\text { tained from ORNL rep } \\
\text { ted as the difference in } \\
\text { FRHOB sales over tot }\end{array}$ & $\begin{array}{l}\text { gh a telephone interview } \\
75 \text { and } 1976 \text { are PNNL es } \\
\text { by Brown et al. (1989), F } \\
\text { mulative sales in Column } \\
\text { urner sales. }\end{array}$ & $\begin{array}{l}\text { Don Farrell, using date } \\
\text { tes. } \\
4.3 \text {, p. } 55 \text {. }\end{array}$ \\
\hline
\end{tabular}




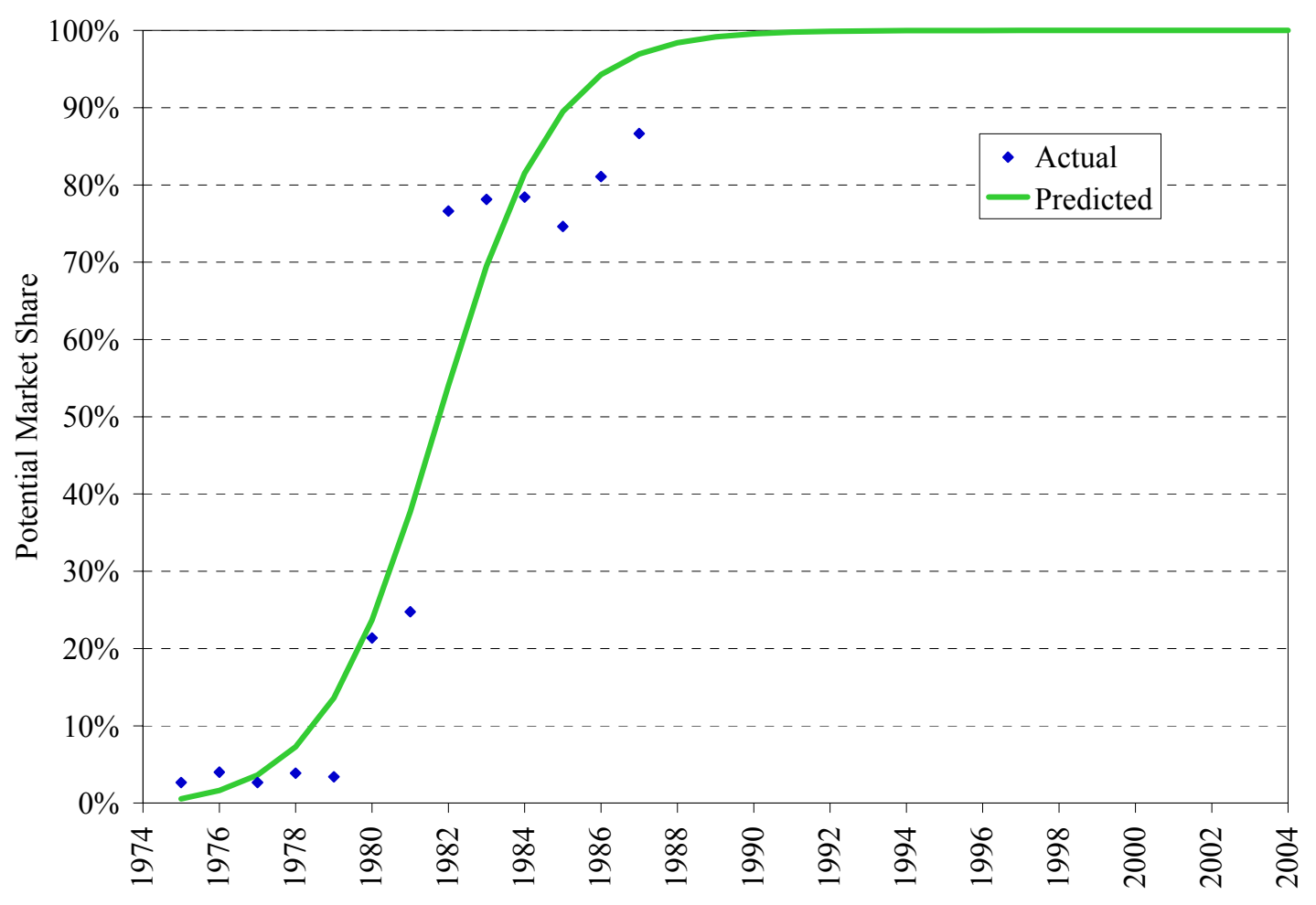

Figure 3.6. Actual and Predicted Market Penetration Rates: Flame Retention Oil Burners 
Table 3.8. Market Penetration of High Efficiency Gas Furnaces

\begin{tabular}{|l|l|l||}
\hline \multicolumn{1}{|c|}{ Year } & \multicolumn{1}{|c|}{ Market Share } & \multicolumn{1}{c|}{ Source } \\
\hline 1981 & 0.005 & PNNL Estimate \\
\hline 1982 & 0.010 & PNNL Estimate \\
\hline 1983 & 0.040 & PNNL Estimate \\
\hline 1984 & 0.111 & GAMA \\
\hline 1985 & 0.123 & GAMA \\
\hline 1986 & 0.158 & GAMA \\
\hline 1987 & 0.160 & PNNL Estimate \\
\hline 1988 & 0.165 & PNNL Estimate \\
\hline 1989 & 0.170 & PNNL Estimate \\
\hline 1990 & 0.175 & GAMA \\
\hline 1991 & 0.205 & GAMA \\
\hline 1992 & 0.210 & PNNL Estimate \\
\hline 1993 & 0.210 & PNNL Estimate \\
\hline 1994 & 0.214 & GAMA \\
\hline 1995 & 0.223 & GAMA \\
\hline 1996 & 0.235 & GAMA \\
\hline 1997 & 0.253 & GAMA \\
\hline 1998 & 0.240 & PNNL Estimate \\
\hline 1999 & 0.233 & GAMA \\
\hline 2000 & 0.236 & GAMA \\
\hline 2001 & 0.279 & GAMA \\
\hline $\begin{array}{l}\text { Note: For } 1984-1987, \text { the fraction relates to annual fuel utilization efficiency } \\
(\text { AFUE) of } 86 \% \text { and greater. For subsequent periods, the fraction relates to } \\
\text { furnaces with AFUE } 8 \% \text { and greater. } \\
\text { AFUE testing procedures, these fractions are roughly comparable. }\end{array}$ \\
\hline
\end{tabular}




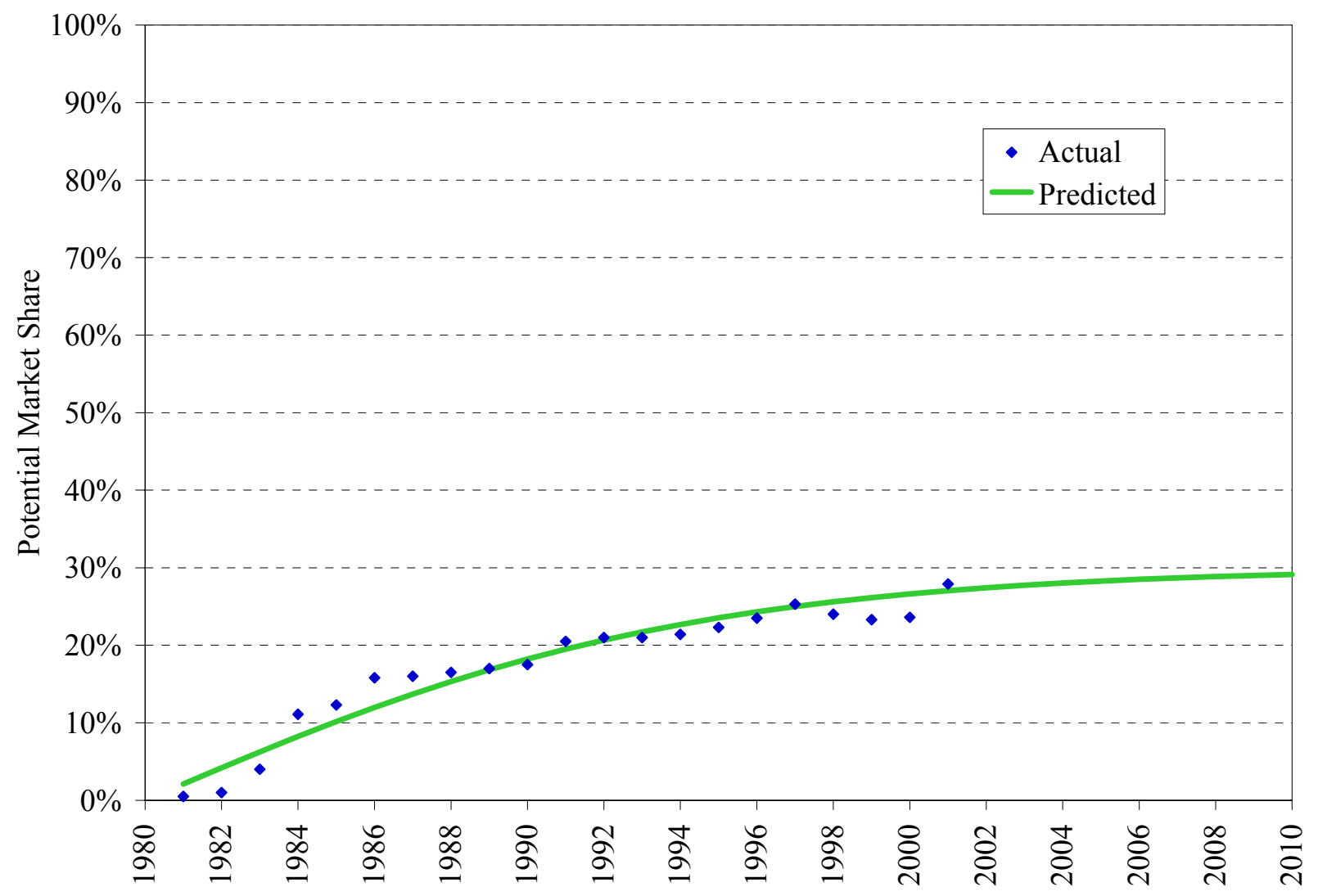

Figure 3.7. Actual and Predicted Market Penetration for Condensing Gas Furnaces 
Table 3.9. Room Air Conditioner Sales

\begin{tabular}{|l|c||}
\hline \multicolumn{1}{|c|}{ Year } & $\begin{array}{c}\text { Sales } \\
\text { (thousands) }\end{array}$ \\
\hline 1949 & 96 \\
\hline 1950 & 195 \\
\hline 1951 & 238 \\
\hline 1952 & 380 \\
\hline 1953 & 1045 \\
\hline 1954 & 1230 \\
\hline 1955 & 1267 \\
\hline 1956 & 1828 \\
\hline 1957 & 1586 \\
\hline 1958 & 1673 \\
\hline 1959 & 1800 \\
\hline 1960 & 1580 \\
\hline 1961 & 1500 \\
\hline Source: Mahajan et al. (1986). \\
\hline
\end{tabular}

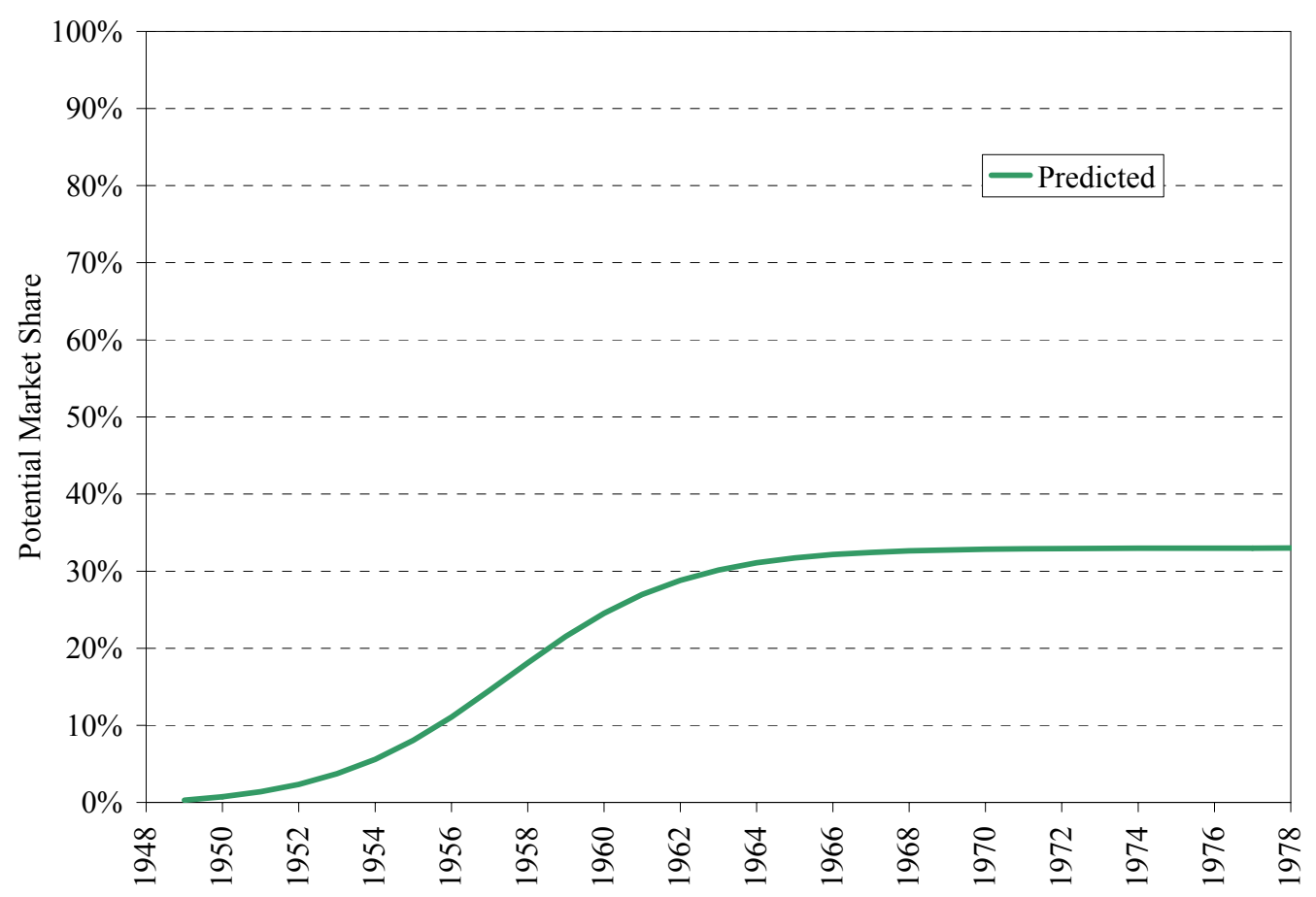

Figure 3.8. Predicted Market Penetration of Room Air Conditioners 


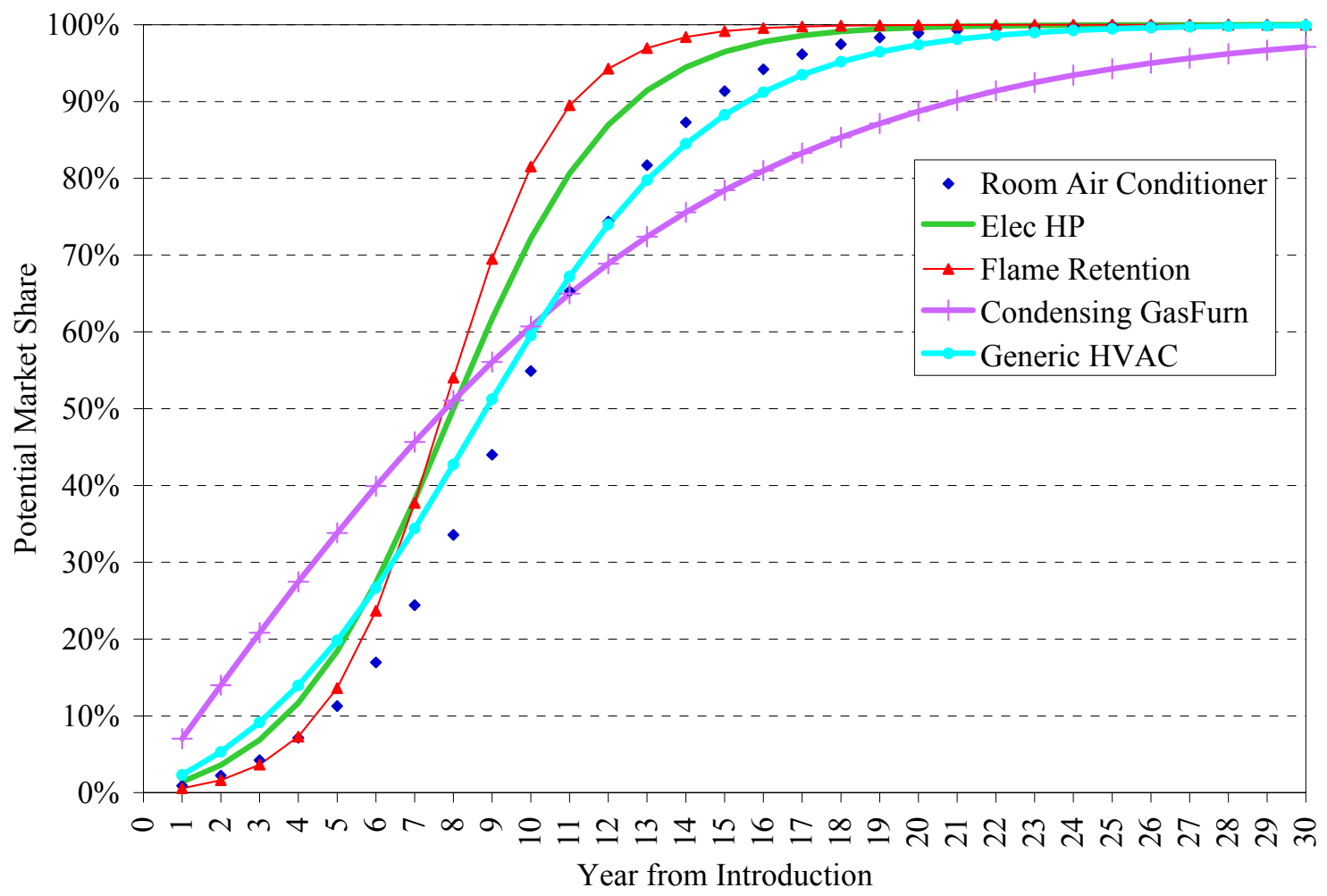

Figure 3.9. Generic HVAC Diffusion Curve Compared With Other HVAC Technology Curves (Normalized to $\mathrm{m}^{*}=1.0$ )

\subsubsection{Envelope and Other Technologies}

Two other technologies were also studied and form the basis for the generic envelope and other technologies diffusion curve. The generic envelope/other diffusion curve is based on the market penetration of the advanced compressor and low-E window technologies. ${ }^{\mathrm{g}}$ Tables 3-10 and 3-11 and Figures 3-10 and 3-11 detail the penetration of these technologies and chart the predicted penetration rates. To develop a generic envelope/other curve, the two technology curves were normalized by setting $\mathrm{m}^{*}$ (the maximum market potential) to 1.0. By plotting the two curves using the normalized market potential, a generic curve was specified by visual determination. The resulting parameters for the generic envelope/other curve are 0.04 (external, or p) and 0.26 (internal, or q). Figure 3.12 charts the diffusion curves for the two technologies and the generic Envelope/Other curve.

$\mathrm{g}$ The influence of the DOE-2 estimates has been removed in the estimation process for the generic curve. 
Table 3.10. Market Penetration of High-Efficiency Refrigerator Compressors for Supermarkets

\begin{tabular}{|l|c|}
\hline \multicolumn{1}{|c|}{ Year } & Market Penetration (fraction) \\
\hline 1982 & 0.03 \\
\hline 1983 & 0.06 \\
\hline 1984 & 0.11 \\
\hline 1985 & 0.16 \\
\hline 1986 & 0.21 \\
\hline 1987 & 0.27 \\
\hline 1988 & 0.34 \\
\hline 1989 & 0.41 \\
\hline 1990 & 0.50 \\
\hline 1991 & 0.58 \\
\hline 1992 & 0.65 \\
\hline 1993 & 0.71 \\
\hline 1994 & 0.76 \\
\hline 1995 & 0.80 \\
\hline Source: Geller and McGaraghan 1996, Figure 3. \\
\hline
\end{tabular}

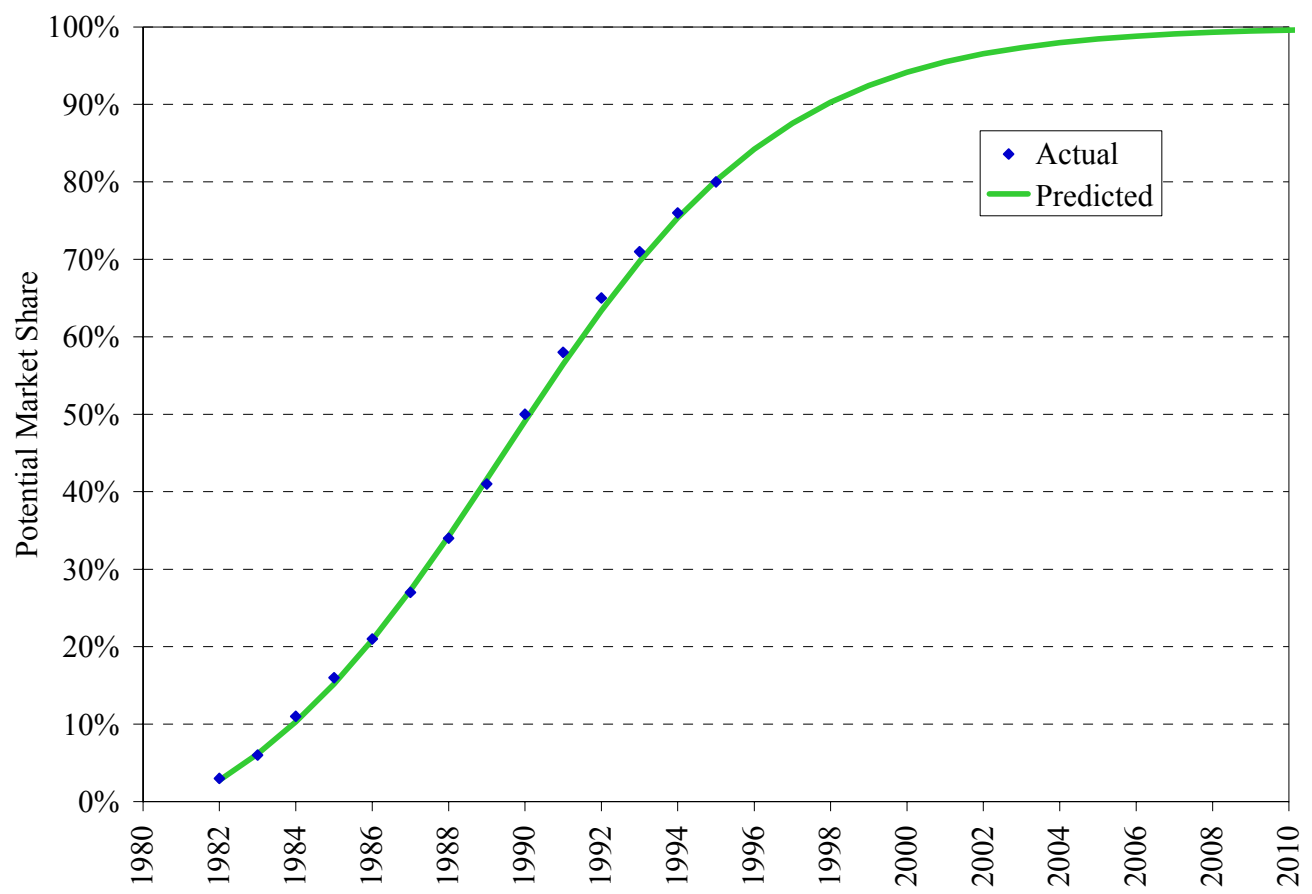

Figure 3.10. Actual and Predicted Market Penetration Rates: Advanced Refrigeration Compressors for Supermarkets 
Table 3.11. Market Penetration of Low-E Residential Windows

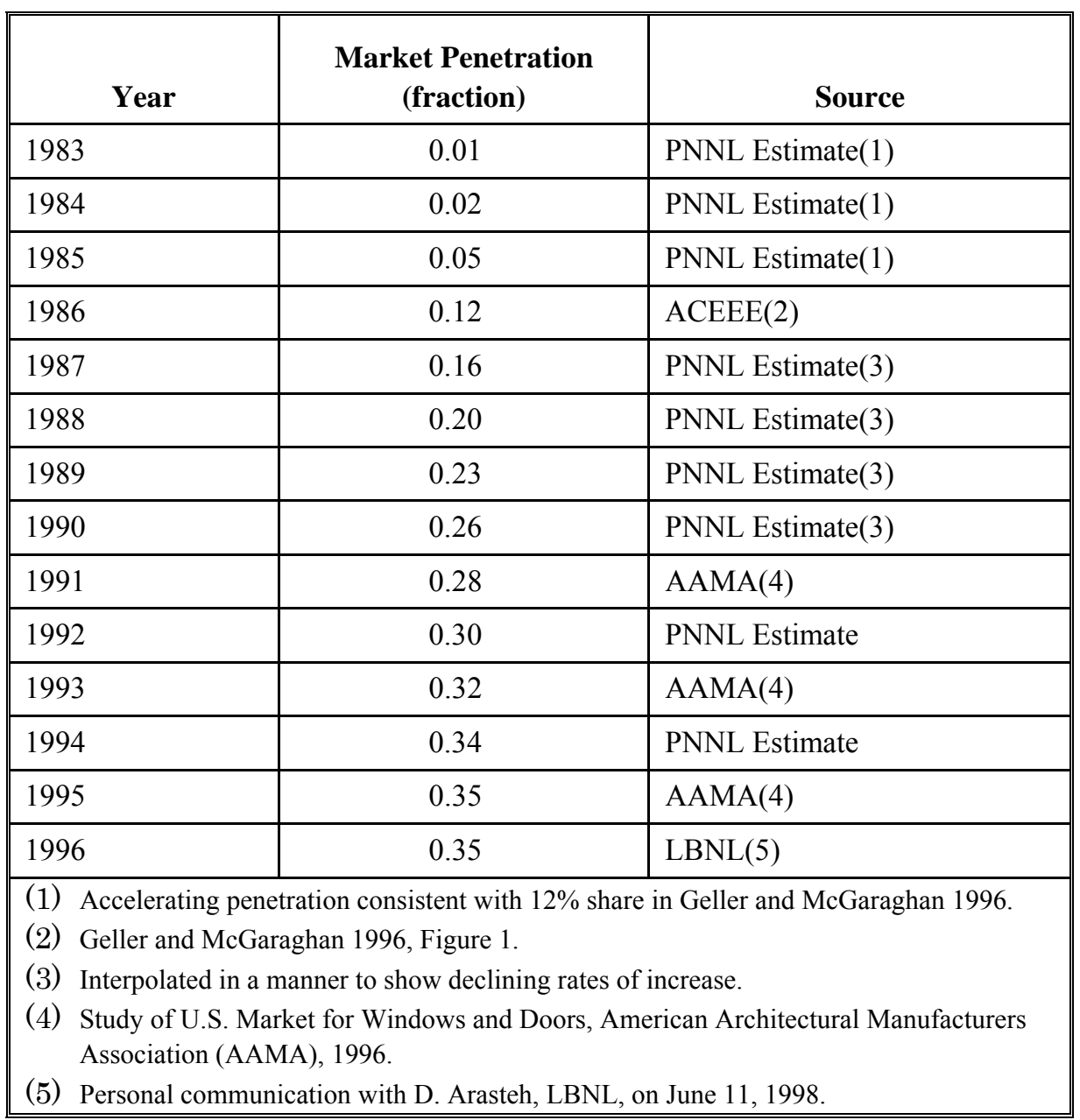




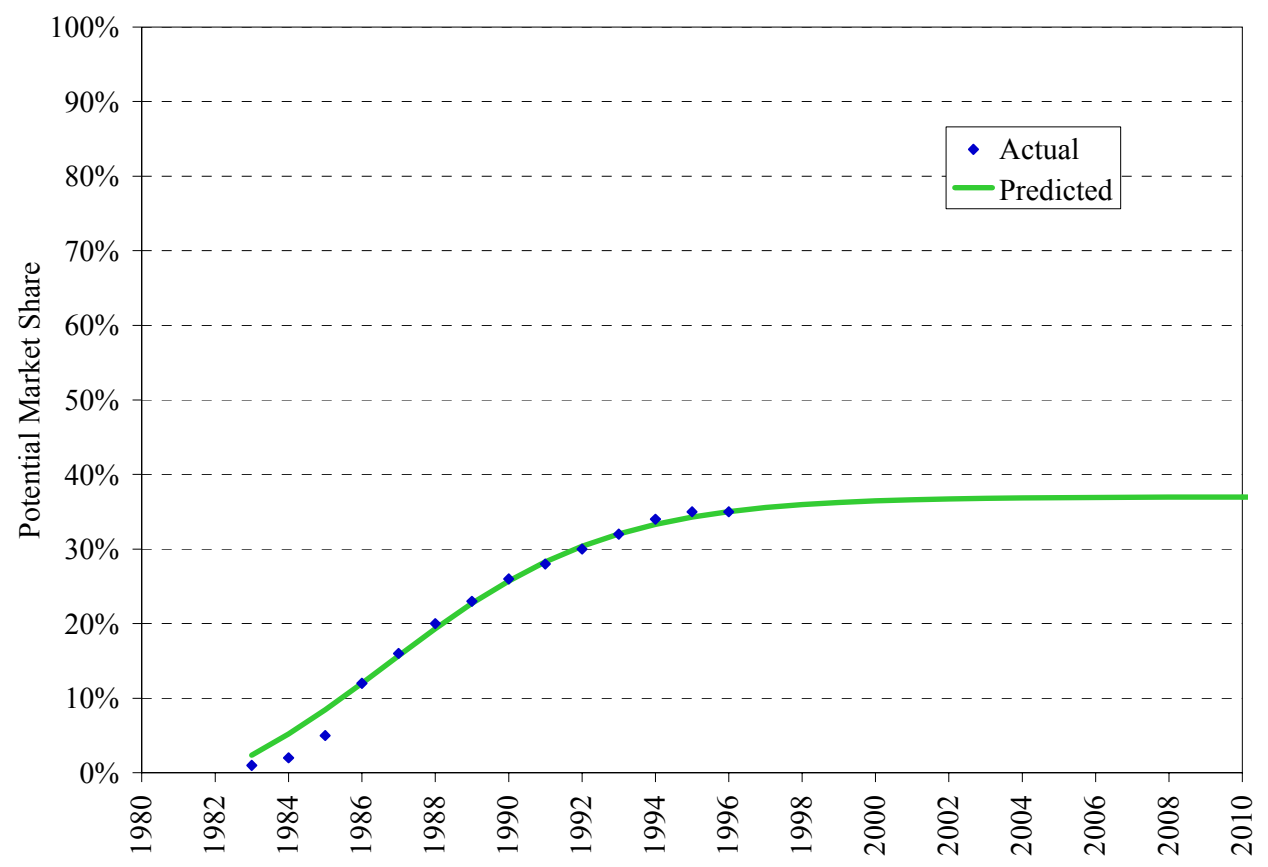

Figure 3.11. Actual and Predicted Market Penetration Rates: Residential Low-E Windows

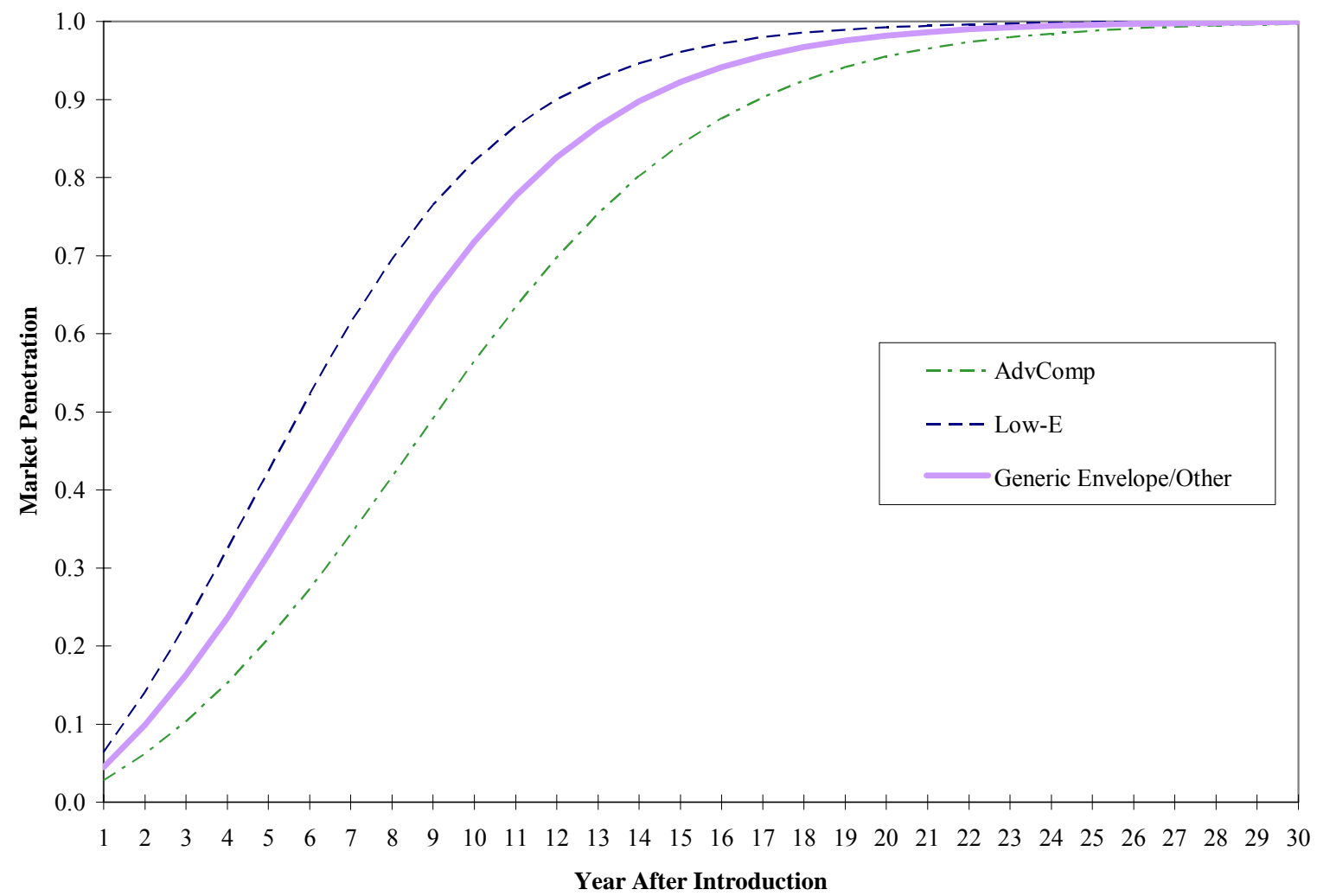

Figure 3.12. Generic Envelope/Other Diffusion Curve Compared With Other Technology Curves (Normalized to $\mathrm{m}^{*}=1.0$ ) 


\subsection{Use of the Generic Curves within the GPRA Analysis}

PNNL used the generic diffusion curves to generate market penetration estimates for buildings-related projects that do not have a forecast of annual sales targets. We created a simple penetration model spreadsheet to generate buildings-related project-specific diffusion curves for input to the BEAMS model. Within the spreadsheet, the user specifies the year of market introduction for the project, the expected maximum market potential in 2020, and the technology classification that best resembles the project (lighting, HVAC, envelope, or other project).

Some of the estimated buildings-related project diffusion curves stray from the generic classifications, depending on their individual characteristics, and use one of the specific technology parameter sets in Table 3.2. 


\subsection{References}

Bass, F.M. 1969. “A New Product Growth Model for Consumer Durables.” Management 15:215-227.

Brown, M.A., L.G. Berry, and R.K. Goel. 1989. Commercializing Government-Sponsored Innovations: Twelve Successful Buildings Case Studies. ORNL/CON-275, Oak Ridge National Laboratory, Oak Ridge, Tennessee.

DOC (See: US Department of Commerce)

Economics and Statistics Administration. 1998. Fluorescent Lamp Ballasts: 1997. MQ365C, US Census Bureau, Washington D.C.

Economics and Statistics Administration. 2002. Fluorescent Lamp Ballasts: 2001. MQ335C(01)-5, US Census Bureau, Washington D.C.

EIA (See: Energy Information Administration)

Electric Power Research Institute. 1992. Survey and Forecast of Marketplace Supply and Demand for Energy-Efficient Lighting Products. EPRI TR-100288, Palo Alto, California.

Electric Power Research Institute. 1991. Market Penetration of New Technology, Programs and Sciences. EPRI CU-7011, prepared by the Research Triangle Institute, Chapel Hill, North Carolina.

Energy Information Administration. 1995. "Commercial Buildings Energy Consumption Survey." US Department of Energy, Washington D.C. Available: http://eia.doc.gov/emeu/cbecs/contents.html

Energy Information Administration. 1997. Residential Energy Consumption Survey. US Department of Energy, Washington, D.C. Available: http://eia.doc.gov/emeu/recs/contents.html

Energy Information Administration. 1999. “Commercial Buildings Energy Consumption Survey.” US Department of Energy, Washington, D.C. Available: http://eia.doc.gov/emeu/cbecs/contents.html

Energy Information Administration. 2001. Annual Energy Outlook 2001. US Department of Energy, Washington, D.C.

Energy Information Administration. 2002. Annual Energy Outlook 2002. US Department of Energy, Washington, D.C.

Energy Information Administration. 2003a. Annual Energy Outlook 2003. US Department of Energy, Washington, D.C.

Energy Information Administration. 2003b. Model Documentation Report: Commercial Sector Demand Module of the National Energy Modeling System. Energy Information Administration, Washington, D.C. DOE/EIA-M066(2003). Available: http://tonto.eia.doe.gov/FTPROOT/modeldoc/m066(2003).pdf 
Energy Information Administration. 2003c. Model Documentation Report: Residential Sector Demand Module of the National Energy Modeling System. Energy Information Administration, Washington, D.C. DOE/EIA-M067(2003). Available: http://tonto.eia.doe.gov/FTPROOT/modeldoc/m067(2003).pdf

EPRI (See Electric Power Research Institute)

ESA (See: Economics and Statistics Administration)

Geller, H., and S. McGaraghan. 1996. Successful Government-Industry Partnership: The US Department of Energy's Role in Advancing Energy-Efficient Technologies. American Council for an Energy Efficient Economy, Washington, D.C.

Government Performance and Results Act of 1993. Public Law 103-62 (S.20), August 3, 1993.

Haddad, B. M. 1994. "Why Compact Fluorescent Lamps Are Not Ubiquitous: Industrial Organization, Incentives, and Social Convention." In Proceeding of the ACEEE 1994 Summer Study on Energy Efficiency in Buildings. Vol. 10, pp. 77-84. American Council for an Energy-Efficient Economy, Washington D.C.

Jain, D., and R. Rao. 1989. "Effect of Price on the Demand for Durables: Modeling, Estimation, and Findings." Journal of Business and Economics and Economics Statistics 8:163-170.

Mahajan, V., and S. Sharma. 1986. "A Simple Algebraic Estimation Procedure for Innovation Diffusion Models." Technological Forecasting and Social Change 30:331-45.

Mahajan, V., C. Mason, and V. Srinivasan. 1986. “An Evaluation of Estimation Procedures for New Product Diffusion Models.” In Innovation Diffusion Models of New Product Acceptance, eds., V. Mahajan and Y. Wind, Ballinger Publishing Company, Cambridge, Massachusetts.

National Research Council. 2001. Energy Research at DOE: Was It Worth It? Washington, D.C.

NRC (See: National Research Council)

Schmittlein, D.C., and V. Mahajan. 1982. "Maximum Likelihood Estimation for an Innovation Diffusion Model of New Product Acceptance." Marketing Science 1(Winter):57-78.

Srinivasan, V. and C. Mason. 1986. "Nonlinear Least Squares Estimation of New Product Diffusion Models.” Marketing Science 5(Spring):169-78.

Sultan, F., J.U. Farley, and D.R. Lehmann. 1990. “A Meta-Analysis of Applications of Diffusion Models." Journal of Marketing Research 27:70-77.

US Department of Commerce. 1973. Census of Manufacturers 1972. Bureau of the Census, Washington, D.C. 
US Department of Commerce. 1978. Census of Manufacturers 1977. Bureau of the Census, Washington, D.C. 


\section{Distribution}

No. of

$\underline{\text { Copies }}$

\section{OFFSITE}

Michael McCabe (3)

U.S. Department of Energy

EERE-Building Technologies

Program (EE-2J)

1000 Independence Ave., S.W.

Washington, DC 20585

John D. Ryan

U.S. Department of Energy

EERE-Building Technologies

Program (EE-2J)

1000 Independence Ave., S.W.

Washington, DC 20585

Jim Rannells

U.S. Department of Energy

EERE-Building Technologies

Program (EE-2J)

1000 Independence Ave., S.W.

Washington, DC 20585

Ed Pollock

U.S. Department of Energy

EERE-Building Technologies

Program (EE-2J)

1000 Independence Ave., S.W.

Washington, DC 20585

Qonnie Laughlin

U.S. Department of Energy

EERE-Building Technologies

Program (EE-2J)

1000 Independence Ave., S.W.

Washington, DC 20585

Bryan Berringer

U.S. Department of Energy
EERE-Building Technologies

Program (EE-2J)

1000 Independence Ave., S.W.

Washington, DC 20585

Jim Brodrick

U.S. Department of Energy

EERE-Building Technologies

Program (EE-2J)

1000 Independence Ave., S.W.

Washington, DC 20585

Ellen Lutz (3)

U.S. Department of Energy

EERE-Weatherization and Intergovernmental

Program (EE-2K)

1000 Independence Avenue, S.W.

Washington, DC 20585

Mark Bailey

U.S. Department of Energy

EERE-Weatherization and Intergovernmental

Program (EE-2K)

1000 Independence Avenue, S.W.

Washington, DC 20585

Phil Hayes

U.S. Department of Energy

EERE-Weatherization and Intergovernmental

Program (EE-2K)

1000 Independence Avenue, S.W.

Washington, DC 20585

Sam Baldwin

U.S. Department of Energy

EERE-Office of Planning, Budget Formulation, and Analysis (EE-3B)

1000 Independence Avenue, S.W.

Washington, DC 20585

Jerry Dion

U.S. Department of Energy

Distr.1 
EERE-Office of Planning, Budget Formulation, and Analysis (EE-3B)

1000 Independence Avenue, S.W.

Washington, DC 20585

Mike Gonzalez

U.S. Department of Energy

EERE-Office of Planning, Budget Formulation, and Analysis (EE-3B)

1000 Independence Avenue, S.W.

Washington, DC 20585

Phil Patterson

U.S. Department of Energy

EERE-Office of Planning, Budget Formulation, and Analysis (EE-3B)

Washington, DC 20585

Peggy Podolak

U.S. Department of Energy

EERE-Office of Planning, Budget Formulation, and Analysis (EE-3B)

1000 Independence Avenue, S.W.

Washington, DC 20585

Randy Steer

U.S. Department of Energy

EERE-Office of Planning, Budget Formulation, and Analysis (EE-3B)

1000 Independence Avenue, S.W.

Washington, DC 20585

Michael York

U.S. Department of Energy

EERE-Office of Planning, Budget Formulation, and Analysis (EE-3B)

1000 Independence Avenue, S.W.

Washington, DC 20585

Mary Beth Zimmerman

U.S. Department of Energy

EERE-Office of Planning, Budget Formulation, and Analysis (EE-3B)
1000 Independence Avenue, S.W.

Washington, DC 20585

Ed Barbour

Navigant Consulting

1801 K Street, NW

Suite 500

Washington, D.C. 20006

Michael Berlinski

National Renewable Energy Laboratory

901 D Street

$9^{\text {th }}$ Floor

Washington, DC 20024-2115

No. of

$\underline{\text { Copies }}$

ONSITE

2 DOE Richland Operations Office

$$
\text { Kim Williams } \quad \text { K8-50 }
$$

19 Pacific Northwest National Laboratory

\begin{tabular}{|c|c|c|}
\hline D. M. Anderson & & K5-06 \\
\hline D. B. Belzer & & K5-06 \\
\hline K. A. Cort & & K5-06 \\
\hline J. A. Dirks & & K6-10 \\
\hline D. B. Elliott & \multicolumn{2}{|c|}{ Portland/1/OS } \\
\hline E. M. Fathelrahman & & K5-06 \\
\hline D. J. Hostick & & \multirow[t]{2}{*}{ K5-06 } \\
\hline S. C. McDonald (2) E & BWO & \\
\hline A. K. Nicholls & & \multirow[t]{2}{*}{ BWO } \\
\hline B. F. Saffell & K5-02 & \\
\hline M. J. Scott & & K5-06 \\
\hline T. M. Weber (2) & & K5-06 \\
\hline Information Release & $(5)$ & $\mathrm{K} 1-06$ \\
\hline
\end{tabular}

D. M. Anderson K5-06

D. B. Belzer K5-06

K. A. Cort K5-06

J. A. Dirks K6-10

E. M. Fathelrahman K5-06

D. J. Hostick K5-06

S. C. McDonald (2) BWO

A. K. Nicholls

M. J. Scott K5-06

T. M. Weber (2) K5-06

Information Release (5) K1-06 